\title{
II.
}

\section{Das Wachstum').}

\author{
Von \\ Lafayette B. Mendel, New Haven, Connecticut, U. S A.
}

Mit 7 Abbildungen im Text und 5 Kurven auf Tafel I-IV.

(Deutsche Übertragung von Frau Else Asher.)

Inhalt.

Literatur . . . . . . . . . . . . . . . . . . . . . 102

Einleitung . . . . . . . . . . . . . . . . . . . . . . . . . . 107

Was ist Wạchstum? . . . . . . . . . . . . . . . . . . . . . . . . . 109

Die Bestimmang oder Messung des Wachstums . . . . . . . . . . . . . . . 113

Die Erscheinungen und Charakteristika des Wachstums . . . . . . . . . . . . 116

Die Zellen während des Wachstoms . . . . . . . . . . . . . . . . . 120

Abgrenzungen des Wachstums . . . . . . . . . . . . . . . . . . . 123

Die Wachstumskurve und die Wachstumsgeschwindigkeit . . . . . . . . . 123

Die Wachstumsfähigkeit . . . . . . . . . . . . . . . . . . . 126

Der normale Verlauf des Wachstums . . . . . . . . . . . . . . . . 132

Wachstum und Seneszenz . . . . . . . . . . . . . . . . . . 135

Anormalitäten des Wachstums. - Die Pathologie des Wachstums . . . . . . . . 138

Beschleunigung des Wachstums . . . . . . . . . . . . . . . . . . . 139

Hemmung des Wachstums . . . . . . . . . . . . . . . . . . . . . 140

Mit dem Wachstum verwandte Prozesse . . . . . . . . . . . . . . . . . . 142

Die Ursache des Wachstums. . . . . . . . . . . . . . . . . . . . . . . 149

Die Wachstumsgesetze . . . . . . . . . . . . . . . . . . . . . . . . 154

Einige das Wachstum betreffende Probleme . . . . . . . . . . . . . . . . . 156

Statistiken des Wachstums. Die Histologie des Wachstums . . . . . . . . 157

Ernährung and Wachstum . . . . . . . . . . . . . . . . . . . . . 157

Die Wachstımsmöglichkeit. - Ihre Dauer, der Einfluss des Alters usw. . . . . 178

Die Funktion des Alters . . . . . . . . . . . . . . . . . . . . . 179

Die Unterdrückung des Wachstums. - Infantilismus .. . . . . . . . . . . 180

Verlust und Regeneration . . . . . . . . . . . . . . . . . . . . . 182

Andere Eigenschaften. . . . . . . . . . . . . . . . . . 182

1) Das Manuskript dieses Essays wurde anfangs 1913 geschrieben und dem Herausgeber der Ergebnisse übergeben. Seit dieser Zeit sind wichtige Beiträge zur Literatur des Gegenstandes erschienen. Unglücklicherweise ist es infolge der unvorhergesehenen Verzögerung des Erscheinens unmöglich gewesen die neueren Beiträge za berücksichtigen, ausser in einer kursorischen und unvollständigen Weise wahrend der Drucklegung der Arbeit. 


\section{Literatur.}

1. Abderhalden, E., Zeitschr. f. physiol. Chem. 26. 497. 1899.

2. Derselbe, Lehrbuch der physiologischen Chemie.

3. Abderhalden, E., Synthese der Zellbausteine in Pflanze und Tier. Berlin 1912 (a). 101.

4. Derselbe, Fütterungsversuche mit vollständig abgebauten Nahrungsstoffen. Zeitsehrift für physiologische Chemie. 77. 22. 1912 (b).

5. Abderhalden, E., und Hirsch, P., Fütterungsversuche mit Gelatine, Ammonsalzen, vollständig abgebautem Fleisch und einem aus allen bekannten Aminosäuren bestehenden Gemisch, ansgeführt an jungen Hunden. Zeitschrift für physiologische Chemie. 81. 323. 1912.

6. Aldrich, T. B., On Feeding Young White Rats with the Posterior and the Anterior Parts of the Pituitary Glands. Amer. Journ. of Physiol. 31. 94. 1912.

7. A r o n, H., Wachstum und Ernährung. Biochem. Zeitschr. 30. 207. 1910.

5. Derselbe, Nutrition and Growth I. Philippine Journ. of Science B. 6. 1. 1911.

9. Derselbe, Weitere Untersuchungen über die Beeinflussung des Wachstums durch die Ernährung. Verhandl. XXIX. Versammlung. Gesellsch. f. Kinderheilkunde. Münster 1912.

9a. Aron, Biochemie des Wachstums des Menschen und der Tiere, Handbuch der Biochemie, Ergänzungsband, Jena 1913. 70.

10. Bang, J., Biockemie der Zelllipoide. Ergebnisse der Physiologie. 6. 131. 1907.

11. Derselbe, Biochemie der Zelllipoide II. Ergebnisse der Physiologie. 8. 463. 1909.

12. Boas, F., The Growth of Children. Science, N. S. 36. 815. 1912.

13. Boveri, Zellenstudien. H. 5. Jena 1905.

14. Bunge, G., Physiologie des Menschen. 51. 122. 1901.

15. Calvary, M., Die Bedeutung des Zuckers in der Säuglingsnahrung. Ergebnisse der inneren Medizin und Kinderheilkunde. 10.699. 1913.

16. Child, C. M., The Process of Reproduction in Organisms. Biologie. Bullet. 23. 1. 1912.

17. Derselbe, A Study of Senescence and Rejuvenation, based on Experiments with Planarians. Arch. f. Entwickelungsmechanik der Organismen. 31. 1911.

18. Conklin, E. G., Body Size and Gell Size. Journ. of Morphology. 23. 184. 1912.

19. Derselbe, Cell Size and Nuclear Size. Journ. of experimental Zoology. XII. 85. 1912.

20. Davenport, C. R., Experimental Morphology. 2. 1899.

21. Derselbe, Experimental Morphology. Part. II. New York. 1899. 290.

22. Donaldson, H. H., The Growth of the Brain. New York. 1903.

23. Derselbe, On the Percentage of Water in the Brain and in the Spinal cord of the Albino Rat. Journ. of Comparative Neurology and Psychology. 20. 119. 1910.

24. Derselbe, The Effect of Underfeeding on the Percentage of Water etc. in the Central Nervous System of the Albino Rat. Ibidem. 21. 1911.

25. Derselbe, President's Address before the Philadelphia Neurological Society. Journ. of Nervous and Mental Disease. 38. 257. 1911.

26. Derselbe, Review of "The Problem of Age, Growth and Death". Anatomical Record. 2. 373.1908.

27. Derselbe, A Comparison of the White Rat with Man in Respect to the Growth of the Entire Body. Boas Memorial Volume. New York. 1906. 19.

28. Dunn, Elizabeth H., A Study in the Gain in Weight for the Light and Heavy Individuals of a Single Group of Albino Rats. Anatomical Record. 2. 109. 1908.

29. Evvard, J. M., Dox, A. W., and Guernsey, S. C., The Effect of Calcium and Protein fed Pregnant Swine upon the Size, Vigor, Bone, Coat and Condition of the Offapring. American Journal of Physiology. 34. 312. 1914.

30. Fingerling, G., Die Bildung von organischen Phosphorverbindungen aus anorganisehen Phosphaten. Biochemische Zeitschrift. 38. 448. 1912.

31. Friedenthal, H., Das Wachstum des Körpergewichtes des Menschen und anderer Sängetiere in verschiedenen Lebensaltern. Zeitschr. f. allg. Physiologie. 9. 487. 1909.

32. Derselbe, Über das Wachstum des menschlichen Körpergewichtes in den verschiedenen Lebensaltern und über die Volumenmessung von Lebewesen. Arbeiten a. d. Gebiet d. experim. Physiologie. 2. 1911. 
33. Fried enthal, H., Daten und Tabellen betreffend die Gewichtszunahme des Menschen und anderer Tierarten. Arb. a. d. Gebiet d. experim. Physiologie. 2. 221. 1911.

34. Derselbe, Die Zeiten der Verdoppelung des Körpergewichtes neugeborener Tiere. Arb. a. d. Gebiet d. experim. Physiologie. 2. 197. 1911.

35. Derselbe, Experimentelle Prüfung der bisher aufgestellten Wachstumsgesetze. Verhandl. d. physiolog. Gesellschaft. Berlin. 1909. 93.

36. Funk und Wagnall's Standard Dictionary. 798.

37. Funk, C., Über die physiologische Bedeutung gewisser bisher unbekannter Nahrungsbestandteile der Vitamine. Ergebnisse der Physiologie. 13. 124. 1913.

38. Derselbe, Studien über das Wachstum. I. Das Wachstum auf vitaminhaltiger und vitaminfreier Nahrung. Zeitschrift für physiologische Chemie. 88. 352. 1913 (b).

39. Derselbe, Die Vitamine. Wiesbaden 1914.

40: Funk, C., und Macallum, A. B., Die chemischen Determinanten des Wachstums. Zeitschrift für physiologische Chemie. 92. 13. 1914.

41. Galton, F., Life History Album. 1884.

42. Hatai, L., The Effect of Partial Starvation on the Brain of the White Rat. Amer. Journ. of Physiol. 12. 116. 1904.

43. Derselbe, Effect of Partial Starvation followed by a Return to Normal Diet, on the Growth of the Body and Central Nervous System of Albino Rats. Amer. Journ. of Physiology. 18. 309. 1907.

44. Heusen, V., Das Wachstum. Hermanns Handbuch der Physiologie. 1881. 6. II. 259.

45. Herter, C. A., Infantilism. New York 1908.

46. Hopkins, F. G., Feeding Experiments Illustrating the Importance of Accessory Factors in Normal Dietaries. Journ. of Physiol. 44. 425. 1912.

47. Hopkins, F. G., Feeding Experiments Illustrating the Importance of Accessory Factors in Normal Dietaries. Journal of Physiology 44. 425. 1912.

48. Hopkins, F. G., and Neville, A., A Note Concerning the Influence of Diets upon Growth. The Biochemical Journal. 7. 97. 1913.

49. Hopkins und Neville, A., A Note Concerning the Influence of Diets upon Growth. Biochem. Journ. 7. 97. 1913.

50. Lee, F. S., American Textbook of Physiology. Edited by Howell, Philadelphia. 1896. 924.

51. Loeb, J., The Dynamics of Living Matter. New York. 1906.

52. Lusk, G., The Elements of the Science of Nutrition. Philadelphia. 1909. (Auch auf Deutsch.)

53. McCollum, E. V., The Nature of the Repair Processes in Protein Metabolism. Amer. Journ. of Physiol. 29. 215. 1911.

54. Me Collum, E. V., Nuclein Synthesis in the Animal Body. American Journal of Physiology. 25. 120. 1909.

55. Me Collum, E. V., and Davis, Marguerite, The Influence of the Composition and Amount of the Mineral Content of the Ration on Growth. Journal of Biological Chemistry. 14. 40. 1913; auch Proceedings of the American Society of Biological Chemists. 2. 128 1918 (a).

56. Dieselben, The Necessity of Certain Lipins in the Diet during Growth. Jonrnal of Biological Chemistry. 15. 167. 1913 (b).

57. Dieselben, Observations on the Isolation of the Substance in Butter Fat which Exerts a Stimulating Influence on Growth. Journal of Biological Chemistry. 19. 245. 1914.

58. Me Coll um, E. V., and Halpin, J. G., Synthesis of Lecithins in the Hen.: Journal of Biological Chemistry. 11. 13. 1912.

59. Min ot, C. S., Senescence and Rejuvenation. Journ. of Physiol. 12. 97. 1891.

60. Derselbe, On the Nature and Cause of Old Age. The Harvey Lectures for 1905-1906. Philadelphia. 1906. 230.

61. Derselbe, The Problem of Age, Growth and Death. 6. Popular Science Monthly. 71. 512. 1907.

62. Derselbe, The Problem of Age, Growth and Death. New York. 1908.

63. Derselbe, The Four Laws of Age. Popular Science Monthly. 71. 511. 1907. 
64. Min ot, The Problem of Age, Growth and Death. III. Popular Science Monthly. 71. 198. 1907.

65. Mendel, L. B., Viewpoints in the Study of Growth. Biochemical Bulletin. 3. 156. 1914.

66. Mendel, L. B., and Mitchell, P. H., Chemical Studies on Growth. I. The Inverting Enzymes of the Alimentary Tract, especially in the Embryo. American Journal of Physiology, 20. 81. 1907.

67. Morgan, T. H, Experimental Zoology. New York. 1907.

68. Derselbe, The Extent and Limitations of the Power to Regenerate in Man and other Vertebrates. The Harvey Lectures for 1905-1906. Philadelphia. 1905.

69. Derselbe, Regeneration. New York. 1901. 23.

70. Morgulis, S., Studies of Inanition in its Bearing upon the Problem of Growth. Arch. f. Entwickelungsmechanik d. Organismen. 32. 1911.

71. Nice, L. B., Comparative Studies on the Effects of Alcohol, Nicotine, Tobacco Smoke and Caffeine upon White Mice. Journ. of experim. Zoology. 12. 133. 1912.

72. Niemann, A., Über die Möglichkeit einer Fettanreicherung der Säuglingsnahrung. Jahrbuch für Kinderheilkunde. 79. 274. 1914.

73. Osborne, T.B, and Mendel, L. B., Feeding Experiments with Isolated Food-Substances. Carnegie Institution of Washington, 1911 (a), Publication 156, Part I.

74. Di eselben, Feeding Experiments with Fat-free Food Mixtures. Journal of Biological Chemistry. 12. 81. 1912.

75. Dieselben. Feeding Fixperiments Relating to the Nutritive Value of the Proteins of Maize. Journal of Biological Chemistry. 14. 31. 1913; auch American Journal of Physio. logy. 31. 16. 1913 (a).

76. Dieselben, The Relation of Growth to the Chemical Constituents of the Diet, Journal of Biological Chemistry. 15. 311. 1913 (b).

77. Die selben, The Influence of Butter-Fat on Growth. Journal of Biological Chemistry. 16. 423.1913 (c).

78. Dieselben, The Influence of Cod liver Oil and Some Other Fats on Growth. Journal of Biological Chemistry. 17. 401. 1914 (a).

79. Dieselben, Nutritive Properties of Proteins of the Maize Kernel. Journal of Biological Chemistry. 18. 1. 1914 (b).

79a. Dieselben, Amino-acids in Nutrition and Growth, Ibid 17. 325.1914.

80. Osborne, T. B., The Nutritive Value of the Proteins of Maize. Science. N. S. 37. 185. 1913.

81. Derselbe, The Chemistry of the Proteins, The Harvey Lectnres for 1910-1911. Philadelphia. 1911. 72.

82. Osborne und Mendel, L. B., Feeding Experiments with isolated Food Substances. Carnegie Institution of Washington. Publication 156. Part. II.

83. Dieselben, Beobachtungen über. Wachstum bei Fütterungsversuchen mit isolierten Nahrungssubstanzen. Zeitschr. f. physiol. Chemie. 80. 307. 1912.

83a. Dieselben, The role of Gliadin in Nutrition. Journ. of biolog. Chemistry. 12, 473 bis 516. 1912.

84. Oseki, S., Untersuchungen über qualitativ unzureichende Ernäbrung. Biochemische Zeitschrift. 6อ̆. 158. 1914.

85. Pearson, Karl, The Grammar of Science. London. 1900.

96. Peritz, G., Der Infantilismus. Erg. d. inneren Medizin u. Kinderheilk. 7. 405. 1911.

87. Pfaundler, M., Über die Behandiung der angeborenen Lebensschwäche. Münchener med. Wochenschr. 54. 1417. 1907.

88. Roberts, C., Manual of Antbropometry. 1878.

89. Robertson, 'L' B., On the Normal Rate of Growth of an Individual and its Biochemical Signifieance. Arch. f. Entwickelungsmechanik d. Organismen. 25. 1908.

90. Derselbe, Further Remarks on the Normal Rate of Growth of an Individual and its Biochemical Significance. Ibid. 26. 1908.

91. Derselbe, Explanatory Remarks Concerning the Normal Rate of Growth of an Individual and its Biochemical Significance. Biolog. Zentralbl. 30. 316. 1910.

92. Röhmann, F., Über künstliche Ernährung. Klinisch-therapeutische Wochenschrift. 40. 1. 1902. 
93. Röhmann, F., Über künstliche Ernährung. Allgem. medizinische Zentral-Zeitung. 1. 1903.

94. Derselbe, Über künstliche Ernährung von Mäusen. Allgemeine medizinische ZentralZeitung. 9. 1208 (a).

95. Derselbe, Biochemie. 109. 1908 (b).

96. Derselbe, Zur Frage der künstlichen Ernährang. Biochemische Zeitschrift. 39. 507, 1912.

97. Derselbe, Uber die Ernährung von Mäusen mit einer aus einfachen Nahrungsstoffen zusammengesetzten Nahrung. Biochemische Zeitschrift. 64. 30. 1914.

98. Rubner, M., Kraft und Stoff im Haushalte der Natur. Leipzig. 1909.

99. Derselbe, Das Problem der Lebensdaner und seine Beziehung zu Wachstum und Ernährung. München und Berlin 1908.

100. Derselbe, Frnährungsvorgänge beim Wachstum des Kindes. Arch. f. Hygiene. 66. 1908.

101. Derselbe, Das Wachstumsproblem und die Lebensdauer des Menschen und einiger Săugetiere vom energetischen Standpunkt aus betrachtet. Arch. f. Hygiene. 66. 1908.

102. Sch if fer, E. A., The Effects upon Growth and Metabolism of the Addition of Small Amounts of Ovarian Tissue, Pituitary and Thyroid to the Normal Dietary of White Rats. Quarterly Journ. of Physiol. 5. 203. 1912.

103. Schapiro, A., On the Influence of Chloroform on the Growth of Young animals. Proc. of the Physiolog. Soc. Journ. of Physiol. 33. XXXI. 1905-1906.

104. Schloss, E., Die Pathologie des Wachstums im Sänglingsalter. Berlin. 1911.

104a. Derselbe, Wachstum und osmotischer Druck bei jungen Hunden. Zeitschr. f. Kinderheilkunde. III. $251-56.1911$.

105. Sedgwick, W. T., und Wilson, E. B., General Biology. New York. 1894. 166.

106. Slonaker, J. R, The Normal Activity of the Albino Rat from Birth to Natural Death, its Rate of Growth and the Duration of Life. Journ. of Animal Behavior. II. 20. 1912.

107. Derselbe, The Effect of a Strictly Vegetable Diet on the Spontaneous Activity, the Rate of Growth, and the Longevity of the Albino Rat. Leland Stanford Junior Univ. Public. 1912.

108. Starling, E. H., Human Physiology. Philadelphia. 1912. 1341.

109. Step p, W., Versuche über Fütterung mit lipoidfreier Nahrung. Biochemische Zeitschrift. 22. 452. 1909.

110. Derselbe, Fütterungsversuche mit lipoidfreier Nahrung. Verhandlungen des Kongresses für innere Medizin. 28. 324. 1911 (a).

111. Derselbe, Experimentelle Untersuchungen über die Bedeutung der Lipoide für die Ernährung. Zeitschrift für Biologie. 57. 135. 1911 (b).

112. Derselbe, Experimente über die Einwirkung langdauernden Kochens auf lebenswichtige Nahrungslipoide. Verhandlungen des Kongresses für innere Medizin. 29. 607. 1912 (a).

113. Derselbe, Weitere Untersuchungen über die Unentbehrlichkeit der Lipoide für das Leben. Über die Hitzezerstörbarkeit lebenswichtiger Lipoide der Nahrung. Zeitschrift für Biologie. 59. 366. 1912 (b).

114. Derselbe, Fortgesetzte Untersuchungen über die Unentbehrlichkeit der Lipoide für das Leben. Über das Verhalten der lebenswichtigen Stoffe zu den Lipoidextraktionsmitteln. Zeitschrift für Biologie. 62. 405. 1913.

115. Voit, G., Die Ernährung. Hermanns Handbuch d. Physiol. 6. 536. 1881.

116. Waters, H. J., The Capacity of Animals to grow nnder Adverse Condition. Proceedings Soc. f. the Promotion of Agricult. Science. 29. 3. 1908.

117. Derselbe, The Influence of Nutrition upon the Animal Form. Ibid. 30. 71. 1909.

118. Derselbe, How an Animal Grows. Kansas State Board of Agriculture, 17th Biennial Report. 1. 208. $1909-1910$.

119. Wats on, J. B, The Effect of the Bearing of Young upon the Body Weight and the Weight of the Central Nervous System of the Female White Rat. Journ. of compar. Neurology and Psychology. 15. 514. 1905.

120. Whe eler. Ruth. . Feeding Experiments with Mice. Journ. of exper. Zoology. 15. 209. 1913.

121. Wheeler, Ruth, and Beister, Alice, A Study of the Nutritive Value of Some Proprietary Infant Foods. American Journal of the Diseases of Children. 7. 169. 1914. 


\section{Einleitung.}

Von welchem Standpunkt aus auch immer der Forscher die lebenden Organismen betrachtet, so sieht er bald, dass es bestimmte grundlegende Charakteristika gibt, welche ihrem lebendigen Protoplasma eigen sind und sie von dem unterscheiden, was man gewöhnlich als anorganische Substanz bezeichnet. Leben ohne Wachstum und Tätigkeit, ohne die Fähigkeit der ,automatischen Entwickelung, Selbsterhaltung und Wiedererzeugung", ist gegenwärtig undenkbar. $\mathrm{Ob}$ es eines Tages möglich sein wird, oder nicht, die künstliche Erzeugung lebendiger Substanz aus dem, was leblos ist, zu vollziehen, kommt für uns jetzt nicht in Betracht. Karl Pearson schrieb: „Es gibt hier genug Geheimnisse, nur wollen wir sie deutlich von der Unkenntnis innerhalb des Gebietes des möglichen Wissens unterscheiden. Das eine ist undurchdringlich, das andere machen wir täglich fruchtbar." Was ist daher wichtiger, was anziehender in der biologischen Forschung, als die Untersuchung jener spezifischen Eigenschaften, welche die lebendigen Organismen charakterisieren?

Es würde kaum nötig sein, irgend eine Untersuchung über das Wachstumsproblem zu rechtfertigen, wenn nicht die Tatsache bestünde, dass hierüber im Vergleich mit anderen Gegenständen der physiologischen Forschung in früheren Jahren so wenig geschrieben worden ist; und vieles von dem, was geschrieben worden ist, besteht aus Hypothese und Spekulation, was in der Tat etwas überraschend ist.

„,Das Wachstum sorgt mit der Vererbung der eiterlichen Eigenschaften dafür", schreibt Rubner, ,dass in der äusseren Erscheinung der lebenden Welt weder Form noch Farben, noch althergebrachte Lebensäusserungen sich ändern. Alles, was wir so mit dem Blicke zu überschauen vermögen, ist in seiner Vielgestaltigkeit nur eine Speziallösung des allgemeinen Lebensprinzips. In die Werkstätte des Lebens auch in dieser Hinsicht des Werdens vorzudringen, muss unsere Aufgabe sein, denn Wachsen ist neben dem Lebendsein die zweite wichtigste Funktion .... Im Akt des Wachstums liegt ein wesentlicher Teil des ganzen Lebensgeheimnisses begründet, es ist die Erschaffung des Lebens im vollsten Sinne des Wortes. Wenn aus der befruchteten Eizelle der, im Verhältnis zu dieser, ungeheure Organismus eines Säugers sich aufbaut, so hat die ganze spätere Körpermasse das Leben aus der Eizelle empfangen, nicht nur die Durchschnittseigenschaften, sondern alle die besonderen Eigenschaften des Individuums bis hinab ins kleinste." (98, S. 97.)

Eine andere Ansicht über die Bedeutung unseres Gegenstandes wird von Davenport ausgesprochen: „Die Wichtigkeit der Forschung des Wachstums kann nicht überschätzt werden, und es ist merkwürdig, dass die Behandlung des Gegenstandes in den Lehrbüchern so sehr vernachlässigt wurde. 
Tatsächlich ist es eine überraschende Tatsache, dass er nicht gründlich und systematisch erforscht worden ist. Denn in der letzten Analyse beruht die Erhaltung der menschlichen Rasse auf jener Eigenschaft, welche das Protoplasma unter allen Substanzen allein entfaltet, indem es sich eine unbestimmte Zeitlang und in unbestimmtem Umfange vergrössert. Und die Möglichkeit, die menschliche Rasse über die Grenzen hinaus zu vergrössern, welche nicht weit ab liegen, beruht auf einer besseren Kenntnis der Wachstumsbedingungen. Der Leser muss nur bedenken, dass die Versorgung der Erde dureh 2500 Millionen Büschel Weizen, 2000 Millionen Büschel Mais, 90 Millionen Tonnen Kartoffeln und die ungemessenen Millionen Tonnen von Rindern, Schweinen und Fischen jedes Jahr durch Wachstum wieder erzeugt werden. Die Mineralbestandteile des Erdbodens werden in das Meer hinaus gewaschen und gehen grossenteils verloren, aber die Fähigkeit zu wachsen geht unter geeigneten Bedingungen. niemals verloren; sie verdoppelt sich, wenn die Menge der wachsenden Substanz vermehrt wird. Das Einzige, was daher das Wachstum begrenzt, sind die Einschränkungen der Wachstumsbedingungen ..... Abgesehen von diesem praktischen Interesse ist das Studium des Wachstums in bezug auf die Frage der Abhängigkeit der Lebenstätigkeiten, besonders der Entwicklung, von äusseren Bedingungen und die Möglichkeit der Kontrolle der Entwickelung durch geeignete Abänderungen dieser Bedingungen, wichtig. Die Wachstumsphänomene scheinen in der Tat besonders geeignet für diese Kontrolle zu sein und sind infolgedessen besonders wertvoll für die experimentelle Untersuchung" (20).

Min ot hat seine Ansicht mit folgenden Worten ausgesprochen: "Nichts ist vielleicht gegenwärtig wünschenswerter, als dass wir wissenschaftliche Einsicht in die regulatorische Kraft gewinnen, welche das Wachstum beherrscht. Es würde von ungeheurer medizinischer Bedeutung sein. Wenn wir sie verstünden, und von unserem Verständnis eine praktische Anwendung unserer wissenschaftlichen Entdeckungen auf dieses Gebiet ableiten könnten, so würden wir davon gerechterweise sagen dürfen, dass sie ein ebenso bemerkenswerter Beitrag zur medizinischen Kenntnis ist, wie die Entdeckung der Krankheitskeime, und sie würde sich zweifellos als ebenso wohltuend für die Menschheit erweisen" (62).

Der herrschende Standpunkt in der Betrachtung der Wachstumsphänomene wird in grossem Umfange bestimmt durch die Ausbildung und das unmittelbare Interesse der Forscher, die mit dieser Analyse beschäftigt sind. Bei weitem die meisten haben ihre Aufmerksamkeit auf die rein morphologischen Seiten des Gegenstandes gelenkt. Zytologische Phänomene, die Veränderungen in der Anzahl und der Grösse der Körperzellen, die gegenseitige Beziehung der Gewebsbestandteile, die Verbältnisse des Kerns und des Zytoplasmas und ähnliche strukturelle Unterschiede, haben ihr Interesse vergrössert. Alle diese Entdeckungen, welche die Morphologie und 
das Mikroskop gemacht haben, besonders für die frühen Stadien des Wachstums und der Unterscheidungsphasen, würden einen Band für sich erfordern. Jedoch würde, wie Minot sagt, ,kein Bild des Wachstums oder der Entwicklung des lebendigen Tieres vollkommen sein, wenn es sich nur auf die Wachstumsfähigkeit in Beziehung zur Zytomorphose beschränken würde. Es muss also auch die Betrachtung und die Untersuchung dieser regulatorischen Kraft der Organe in sich schliessen" (62). Andere haben wiederum die Wachstumsprobleme von einem, wie man ihn nennen kann, dynamischen Standpunkt aus, ins Auge gefasst. Von diesen werden die Entwickelungsprozesse als Ausdruck der Gleichgewichtsveränderungen betrachtet. Chemische und physikalisch-chemische Reaktionen werden miteinbezogen. Demnach findet man Hinweise auf einen Mechanismus in gewissen Stadien der Entwickelung, so z. B., dass es ,eine Umwandlung der flüssigen Bestandteile des Blutes in feste Bestandteile innerhalb jener Zellen gibt, welche ein rasches Wachstum oder eine Umwandlung in verschiedene Verbindungen zeigen" (51, S. 4). Die Ansicht des Chemiker's zeigt sich in der Auffassung, dass das Wachstum ,der Ausdruck der autokatalytischen chemischen Reaktion zu sein scheint", und es ergibt sich dabei, dass besondere Zyklen des Wachstums eines Organismus - einer genauen mathematischen Formel folgen (89, 90, 91, S. 58, 108, 316).

Etwas fassbarer als die deutlich hypothetische Analyse des chemischen Charakters der Lebensvorgänge und der physikalischen Struktur der lebendigen Substanz sind die Ansichten jener Forscher, welche dahin streben, das Wachstum mit der Ernährung in Beziehung zu bringen, wobei sie in manchen Fällen die materielle Seite hervorheben und die Beziehungen in Substanzeinheiten ausdrücken, oder in anderen, wo sie damit Energiebilder verbinden und in Ausdrücken von Kalorien sprechen. Endlich gibt es noch die Beobachtungen der groben Zunahme an Grösse und Form und anderen Eigenschaften, bei welchen statistische Faktoren die vorherrschende Bedeutung haben.

Keine dieser Anschauungsweisen ist ohne Bedeutung für den Begriff des Wachstums, und wenn dessen Biologie noch dunkel ist, müssen wir an die Verwickeltbeit der Faktoren und der Kräfte denken, welche im Leben eine Rolle spielen. „Das Mass des ganzen Menschen ist weder die Anzahl von Pfundev, welche er heben, noch die Tatsachen, welche er entdecken, noch der Einfluss, welchen er auf seine Mitmenschen ausüben, noch das Alter, welches er erreichen kann, sondern etwas von allen diesen und wozu alles dieses dient, zusammengenommen" (22, S. 64).

\section{Was ist Wachstum?}

Bei dem Versuche, eine Antwort auf diese Frage zu geben, kann man nicht weit in die Literatur des Gegenstandes eindringen, ohne auf 
eine erstaunliche Verwirrung in der Bedeutung des Ausdrucks Wachstum zu stossen, wie er.von den verschiedenen Forschern angewandt wird. Es sind verschiedene Ausdrücke, wie Wachstum, organisches Wachstum, Entwickelung und Euplasie auf dieselben Phänomene angewandt worden; und die zahlreichen Versuche, ibre Bedeutung und ihre richtige Anwendung zu definieren, haben fast immer in einem Versagen der Kritik, wolche gegen jede gegebene. Definition ausgesprochen werden konnte, geendigt.

Die allgemeine Definition des Wachstums ist "Zunahme im Volumen" oder "Zunahme in der Grösse" ( $\mathrm{H}$ uxley). Es ist jedoch darauf hingewiesen worden, dass Volumenzunahme nicht immer als ein Zeichen für organisches Wachstum dient; denn die Zunahme kann nur von einer Schwellung herrühren. Sachs definjerte Wachstum als eine Volumenzunahme, die von einer Formveränderung begleitet ist. Morgan widerspricht dem auf Grund der Behauptung, dass Wachstum manchmal vorkommen kann, auch ohne dass eine Formveränderung beobachtet wird. Er schliesst daher in die Definition des Wachstums die Idee „einer Zunahme des Volumens der lebendigen Substanz" mit ein (67, S. 240) und Verworn betrachtet das Wachstum als die Zunahme der lebendigen Substanz, während es in Friedenthals Schema die Zunahme der "zellteilungsfähigen Substanz" ist. Diese wenigen Zitate sollen vorläufig allein dazu dienen, die Schwierigkeiten der Definition zu zeigen, welche hier ebenso wie bei anderen biologischen Vorgängen zu beobachten sind. In Wirklichkeit ist noch keine allgemein annehmbare Definition formuliert worden; es ist auch nicht wahrscheinlich, dass man alle die mannigfachen Eigenschaften des Wachstums in eine einzige Kategorie verlegen kann. Jede Phase muss in Ausdrücken beschrieben werden, welche besonders anzuwenden sind. Vor allem müssen wir die Tendenz vermeiden, unsere Definitionen in hypothetischen Ausdrücken zu gestalten. Eine Kritik dieser Art wendet sich, wie Schloss (104, S. 2) gezeigt hat, gegen Bezeichnungen, wie die von Roux, nach welchem das Wachstum ,als Überkompensation in Ersatz des Verbrauchten", oder die von Camerers, dass es als ,einseitige Verwendung der Nährstoffe zum Zwecke der Neubildung" bezeichnet wird. Die vage Mischung von Verallgemeinerung und Hypothese tritt in auffallender Weise in einer Wörterbucherklärung des Wortes ,wachsen" hervor. Es soll bedeuten „durch den Prozess des organischen Lebens an Umfang zunehmen, sich durch die Assimilation der nährenden Substanz durch die verschiedenen Organe vergrössern, d. h. von lebendigen Dingen oder deren Teile" (36). . Es wird auch nicht viel gewonnen, wenn man das Wachstum als die Folge eines Vorganges der molekularen Intussusception (Huxley) oder als die Folge eines Überschusses von Assimilation, über Dissimilation definiert (Verworn). Was wir heute brauchen, ist weniger Theorie und mehr Tatsachen, auf welchen wir eine greifbarere Auffassung des Wachstums aufbauen und seine fixierten Charakteristika in Worten formulieren können. 
Noch unwissenschaftlicher und verwirrender sind die gebräuchlicheren Anwendungen des Wortes Wachstum. So sagt man, dass ein Tumor „wächst", obgleich der beschriebene Vorgang dem Wachstum eines Organismus ganz unähnlich sein kann. Und in dem "Wachstum" eines Hydrozephalen wird die Analogie noch weiter ausgedehnt. Donaldson hat bemerkt, dass „dem Ausdruck Wachstum, welcher die Zunahme an Grösse in sich schliesst, gewöhnlich der Begriff einer Zunahme an Kraft und Fähigkeit zu arbeiten, anhaftet, was qualitative Veränderungen sind. Das Wort Wachstum hat daher infolge seiner vielen Nebenbegriffe gewisse Nachteile, so dass es besser sein wird, soweit wie möglich andere Ausdrücke, die genauer sein sollen, zu benützen" (22, S. 46). Trotz der Inadäquatheit und Verwirrung, die in allen den verscbiedenen erwähnten Beispielen angeführt worden sind, kann jedoch etwas aus einer weiteren ausführlichen Übersicht über die adäquateren Definitionen, welche von Zeit zu Zeit vorgeschlagen worden sind, gewonnen werden. Eine Analyse und Kritik derselben kann sogar dazu dienen, manche Probleme hervorzuheben, welche in den Begriff des Wachstums mit eingeschlossen sind.

"Organisches Wachstum" schreibt D a v e n port, ,ist Zunahme an Volumen. Es ist nicht Entwickelung; es ist nicht Differenzierung, es ist nicht Zunabme an Masse, obgleich letztere als ein bequemes Mittel des Wachstums dienen kann“ (20, S. 281). „Wachstum ist Zunahme an Grösse und kann entweder znfolge von Vergrösserung der gebildeten Substanz durch Absonderung des Plasmas durch Assimilation oder des Enchylems durch Aufsaugen entstehen. Diese Zunahme kann entweder vorübergehend oder beständig sein; die letztere Art beschäftigt uns hier hauptsächlich (21)." Diese Definitionen, welche hier besonders auf Pflanzen angewandt sind, bringen sofort die Verwickeltheit der in Rede stehenden Vorgänge zum Ausdruck. Dies wird noch deutlicher, wenn man es nicht mit dem Wachstum einer einzelnen Zelle oder kleinen Ansammlungen derselben, sondern mit ganzen Organismen zu tun hat, so wie sie bei den höheren Tieren und beim Menschen bestehen. Für diese hat Lee die Analyse des Wachstums einen Schritt weiter in derselben Richtung geführt. "Alles Wachstum, sei es der Zellen, der Gewebe oder der Organe, ist das Resultat von nicht mehr als von drei Prozessen, nämlich der Vervielfältigung der Zellen, der Vergrösserung der Zellen und der Ablagerung von interzellulärer Substanz, wovon die beiden ersten die mächtigsten von allen sind. Die Zunahme in der Anzahl von Zellen ist grossenteils, wenn auch nicht ganz, ein embryonales Phänomen; die Zunahme im Zellumfang und die Ablagerung der interzellulären Substanz sind von der späteren embryonalen Periode an, während der Zeit der Geburt und bis zum Schluss des Körperwachstums besonders wichtig . . Das auffallendste Resultat des Wachstums der Zellen, der Gewebe und der Organe ist das Wachstum oder die Zunahme in der Körpergrösse (50)." 
Es wird aus einigen der vorangehenden Definitionen klar, dass insofern die Organismen sowohl aus lebender wie aus geformter Substanz zusammengesetzt sind - wenn eine solche Unterscheidung erlaubt ist - das Wachstum aus der Volumenzunahme von einem von beiden entsteht. Dieser Standpunkt ist jedoch etwas breiter als meist bei den Physiologen. „Unter Wachstum im weiteren Sinne verstehen wir zwar jede Grössenzunahme irgend einer Funktion, der Physiologe versteht aber unter Wachstum eines Lebewesens im engeren (eigentlichen) Sinne nur Vermehrung der Masse der lebendigen Substanz" (33, S. 487). An einer anderen Stelle schreibt F riedenthal: „Ein Lebewesen wächst, solange die Zunahme der Masse der lebendigen Substanz in seinem Körper den Verbrauch an lebendiger Substanz durch die Lebensschädigungen im ganzen überwiegt. $\mathrm{Ob}$ das Körpergewicht zunimmt oder abnimmt, hängt nicht allein von dem Wachstum der lebendigen Substanz ab“ (32, S. 40).

Wir werden später besprechen, in welchem Umfange das Körpergewicht als ein Massstab des Wachstums angenommen werden darf. Der Punkt, welcher hier betont werden soll ist, dass das Körpergewicht durch Ablagerung oder Verbrauch des Reservematerials, wie Glykogen und Fett, ebenso wie durch die Zurückhaltung von Wasser und auderen Produkten deutlich verändert werden kann. Im engeren und genaueren Sinne ist das nicht Wachstum. Bei vielen Individuen wird das Ende des Wachstums erreicht, wie der Physiologe den Ausdruck anzuwenden wünscht, lange ehe der Gewinn an Körpergewicht aufhört sich zu zeigen. Das wahre Wachsen soll z. B. beim Menschen gewöhnlich im Alter von 25-30 Jahren aufhören, zu welcher Zeit die Körperlänge ihr Maximum erreicht hat. Viele Individuen fahren bis zu ihrem 50. Jahre fort an Gewicht und Grösse zuzunehmen; aber in ganz anderer Art wie in den früheren Jahren.

„Unter. Wachstum“, schreibt Rubner, „möchte ich im wesentlichen nur die unter Zellteilung und -Vermehrung erfolgenden Prozesse erfasst wissen. Naturgemäss muss dem Wachstum eine Zunahme der Masse der Zelle und, wie man weiss, eine solche des Kernes und Protoplasmas vorausgehen, wodurch, wie das Richard Hertwig näher auseinandergesetzt hat, das Verhältnis zwischen Kernmasse und Protoplasma eine Änderung erfährt (98, S. 98).

Verallgemeinerungen wie die vorangehende ziehen einige der auffalleudsten Charakteristika des Wachstums nicht in Betracht, da sie auf höhere Organismen angewandt werden. Vollkommenes Wachstum und Entwickelung schliessen eine viel weiter reichende Beziehung der verschiedenen Körperteile in sich. Ein Abweichen von einer solchen schön ausgeglichenen Beziehung wird rasch als anormal erkannt. Energie und Stoff genügen nicht, um den Verbrauch und die Erhaltung einer normalen, im Gegensatz zu einer anormalen Zusammensetzung der Zellen zu erklären. Die Spezifität des Wachstums ist etwas 
ausgesprochenes, besonders wenn wir das normale dem anormalen Wachstum gegenüberstellen.

Die Regelmässigkeit und charakteristische Individualität der autogenetischen Entwickelung, welche bei jeder Art zu sehen ist, hat ihren Ausdruck in der klaren Definition von S chloss (104, S. 4) gefunden: „So können wir das normale Wachstum eines jeden Organismus auffassen als artspezifische korrelative Vermehrung der Körpermasse in bestimmten Zeitabschnitten." Daraus kann man auf die an den Anomalien oder Unregelmässigkeiten des Wachstums beteiligten Vorgänge sofort schliessen. Anormales Wachstum kann sich beziehen auf (a) das Korrelationsbild, oder (b) das zeitliche Element, wodurch die charakteristische Geschwindigkeit dieser Veränderungen nicht aufrecht erhalten wird. „Die Korrelation bezieht sich einmal auf die rein stoffliche Zusammensetzung, den materiellen Aufbau; sie legt also ein bestimmtes Verhältnis (Quantum) von protoplasmatischen und nichtprotoplasmatischen Substanzen von Eiweiss, Fett, Kohlehydraten, von Wasser und Salzen usw. fest; dann aber auch auf den formalen Aufbau der einzelnen Organe und Teile, somit des ganzen Körpers, indem sie pathologische Organ- oder Gewebsbildung (Hypertrophien und Atrophien, Geschwülste, Hydrozephalus etc.) ausschliesst. So fällt auch das Längenwachstum, das Wachstum der Gestalt ohne weiteres unter diese Definition" (104, S. 4). Auch hier haben, wie andern Orts oft in der Physiologie, die Anormalitäten den Schlüssel zu dem Verständnis der normalen Prozesse gegeben.

\section{Die Bestimmung oder Messung des Wachstums.}

Da das Wachstum eine mehr oder weniger konstante Veränderung in sich schliesst, entsteht das Bedürfnis nach einer geeigneten Methode, dieselbe festzustellen und zu messen. Die einfachste und gebräuchlichste besteht darin, das Gewicht des Individuums zu verfolgen. In welchem Umfange dieses Verfahren geeignet ist, das Wachstum zu bestimmen, hängt von unserer Definition des letzteren und von unserer Auffassung ab, was wir in Wirklichkeit darunter verstehen. Es gibt z. B. vorübergehende Gewichtszunahmen und solche, welche konstant sind. Die letzteren kommen für uns hier hauptsächlich in Betracht. Wie schon gezeigt worden ist, können korrelative Zunahmen der Masse im Körper vorkommen, lange nach Abschluss dessen, was eigentlich als Wachstumsperiode bezeichnet wird. Eine Gewichtszunahme im mittleren Lebensalter kann von der Ablagerung von Reservestoffen „Ballaststoffe", wie sie ein Forscher (Pfaundler) genannt hat - herrühren. Ein anderes Anzeichen des Wachstums wird in einer Zunahme der Figur und gewisser anderer Dimensionen gefunden. Diese sind nicht wertlos, besonders insofern sie uns instand setzen, die Korrelation zwischen Gewicht und Grösse zu bestimmen; denn ohne diese geeignete Anpassung oder geeignete 
Proportionalität kann vollkommenes Wachstum (um das wenigste $\mathrm{zu}$ sagen) nicht vor sich gehen.

„Eine beständige Gewichtszunahme ist ein endgültiger Beweis für das normale Wachstum eines jungen Tieres." Diese von A ron $(8$, S. 5) aufgestellte Behauptung kann nicht als richtig angenommen werden, wenn wir entsprechend unserer früheren Auffassung im normalen Wachstum etwas Spezifisches in bezug auf die Gewinne sehen, die innerhalb vernünftig festgesetzter Zeitintervalle gemacht werden. Die Beständigkeit der Zunahme sichert an sich kein normales Wachstum. Es kann, obgleich es beständig ist, langsamer als in der Norm sein. Die Adäquatheit der Gewichtsbestimmung als massgebend für das Studium des Wachstums ist auf etwas indirekte Weise von Aron herangezogen worden. Er schreibt: „Wenn das Körpergewicht beständig bleibt, beweist diese Tatsache, dass kein Wachstum stattindet? Das Wachstum, wie wir es vom biologischen Standpunkt aus und in seiner Beziehung zur Energie verstehen, bedeutet eine allgemeine, mehr oder weniger gleichmässige Zunahme aller Körperteile. Kein Wachstum bedeutet keinerlei Veränderung im Körper. Es kann jedoch das Gewicht eines Tieres sich überhaupt nicht ändern, während innere bezw. Veränderungen zwischen den verschiedenen Körperteilen stattfinden können. Offenbar ist ein konstantes Gewicht kein Zeichen für Mangel an Wachstum in unserem Sinne. Die Frage, inwieweit Zunahme oder Konstanz des Gewichtes parallel mit Steigerung oder Aufhören des Wachstums verlaufen, ist wichtig und von praktischem Wert und verdient grosse Aufmerksamkeit." (8, S. 5.) Arons Versuche an jungen Hunden, ebenso wie diejenigen von Waters an jungen Rindern, zeigen, dass wenn durch Einschränkung der Nahrung die Gewichtszunahme gehemmt wird, das Skelett auf Kosten anderer Körperteile, besonders des Fleisches, wächst. Die meisten Organe behalten ihr Gewicht und ihren Umfang, während das Gehirn wächst und sein normales Gewicht erreicht. Wenn man den Ausdruck „Wachstum" für die Phänomene der hier erwähnten atypischen Veränderung gebraucht, so muss man A r o n zugeben, dass das Wachstum hauptsächlich von der Tendenz zu wachsen abhängt, die das Skelett besitzt $(8,82,116,117,118)$.

Weder das Gewicht noch andere Messungen können allein als ein Zeichen für das „Lebenspotential“ angenommen werden, welches ,als die Fähigkeit sich mittelst Assimilation und Energieumsatz in seiner Eigenart zu erhalten, $\mathrm{zu}$ wachsen und sich fortzupflanzen" definiert worden ist; sie lassen die akzessorischen „Ballaststoffe" ausser Betracht, welche zu einem Organismus, ganz unabhängig von wahrem Wachstum oder Entwickelung, hinzukommen können (87). Von diesem Standpunkt aus hat Friedenthal die Grenzen der Gewichtsmessungen angegeben. „Wir sind nicht imstande", schreibt er, „aus den Gewichtskurven der höheren Tiere Wachstumsgesetze abzuleiten, weil die Masse der lebendigen Substanz, je weiter das Leben fortschreitet, um so mehr hinter der Menge von nichtprotoplasmatischen Substanzen ver- 
schwindet, welche von dem Protoplasma abgeschieden und von dem Zellenstaate mitgeführt werden. Bei den höheren Tieren übernehmen, je weiter das Leben fortschreitet, statt der Zellen Fibrillen, die zu den paraplasmatischen Substanzen gehören, die Funktionen der Formgestaltung, der Bewegung und der Reizleitung, so dass der Körper des erwachsenen Menschen für eine Reihe von Funktionen aus einem Zellenstaat in eine Fibrillenmaschine übergeht. Entlastet von den Funktionen der Fortpflanzung und Regeneration arbeitet diese Fribrillenmaschine weit ökonomischer als ein Zellenstaat, bei welchem jedes Zellindividuum neben seiner Sonderfunktion noch die Regenerationsfähigkeit sich bewahrt hat. Um die Wachstumsgesetze bei den höheren Organismen aufzufinden, müssen wir das Gesamtgewicht, wie wir es mit der Wage feststellen können, in mindestens vier gauz verschiedenartige Bestandteile zerlegen. Das Gewicht eines höheren Lebewesens setzt sich im wesentlichen zusammen: aus dem Gewicht des Zellenstaates, der Masse der Fibrillen und sonstiger paraplasmatischer Substanzen, aus der Masse der Reservestoffe (wie Fette, Glykogen u. a.) und schliesslich aus der Masse der flüssigen und festen Sekrete und Abscheidungen. Jede der letztgenannten drei Kategorien kann an Gesamtmenge die Masse des Zellenstaates weit übertreffen. Man denke an das Gewichtsverhältnis mancher Muschelschalen zu der Masse lebendiger Substanz des erzeugenden Muscheltieres. Das Körpergewicht eines Lebewesens spiegelt auch deshalb die Wachstumsleistung der befruchteten Eizelle nicht wieder, weil ständig ein Teil der erzeugten lebendigen Substanz der Vernichtung anheimfällt, ganze Organe abgestossen werden und nur ein kleiner Bruchteil der Masse der erzeugteu lebendigen Substan\% im späteren Leben im Zusammenhange mit dem Zellenstaate verbleibend, der Wägung unterworfen wird. . . . Um das Wachstum des Menschen und anderer Säugetiere kennen zu lernen, bedürfen wir einer Kenntnis der Zahl der Zellteilungen, welche von der Befruchtung der Eizelle ab bis zum Tode durchschnittlich sich vollziehen, sowie eine Kenntnis der Verteilung der Zahl der Zellteilungen auf die verschiedenen Lebensabschnitte. Auf den ersten Lebensstufen geht die Gesamtvermehrung und das Wachstum der lebendigen Substanz der Zahl der Zellteilungen in der Zeiteinheit ungefähr parallel." (31, S. 48) (32, S. 49.)

Trotz der mehr oder weniger naheliegenden Kritiken der vorgeschlagenen Messungsmethoden, für sich allein genommen, stimmen wir mit Donaldson überein, dass das Studium des Wachstums durch Wiegen das beste Mass für die gesamten Veränderungen im Körper liefert. „Es ist leicht einzusehen, warum diese Messung die beste ist, wenn wir einen Augenblick die Bedeutung der linearen Messungen betrachten, welche manchmal statt derselben angewendet werden. Unsere Körper entwickeln sich in drei Dimensionen und bilden eine unregelmässige geometrische Figur, welche sich überdies mit dem Alter verändert. Infolgedessen dient die Veränderung irgend eines linearen Masses, wie der Figur, z. B, nur als ein grobes Zeichen 
für die Veränderungen, welche in den beiden anderen Durchmessern statt gefunden haben" (22, S. 49).

Während des Wachstums unterliegen die Bestandteile und Elemente des Körpers Veränderungen und chemischen Variationen. Eine genaue Kenntnis derselben ist von vielen Standpunkten aus wünschenswert. Bis jetzt sind erst die Anfänge in dieser Richtung gemacht worden. Wenn man Statistiken über die verschiedene chemische Zusammensetzung der Bestandteile des wachsenden Organismus in den verschiedenen Entwickelungsperioden zu erbalten sucht, so schliesst das mühsame Analysen in sich, wozu noch die weitere Schwierigkeit hinzukommt, dass man um die Daten zu sichern, den Versuch durch die Opferung des Versuchsobjektes abschliessen muss. Die Beziehung in der Entwickelung zwischen den verschiedenen Organen und Geweben, die geeignete Symmetrie und die wechselseitige Beziehung der Teile, die Veränderungen sowohl in der körpergestaltenden wie in der körpervermehrenden Funktion verdienen genaue Untersuchung. Die Inangriffnahme dieser und verwandter Gebiete ist begonnen worden, namentlich von Donaldson und seinen Mitarbeitern im Wistar Institute in Philadelpbia ${ }^{1}$.

\section{Die charakteristischen Erscheinungen des Wachstums.}

„Wean wir eine grosse Anzahl von Individueu derselben Lebensart untersuchen, finden wir Typen, Variabilitäten und Beziehungen yon ebenso vielen Organen und Charakteren, wie wir wählen. So bestimmen das Mass, die Variabilität und Korrelation die numerische Spezifizierung jeder Form des Lebens, und wenn wir sagen, dass Entwickelung stattindet, verstehen wir darunter, dass progressive Veränderungen in einem oder in allen den zahlreichen Werten vor sich gehen, welche das Mass, die Variabilität und Korrelation des Systems der Organe und Eigenschaften bestimmen. Innerhalb des Organismus, wenn er ähnliche Organe produziert - Blumen, Samenkapseln, Blätter, Blutkörperchen, Haare, die Schuppen usw., die im ganzen oder teilweise nicht differenziert sind - können wir einen individuellen Typus haben, eine individuelle Variabilität und eine individuelle Korrelation (wir können z. B. die Beziehung zwischen Gewicht und den Adern auf den Blättern desselben Baumes, oder zwischen Länge oder Breite der Blutkörperchen im selben Frosche oder in derselben Sumpfeidechse usw. untersuchen). Diese müssen sorgfältig von dem ursprünglichen Typus, der ursprünglichen Variabilität und der ursprünglichen Korrelation unterschieden werden. In der Tat macht diese Unterscheidung den Organismus za einem individuellen; er vergrössert seine gleichen Teile, welche einander ähnlicher sind als jene eines anderen Individuums; er vergrössert seine ungleichen Teile, welche

1) Siehe zahlreiche Arbeiten im Journal of Comparative Neurology, Anatomical Record und Journal of Nervous and Mental Diseases. 
miteinander enger verbunden sind als mit jenen eines anderen Individuums.... Es entsteht dann eine sehr wichtige Frage, nämlich: Wachsen alle Individuen, gleichgültig welcher Rasse, auf dieselbe Weise? Ist die Beziehung zwischen Paaren von nicht differenzierten gleichen Organen in dem Individuum dieselbe oder annähernd dieselbe für alle Lebensformen? Wenn dem so ist, haben wir quantitativ ein ebenso verständliches Wachstumsgesetz für lebende Organismen, wie das Gesetz der Schwere für molare Massen ist, aufgestellt. Meine Untersuchungen über jenen Punkt sind noch nicht vollständig, aber sie weisen darauf hin, dass folgendes Gesetz richtig ist. Der Grad der Ähnlichkeit zwischen nicht differenzierten gleichen Organen im einzelnen Individuum ist annähernd derselbe für alle Lebensformen . . . . Ausser diesem Gesetz für das Wachstum gleicher Teile müssen wir ein Gesetz erforschen, welches das Wachstum bei der Veränderung mit dem Alter angibt. Denn ohne ganz genaue Beobachtung des Alters können wir nicht viel in bezug auf die Entwickelung voraussagen; Typus, Variation und Korrelation, alles wechselt mit dem Alter des Individuums; und diese Ver. änderung kann ebensogut vom Wachstum wie von einer selektiven Absterbegeschwindigkeit herrühren. Es ist z. B. ganz klar, dass sich das mittlere Gewicht und die mittlere Länge von neugeborenen Kindern von jenen von Erwachsenen, sagen wir von 20-22 Jahren, unterscheiden, aber die Kinder haben eine ganz andere Veränderlichkeit und eine höhere Korrelation in bezug auf diese beiden Eigenschaften als die Erwachsenen. Rührt dies von einer selektiven Geschwindigkeit des Absterbens oder nur von einem Wachstumsphänomen her? Natürlich muss die Lebensperiode jeder Klasse festgestellt werden, und wir dürfen unsere numerische Spezifizierung einer Lebensform nicht an Individuen von weit auseinander liegenden Lebensaltern ausbilden" (85, S. 402).

Insofern der Ausdruck Wachstum gewöhnlich mit den verschiedenen Einschränkungen, welche ziemlich genau besprochen worden sind, auf bestimmte physische Veränderungen angewendet wird, welche von früher Jugend an bis zur Reife fortdauern, d. h. der Zustand, in welchem es auf jeden Fall während einer relativ langen Zeit keine füblbare Veränderung im Typus oder in der Variabilität gibt, kann das Wachstum beschrieben werden, indem man quantitative Methoden auf die Veränderungen dieser physischen Eigenschaften anwendet. Die Resultate, welch $\ominus$ durch periodische Messungen der fortwährend vor sich gehenden Veränderungen erhalten werden, besonders die Veränderungen im Gewicht oder in der Figur, können in graphischer Form ausgedrückt werden. Auf diese Weise erhaltene "Wachstumskurven" gelten heute für beide Geschlechter von einer Reihe von Arten $(88,41,27,59,106$, 82, 33). Ein typisches Beispiel folgt hier aus unserer eigenen Erfahrung.

Dabei zeigen sich gewisse charakteristische Eigenschaften des Wachstums. Die Wachstumsgeschwindigkeit bleibt nicht während des ganzen Zyklus unver- 
ändert, da es Variationen in der Zunabme des absoluten Gewichts des Einzelnen gibt. Es gibt Perioden einer mehr oder weniger raschen Steigerung. Es werden so die Wachstumsphasen besonders hervorgehoben. Zur Erklärung derselben schreibt Donaldson: ,Wir erkennen zuerst, dass das Wachstum, mit welchem wir es zu tun haben, hauptsächlich von der Vervielfältigung und von der Vergrösserung der Zelle abhängt; ferner, dass, sobald mehrere Klassen von Zellen im Organismus entstehen, wahrscheinlich Modifikationen im Wachstum einer Klasse vorhanden sind, welche von der Tätigkeit anderer herrühren. Wenn wir die Lebensspanne von Anfang bis zu Ende überwachen, finden wir, dass hauptsächlich in der ersten und zweiten Phase die Zellteilung stark tätig ist, während in allen späteren Phasen die Zellvergrösserung die Hauptursache für die Zunahme im Gesamtumfang ist. Überdies wird der letztere Vorgang durch die Anzahl von Zellen beeinflusst, welche bei jeder Art eine Vergrösserung zu erfahren bestimmt ist. Da bei der Ratte die Geburt während der dritten Phase eintritt, scheint die Zellteilung als ein Wachstumsfaktor zwischen Goburt und Reife verhältnismässig unbedeutend zu sein, da hauptsächlich Zellvergrösserungen vor sich gehen. Wir sollten a priori erwarten, dass dieser Vergrösserungsprozess uns eine einfache konstant ansteigende Kurve gäbe, welche sich ziemlich rasch wendet und abflacht, wenn sich die Reife nähert. Da aber die Kurve deutlich von dieser Form abweicht, da nach der Geburt drei wohl bezeichnete Phasen vorhanden sind, von denen sie in der ersten und letzten langsam ansteigt, getrennt durch eine (vierte Phase), in welcher sie rascher steigt, scheint es höchstwahrscheinlich, dass die Vergrösserung des Körpers im ganzen ein Resultat der gesamten Einflüsse ist, welche durch die Zwischenwirkung mehrerer Systeme entstehen" (27, S. 22).

Es gibt Organismen, bei welchen der vollständige Wachstumsstillstand unter geeigneten Bedingungen der Umgebung nicht auffallend ist. Sie gehören zu den niederen Formen. Es gibt Wirbeltiere, wie z. B. manche Fische, Amphibien und Reptilien, bei welchen Wachtumsveränderungen von gleicher Dauer wie das Leben sind. Vielleicht ist das eher scheinbar als wirklich, und zwar infolge der Tatsache, dass wir ihre wabre Lebensspanne nicht auf geeignete Weise festgestellt haben. Bei der grössten Mehrzahl der höheren Formen ist jedoch die Grösse des Tiers in dem Sinne festgesetzt, dass lange vor dem natürlichon Ende des Lebens das Wachstum aufhört. Die Beständigkeit der Wachstumskurve der verschiedenen Arten und, insoweit wie dieser Punkt untersucht worden ist, der Geschlechter in jeder Art, ist vielleicht das bemerkenswerteste Wachstumsphänomen. ,Wir werden keiner Bedingungen gewahr, welche mit dem Leben verträglich sind, in welchem der Hauptcharakter der Wachstumskurve mit ihrer Beschleunigung während des Heranwachsens, verändert werden können. Kleinere Veränderungen können jedoch entstehen" (22, S. 59). „Gewiss ist die mittlere Wachstumskurve aus Tausenden von Fällen abgeleitet 


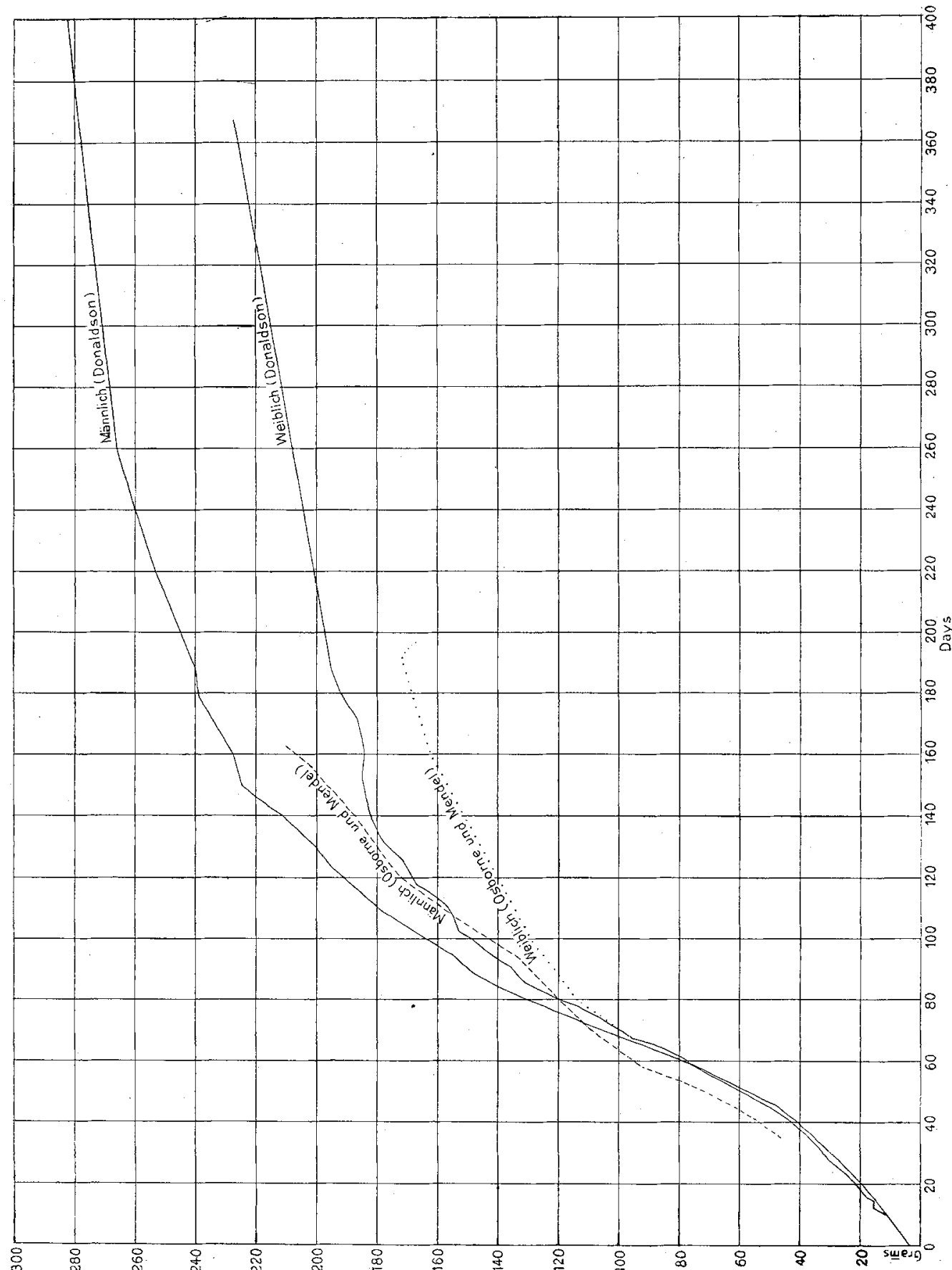

Fig. 1.

Diese Figur zeigt die durchschnittlichen normalen Wachstumsgeschwindigkeiten von männlichen und weiblichen weissen Ratten, nach Donaldson und nach Osborne und Mendel. Nach unseren Versuchen erreicht das Weibehen nicht dieselbe Grösse wie in Donaldsons Versuchen. Die Wachstumskurven stimmen überein, bis die Tiere ungefähr ein Alter von 70 Tagen erreichen. 
für jede Spezies eine konstante Grösse, aber von dem Mittelwerte weichen die Individualwerte ab mit kleinen Schwankungen in der Mehrzahl und mit grossen Schwankungen in Ausnahmsfällen. Die Unterschiede im individuellen Wachstum sind wohl meist angeboren, sozusagen Grundkonstanten des eigenartigen Lebens. Es gibt kein Mittel, die Wachstumseigentümlichkeiten zu verändern, jedenfalls kann die Ernährung nichts anderes erzielen, als dem individuellen Wachstumstrieb freie Bahn zu lassen. Den letzteren ursächlich abzuändern, vermögen wir nicht, es wäre die Absicht hierzu ein ebenso utopisches Ziel wie der Versuch einer Änderung der Lebensdauer im Sinne einer spezifischen Beeinflussung" (99, 100, S. 81).

\section{Die Zellen während des Wachstums.}

Es ist schon erwähnt worden, dass die Zellen nicht die einzigen Faktoren zu sein brauchen, welche an der das Wachstum begleitenden Grössenzunahme beteiligt sind. Extrazelluläre Teile können dabei eine Rolle spielen. Trotzdem hat die Bedeutung der Zellen, als stofflicher Grundlage der biologischen Phänomene und als Sitz der physiologischen Funktionen, die Aufmerksamkeit auf diese histologischen Wachstumseinheiten konzentriert. Bei niederen Arten und im embryonalen Leben spielt die Zellteilung eine wichtige Rolle im Wachstum. Letzteres kann von ersterer begleitet sein oder auch nicht. „Bei dem Wachstumsprozess einer ganz geringen sphärischen Menge des Protoplasmas nehmen ihr Umfang und ihre Masse im Kubus zu, während die Oberfläche nur wie das Quadrat des Radius zunimmt. So nimmt das Verhältnis der Oberfläche zurr Masse mit zunehmender Grösse der protoplasmátischen Einheit zu; je grösser die Einheit, um so geringer muss ibre Tätigkeit sein. Es folgt daraus, dass es daher eine Grenzgrösse für die lebendige Protoplasmaeinheit geben muss, und aus diesem Grunde ist tatsächlich kein einzelliges Tier oder Pflanze im Durchmesser grösser als der Bruchteil eines Millimeters. Wenn ein Organismus irgend einen grösseren Umfang erreichen muss, kann das nur durch eine Vervielfältigung von Einheiten geschehen, von denen jede dieselbe Menge an Oberfläche darstellt, wie ein vollständiger einzelliger Organismus, obgleich die Oberfläche einem inneren und nicht einem äusseren. Medium exponiert werden kann"“ (108, S. 1341).

Was die hier erwähnten Vorgänge bei höheren Organismen anbetrifft, so stehen wir vor der Frage, ob die Grösse eines Organismus von der Grösse seiner Bestandteile - seiner Zellen - abhängt, oder von ihrer Anzahl. Wächst ein Organismus durch Zunahme in der Anzahl der neuen Zellen oder durch eine Vergrösserung der alten? Gibt es, mit anderen Worten, eine Beziehung zwischen Körpergrösse und Zellgrösse?

Es würde uns zu weit abführen, wenn wir im einzelnen den darauf bezüglichen Beweis und verwandte morphologische Fragen über die Natur des Wachstums untersuchen würden. Morgulis schreibt: „Die Frage ist 
von grosser theoretischer Bedeutung, denn wenn die Zellen in einem bestimmten Organ immer dieselbe Grösse hätten, gleichgültig, wie gross oder wie klein das einzelne Individuum sein mag, so würde natürlich daraus folgen, dass die Grösse der Zelle eine spezifische Eigenschaft ist, welche durch Erbschaft überliefert wird. Der Unterschied, welchen einige Deutsche zwischen „Wachstum" oder eigentlichem Wachstum, wenn die Zellen an Anzahl zunehmen, und „Ansatz" (postembryonales Wachstum?) machen, wo die Zellen an Volumen zunehmen können, kann, obgleich er sehr bequem ist, nicht als allgemein anwendbar betrachtet werden, da tatsächlich in keiner Phase der tierischen Existenz die Proliferation neuer Zellen überhaupt aufhört. . . . Eine Veränderung im Volumen der Zellen während des Wachstums des Individuums ist noch wenig bekannt, aber die Tatsachen weisen darauf hin, dass die Zellgrösse ein sehr wichtiger Faktor zur Bestimmung der Grösse des Organismus ist. Mac Callum (1898) äussert sich folgendermassen über die Resultate seiner Untersuchung des Wachstums des M. Sartorius beim Menschen. - „In einem frühen Stadium der Entwicklung sind die Zellen klein und spindelförmig und in losen Bündeln verstreut. Zuerst fehlen Fibrillenbündel und der Kern liegt zentral. Später erscheinen die Fibrillenbündel um die Peripherie der Zelle herum, die Zellen vervielfältigen sich und nehmen an Umfang zu bis der Embryo zwischen $130 \mathrm{~mm}$ und $170 \mathrm{~mm}$ in der Länge vom Kopfe bis zum Steisse erreicht hat. In diesem Stadium werden die Zellenbündel kompakter..., die Fasern wächsen nun in der Länge und in der Dicke, nehmen aber wahrscheinlich nicht mehr an Zahl zu. Bei Embryonen, welche kleiner als $170 \mathrm{~mm}$ lang sind, zeigt sich eine regelmässige Zunahme der Anzahl der Fasern, die man in einem Querschnitt findet. Danach bleibt jedoch die Anzahl annähernd konstant". Es folgt hieraus, dass die enorme Zunahme der Muskulatur beim Erwachsenen, sowie die Fälle von Muskelhypertrophie offenbar nicht von einer Vervielfältigung der Anzahl der Zellen, sondern vielmehr von ihrer Zunahme im Umfang herrühren. Ähnliche Beobachtungen wurden von Illing (1905) über das Wachstum der Leber bei verschiedenen Vertretern der Haustiere gemacht. Man kann aus seinen Resultaten ersehen, dass, während die Zellen an Umfang zunehmen, solange das Tier grösser wird, kein direktes Verhältnis zwischen der Grösse einer besonderen Art und der Grösse ihrer Zellen existiert. Wenn wir die im Vorangegangenen erwähnten Tatsachen betrachten, so können wir zu folgenden Schlüssen kommen: 1. Die Hypothese der festen Grösse der Zellen ist nicht allgemein anwendbar. 2. Die Grösse der Zellen und der Kerne ist experimentell modifizierbar. 3. Die Grösse der Zellen ist für die Bestimmung der Grösse des Tieres und besonders der Grösse der einzelnen Orgaue ein wichtiger Faktor" (70, S. 255).

Für niedere Formen hat Conklin gefunden, dass trotz grosser Unterschiede in der Körpergrösse die Grösse der Gewebszellen bei allen untersuchten Arten und bei allen Individuen beider Geschlechter und sehr verschiedener Grössen 
annähernd dieselbe ist. „Hauptsächlich hängen Unterschiede in der Körpergrösse von Unterschieden in der Anzahl der vorhandenen Zellen und nicht von Variationen in der Grösse der einzelnen Zellen ab. Ganglienzellen und Muskelzellen bilden die Hauptausnahme für diese Regel. Diese Resultate stimmen mit den meisten Arbeiten überein, welche über Zellgrösse in Beziehung zur Körpergrösse gemacht worden sind und insbesondere mit den Resultaten von Levi (1905). Andererseits findet Berezowski (1910), dass die Epithelzellen des Darmes bei jungen Mäusen kleiner sind als bei älteren, und dass mit dem allgemeinen Wachstum eines Tieres ein Wachstum in der Höhe dieser Zellen eintritt" (18, S. 184). Man muss dabei daran denken, dass die von Conklin erwähnte Gleichheit der Grösse sich auf Tiere gleichen Alters bezieht. Entwickelungsveränderungen kommen dabei nichtsehr in Frage; und Conklin fügt hinzu, dass bei der von ihm untersuchten Crepidula, ebenso wie bei den von Bereszowski untersuchten Mäusen, jüngere Tiere kleinere Zellen haben als ältere. „Es ist wohlbekannt, dass die Grösse der Zellen von einem gewissen Umfange von der Geschwindigkeit der Zellteilung und der Länge der Ruheperiode abhängt, die Geschwindigkeit der Zellteilung ist langsamer und die Ruheperioden sind bei reifen Tieren länger als bei jungen" (18, S. 185). Wenn daher bei derselben Art Unterschiede in der abschliessenden Körpergrösse hauptsächlich von Unterschieden in der Zellanzahl herrühren, da die Zellgrösse annähernd konstant ist, folgt daraus keineswegs, dass dieser Befund während der ganzen progressiven Wachstumsstadien bei höheren Organismen gilt, wo auch andere Faktoren als Zellvergrösserung und Zunahme beteiligt sind. Vielleicht können wir zwischen den Vorgängen der Gewebsdifferenzierung und Wachstum durch Hinweis auf die Veränderungen in der Anzahl und bez. der Grösse der Zellen unterscheiden.

Es ist viel Wert auf die Notwendigkeit gelegt worden, dass ein bestimmtes Verhältnis zwischen der Grösse des Kernes und der des Zytoplasmas, welche den Zellkörper bilden, besteht. Zweifellos sind physiologische Funktionen eng mit der Existenz des Kernes verbunden und es scheint, dass, wenn eine Zelle einen sehr grossen Umfang erreichen soll, sie fast immer mehrere Kerne enthält. „Im allgemeinen schliesst die Zytomorphose eine Zunahme der Zellgrösse mit dem Alter in sich. Zu gleicher Zeit ist das Wạchstum des Zytoplasmas rascher als das des Kernes, während die endgültige Grösse der Zelle hauptsächlich durch die Zwischenwirkung dieser beiden Teile reguliert $\mathrm{zu}$ werden scheint. Ein struktureller Unterschied ist besonders im Zyto. plasma zu sehen. Dieser Unterschied hat eine bestimmte letzte Phase, welche für den Organismus als ein Ganzes wertvoll ist, aber sie hat die Tendenz derart weiter zu bestehen, dass die Zelle überdifferenziert wird und schliesslich zerfällt" (26, S. 373). Min ot hat diese Zunahme im Zytoplasma mit begleitender Differentiation als die nächste Ursache des Alterns dargestellt. Die Haltbarkeit seiner Ansichten wird später besprochen werden. 
,Gemäss dem in der Biologie allgemein geltendem Standpunkt, dass die normale Funktion an eine normale Konfiguration gebunden ist, müssen wir auch annehmen, dass auch in der Periode des Wachstums die normale funktionelle Energie nur einem solchen Individuum zukommt, bei dem die oben bezeichnete normale Wachstumssituation vorliegt" (104, S. 6). Diese Verallgemeinerung kann dazu dienen, die vorhergehenden Erwähnungen der materiellen Basis des Wachstums, die Struktur der Gewebe mit inbegriffen, $\mathrm{zu}$ rechtfertigen.

\section{Abgrenzungen des Wachstums.}

Die Erfahrung zeigt, dass es eine ziemlich bestimmte obere Grenze in der Grösse gibt, welche die Individuen jeder Art selten überschreiten. Es gibt Formen, für welche die Variationen sehr weite sein können (wie schon gezeigt worden ist); und es wird berichtet, dass manche niedere Form, z. B. Actinien, durch geeignete Fütterung dazu gebracht werden kann, eine kolossale Grösse zu erreichen, die weit über das hinausgeht, was sonst erreicht wird (44). Auf die Arten von Säugetieren, mit welchen wir es hier zunächst zu tun haben, lässt sich das nicht, ausser im beschränkten, durch die Heredität bestimmten Grade anwenden. Warum die Körpergrösse so festgesetzt ist, ist nicht bekannt. Die Tatsache ihres unveränderlichen Charakters ermöglicht es für das Studium des Wachstums quantitative Methoden und bestimmte Standardwerte mit einiger Zuversicht in die Resultate anzuwenden.

\section{Die Wachstumskurve und die Geschwindigkeit des Wachstums.}

Der Verlauf des Wachstums wird gewöhnlich mit Kurven untersucht, deren Abszissen Zeitinterwalle und deren Ordinate Grösse oder Gewichte darstellen. Für eine gegebene Art können auf diese Weise hergestellte Kurven eine charakteristische Form zeigen. Die prozentualen Steigerungen werden durch diese Kurven nicht direkt gezeigt. Minot $(59,62)$ hat bewiesen, dass die frühere Art, das Wachstum darzustellen, die wirklichen Tatsachen befriedigend aufzeichnet und die allmählichen Gewichtsveränderungen, so wie sie richtig vorkommen, zeigt, aber sie gibt keinen richtigen Einblick in die Geschwindigkeit des Wachstums. Er ist der Meinung, dass für einen gegebenen Zeitraum die Geschwindigkeit als der Bruchteil des Gewichts ausgedrückt werden sollte, welcher während jener Zeit hinzukommt. Wenn Zahlenwerte auf diese Weise graphisch dargestellt werden, erscheint es, als ob sofort eine frühe Periode des raschen Abfalls auftrete, in welcher die Geschwindigkeit des Wachstums (im Gegensatz zur Zunahme in der Körpergrösse) abwärts ginge. Der Gegensatz in diesen beiden graphischen Ausdrucksformen der Wachstumsphänomene wird in beistehender Kurve illustriert (Fig. 2).

Minot schreibt: „Wenn Tiere wachsen, ist das, was wächst, natürlich die wirkliche Substanz des Tieres. Nun könnten wir sagen, dass es bei gegebener Substanz eine gleiche Geschwindigkeit des Wachstums geben müsste, 
und wir sollten erwarten, dass möglicherweise die Geschwindigkeit mehr oder weniger konstant ist. Ich kann meine Ansicht vielleicht klarer erläutern und sie Ihrem Gedächtnis deutlicher und kurz einprägen, indem ich behaupte, dass, wenn die Geschwindigkeit des Wachstums, so wie ich sie verstehe, konstant sein soll, jedes Tier in jedem Alter dieselbe Zeitlänge brauchen müsste um 10\% zú seinem Gewicht hinzuzufügen; es würde keine Frage sein, ob ein Säugling eine Unze in einer gewissen Zeitlänge und ein Knabe in derselben Zeit ein Pfund zunimmt, denn das Pfund braucht für den Knaben nicht derselbe prozentuale Fortschritt zu sein, wie die Unze für den Säugling. Tatsächlich könnte das kleine Kind mit der Zunahme einer Unze rascher wachsen als der ältere Knabe mit der Zunahme des Pfundes" (64, S. 193).

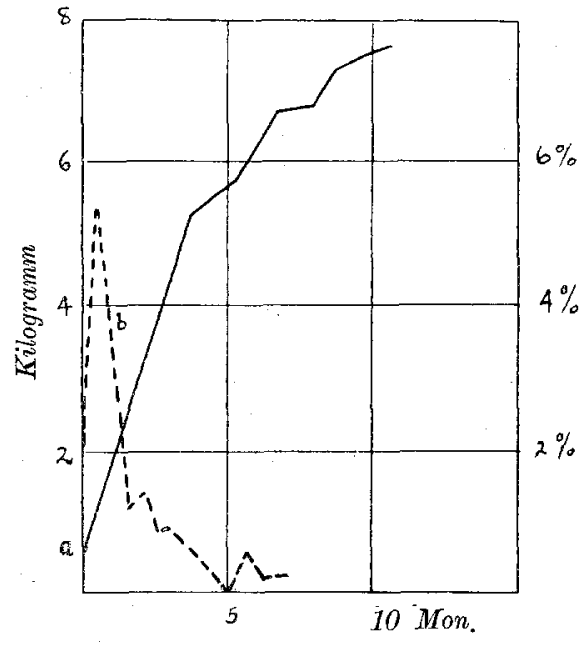

Fig. 2.

Die fortgesetzte Linie (a) stellt die Gewichte in Bruchteilen eines Kilogrammes dar, welche von einem Meerschweinchen von der Geburt an bis zu 12 Monaten erreicht wurden. Die gestrichelte Linie (b) stellt die täglichen prozentualen Zunahmen desselben Meerschweinchens bis zu 7 Mon. dar.

Donaldson hat die Eigenschaften der beiden Typen von Kurven folgendermassen ausgedrückt: „Da, wo die Kurve der Gewichtsvieränderung als eine gerade Linie erscheint, wissen wir, dass das gleiche, absolute Zunahmen in gleichen Zeiten bedeutet. Wenn sich jedoch die Kurve irgend wann in ihrem Verlaufe nach der Horizontalen neigt, zeigt das, dass während dieser Periode die absolute Zunahme geringer ist, als während der vorangehenden, und wenn sie sich nach der Vertikalen neigt, dass sie grösser ist. Es erseheint jedoch, wie von Minot gezeigt worden ist, dass die Wachstumsgeschwindigkeit, so wie sie durch die prozentuale Zunabme von Intervall zu Intervall gemessen wird, in allen beobachteten Fällen sehr rasch abnimmt, und zwar nur mit sehr kleinen Schwankungen von dem frühesten Augenblick, in welchem wir den Wachstumsprozess messen können, bis zum Ende der Wachstumsperiode. Die Kurve, welche nötig wäre, um eine gleichmässige Wachstumsgeschwindigkeit darzustellen, würde eine Exponentialkurve sein, welche sich mit grösserer oder geringerer Geschwindigkeit, je nach dem Werte der Geschwindigkeit, der Vertikalen nähert. Hieraus folgt, dass wir es bei den vorliegenden Fällen immer mit einer abnehmenden Geschwindigkeit zu tun haben, und dass die Veränderungen nur die Geschwindigkeit betreffen, mit der diese Abnahme vor sich geht. Daher sahen wir in den vielen Phasen auch Kurventeile, welche eine rasche oder langsame Steigerung zeigen, gleichzeitig mit Veränderungen in der Zunahme des absoluten Ge- 
wichtes des Tieres auch Veränderungen, welche im allgemeinen eine rasche, obgleich leicht variierende Abnahme in der Wachstumsgeschwindigkeit darstellen" (27, S. 21). Bei der Erläuterung der festgestellten Bedeutung der Kurve der prozentualen täglichen Zunahme bemerkt Da ven port (21, S. 289), dass, da der grössere Teil der Körpersubstanz zur Zeit ihres grössten Wachstums nicht, wie angenommen, „wachsende Substanz", sondern Wasser ist, der besondere Wert der Kurve der prozentualen Steigerungen zweifelhaft ist.

Es gibt noch andere Methoden, um die Veränderungen in der Wachstumsgeschwindigkeit darzustellen. Es kann z. B. die Kurve, welche die Länge der Zeit zeigt, welche erforderlich ist, um jede sukzessive Steigerung von z. B. $10 \%$ Gewicht zu verursachen, punktiert werden. Eine solche graphische Darstellung der Tatsache, dass, je älter wir sind, es um so länger dauert, bis wir um eine bestimmte proportionale Menge wachsen, hier zu vervielfältigen, würde nur verwirrend wirken.

Es besteht die landläufige Annahme, dass die Veränderungen, welche zum Wachstumsstillstand führen, nicht konstant, sondern periodisch sind. „Es ist gefunden worden, dass die Zunahme an Grösse and Gewicht der höheren Tiere eine periodisch fortschreitende Geschwindigkeit zeigt" (22, S. 40). Es ist sogar ein Element möglicher Rhythmik erwähnt worden.

Weibchen wachsen zuerst schneller. Die Periode des rascheren Wachstums beim Weibchen ist mit der Pubertät in Zusammenhang gebracht, es ist aber keineswegs eine feste Beziehung nachgewiesen worden. Diese allgemeinen Eigenschaften der Wachstumskurve, wie die konstanten Ungleichbeiten der beiden Geschlechter scheinen für zahlreiche Arten charakteristisch zu sein und lassen stark vermuten, dass Säugetiere als eine Klasse in ähnlicher Weise wachsen. Donaldson hat gezeigt, dass bei der Ratte „die Gewichtskurve des Weibchens der des Männchens ebenso entspricht, wie die bezüglichen Kurven beim Menschen. Hier haben wir es nun mit einem Tier zu tun, dass in der zoologischen Skala weit vom Menschen entfernt ist, da es zu einer paläontologisch alten Art gehört, und phylogenetisch nur eine geringe Tendenz zu Variation zeigt; dabei zeigten sich eine Reihe von Wachstumsanalogien, welche ähnlich beim Menschen beobachtet worden sind" (27, S. 19). Dies ist natürlich von grosser Bedeutung, da man hoffen kann, die aus der Untersuchung anderer Arten gewonnene Erkenntnis auf die menschlichen Verhältnisse zu übertragen.

\section{Die Wachstumsfähigkeit.}

Ganz abgesehen von der Frage, was das Wachstum verursacht, wird die Fähigkeit zu wachsen - die ,Wachstumsfäbigkeit", „Wachstumsmöglichkeit", wie sie häufig genannt wird (7), im allgemeinen zu einer Eigenschaft der Zellen des Organismus gemacht.

"Inwieweit eine Zelle wachstumsfähig ist", schreibt Friedenthal, 
„,hängt in hohem Masse von der Zahl der bereits abgelaufenen Zellteilungen ab, welche zur Bildung dieser Zelle von der befruchteten Eizelle her führte. Wir dürfen jeder befruchteten Eizelle die Möglichkeit der Erzeugung einer artmässig verschiedenen Zahl von Zellteilungen zuschreiben, nach deren Ablauf die Regenerationskraft des Organismus erschöpft ist, so dass der Tod als notwendige Folge der nun irreparabel gewordenen Schädigungen der Arbeitsmaschine des Lebewesens anzusehen ist. Je mehr wir imstande sein werden, den Rhythmus der Zellteilungen beim Menschen zu verlangsamen, um so höher werden wir die Lebensdauer und die Gesamtleistung des Menschen zu steigern vermögen. Da Denken und Handeln des Menschen weit unmittelbarer von dem Zustand der Fibrillenmaschinerie als von dem Leben seines Zellenstaates abhängig ist, so steht die Leistungsfähigkeit des Menschen in einem klar erkennbaren Gegensatz zu seiner Wachstumsarbeit" (3, S. 487).

Welches auch immer die letzte Ursache des Wachstums sein mag, die Wachstumsfähigkeit ist stets mit einem jugendlichen Charakter der beteiligten Zellen verknüpft. Von diesem Standpunkt ist das Alter ein wichtiger Faktor bei der Wachstumsmöglichkeit. Ein embryonaler Zustand der Zellen ist demnach höchst günstig für das Wachstum. Minots drittes Altersgesetz, welches sich mit der Wachstumsfunktion beschäftigt, lautet: "Die Wachstumsgeschwindigkeit hängt von dem Grade des Alters ab" (63, S. 523).

Vom rein theoretischen Standpunkt aus ist es ganz begreiflich, dass das gewöhnliche Aufhören des Wachstums von einem natürlichen hemmenden Faktor herrühren kann, welcher sich im Laufe der Zeit stärker entwickelt, weil die Fähigkeit zu wachsen, verloren gegangen ist. Trotzdem hat die Idee, dass die Wachstumsmöglichkeit unvermeidlich sinkt und mit dem Alter verloren geht, in der physiologischen Literatur eine feste Stütze gefunden. Die Bedeutung dieser Phase des Gegenstandes rechtfertigt einige weitere Erörterungen über diesen Punkt. So hat Donaldson betont, dass bei jenen Tieren, welche frühe eine bestimmte Grösse erreichen, die Zellentwickelung in einen kurzen Zeitraum zusammengedrängt wird; er sagt: „Entwickelung und die Veränderungen, welche beim Altern beteiligt sind, sind jedoch keineswegs synonym, so dass, obgleich bei Tieren von einer bestimmteu Grösse immer unentwickelte Zellen gefunden werden, es doch kein richtiger Einwand ist, dass diese Zellen auch in dem Sinne jung sind, dass sie ihre Entwickelung noch vervollständigen könnten. Es scheint eher, dass die Fähigkeit einer expansiven Veränderung vorübergehend ist, und dass jene Zellen, welche nicht während der eigentlichen Wachstumsperiode eines Tieres reagieren, ihre Möglichkeit für immer verloren haben" (22, S. 37).

Dies ist ebenfalls von Rubner ausgesprochen worden. „Wir wissen eigentlich gar nicht, ob die Natur ein absolut gleichmässiges tägliches Wachstum verlangt, oder ob Remissionen zulässig oder gar zweckmässig sind. Nur das steht sicher, dass die Behinderung des Wachstumstriebes, 
wie dies wirklich vorkommt, nicht während der ganzen Wachstumsperiode andauern darf, da sonst allerdings die Grösse des Individuums dauernd Schaden leidet. Verlorene Körpergrösse in der Jugendzeit kann nach Vollendung der Wachstumsperiode nimmermehr ausgeglichen werden" $(99,100$, S. 82). Ferner lesen wir: „Das schliessliche Versagen des Wachstums bängt auch natürlich nicht mit einer ungenügenden Ausbildung der Resorption der Nahrung zusammen; ein eben ausgewachsenes Individuum kann das Mehrfache an Nahrung resorbieren von dem, was an Unterbalt nötig ist, den Wachstumstrieb wird man nimmer wecken. . . . Das Tier hört bei geringer Eruährung auf, überhaupt zu wachsen, vollzieht aber seine sonstige biologische Entwickelungsperiode. Obschon das Wachstum künstlich gehemmt werden kann und somit latent bleibt, verliert sich trotzdem der Wachstumstrieb. Die Wachstumsfähigkeit kann in ihrer Begrenzung nicht von einer nur im Wachstum selbst entstehenden Schädigung oder einem mit der Zellmasse und Zellbildung unmittelbar zusammenhängenden Vorgang gebunden sein, weil sie auch da schliesslich schwindet, wo sie überhaupt nicht in Anspruch genommen worden ist" (98, S. 116-117). Ferner ,alle Mittel, alle Versuche, unsere alternden Zellen mit verjüngender Kraft zu versehen, sind eitel; nichts kann den Verfall hemmen. Nur die Befruchtung vermöchte neues Leben zu schaffen. Diese Hilfe ist uns aber versagt, sie gilt nur den Fortpflanzungszellen, der neuen Generation, der Zukunft" (98, S. 180).

Dass noch einige andere Faktoren, ausser Ernährung und Alter in das Problem eingreifen können, wird von Minot angedeutet: „Mit dem, was ich bis jetzt in bezug auf die Wachstumsmöglichkeit gesagt habe, habe ich Thre Aufmerksamkeit hauptsächlich auf die Wachstumsmöglichkeit gelenkt, sowie sie in einer Zelle infolge des Zustandes jener Zelle existiert. Wenn sich die Zelle in jugendlichem Zustande befindet, kann sie rasch wachsen; sie kann sich frei vervielfältigen; wenn sie altert, verliert sie jene Fähigkeiten und ihr Wachstum und ihre Vervielfältigung werden entsprechend gehemmt, und wenn die Organisation bis zu einem äussersten Punkt gekommen ist, hören Wachstum und Vervielfältigung der Zelle überhaupt auf. Wir finden jedoch, dass noch etwas Kompliziertes in Betracht zu ziehen ist, denn es ist nicht nur eine Frage der Fähigkeit der Zellen, sondern auch der Übung dieser Fähigkeit, mit welcher wir zu rechnen haben. Hier kommt ein Faktor hinzu, den wir aus dem Studium der Regeneration kennen lernen“ $(61$, S. 462$)$.

Die Tatsachen, die anderen Orts von Osborne und mir dargestellt worden sind, geben den sicheren Beweis, dass das Wachstum von Ratten und Mäusen unterdrückt, oder während sehr langer Zeit zurückgehalten werden kann, selbst über das Alter hinaus, in welchem irgend eine deutliche Zunahme der Grösse gewöhnlich vorkommt, ohne Verlust der Fähigkeit späteren Wachstums unter geeigneten Diätbedingungen $(82,83,120)$. 
Ehe wir über unsere eigene Erfahrung auf diesem Gebiet berichten, müssen wir auf einen Unterschied zwischen Wachstum, so wie wir ihn verstehen, und die verwandten Prozesse der Regeneration verstümmelter Teile oder Organe hinweisen. Es sind schon brauchbare Anzeichen dafür vorhanden, dass die chemischen oder Stoffwechselprozesse der Regeneration keineswegs mit dem. Wachstum identisch sind. Sie brauchen nicht die Zerstörung und den Wiederaufbau eines ganzen Eiweissmoleküls oder der ganzen protoplasmatischen Zellstruktur in sich zu schliessen. Ferner ist es eine anerkannte Tatsache, dass Regeneration oder Wiederherstellung in jedem Alter und sogar nach Vollendung des normalen Wachstums stattfinden kann, obgleich es wünschenswert sein könnte, die Fähigkeit zu regenerieren in bezug auf das Alter zu untersuchen. Es wird allgemein angenommen, dass Kinder ihr Gewicht rascher wieder gewinnen als Erwachsene. Wir haben wiederholt beobachtet, dass Tiere, welche merklich an Körpergewicht abgenommen hatten, ihr für ihr Aiter normales Gewicht wieder erlangen, wenn sie zu richtiger Kost und gesunden Bedingungen zurückkehren, mit einer Geschwindigkeit, welche bei weitem die beim normalen Wachstum des Individuums durch dieselbe Reihe des Körpergewichts übertrifft. Der Prozess der Wiederherstellung vollzieht sich mit wunderbarer Geschwindigkeit (70). Ein auffallend deutliches Beispiel hiervon ist auf Tafel I abgebildet. Trotzdem muss als wahrscheinlich, aber als kaum möglich angenommen werden, dass wiederhergestellte Individuen, nicht in jeder Hinsicht normal sein brauchen. Qualitative Veränderungen, welche durch die flüchtigen Untersuchungen nicht bestimmt worden sind, können beständig geworden sein (25).

Dass das Wachstum im f r ühen Alter verzögert oder.während kurzer Perioden ganz gehemmt sein kann, ohne Verlust der Fähigkeit es zu vollenden, ist bekannt. Hatai hat z. B. gefunden, dass ,soweit wie das Gewicht des Körpers und des Zentralnervensystems in Betracht kommt, die Wirkung einer einundzwanzigtägigen teilweisen Hungerperiode auf Albinoratten, die 30 Tage alt sind, eventuell vollständig ausgeglichen wird" (43).

Hans A ron verdanken wir mühsame Versuche über den Einfluss der Hemmung des Wachstums während der frühen Lebensperiode auf die Fähigkeit der Tiere ihre normale Entwickelung zu vollenden. Er brachte diese Verzögerung durch Unterernährung zustande. Die früher von A ron $(7,8)$ an Hunden ausgeführten Versuche zeigten, dass die Tiere trotz der beträchtlichen Wachstumshemmung, welche jedoch nicht während der ganzen Periode der Adoleszenz ausgedehnt wurde, noch eine Fähigkeit energisch zu wachsen behielten. Das steht im Gegensatz zu der weiteren Beobachtung, dass; wenn die Verminderung der Kost und die Hemmung des Wachstums über die ganze gewöhnliche Periode des Wachstums ausgedehnt worden ist, die Tiere die Fähigkeit zu wachsen offenbar verloren haben. Z: B. wurden von zwei, ungefähr 3 Monate alten Hunden einer normal ernährt und der andere auf 
einem annähernd konstanten Gewicht von ungefähr $2400 \mathrm{~g}$ während 310 T'agen gehalten. Am Ende dieser Periode hatte das normale Tier ein Gewicht von $6800 \mathrm{~g}$ erreicht. Das unterernährte Tier wurde nun reichlich gefüttert, worauf es reichlich Fett ansetzte. Trotzdem zeigte es nach 500 Tagen wenig $\mathrm{Zu}$ uahme an seiner Körperlänge, trotz der Gewichtszunahme, und es blieb an Umfang beträcbtlich hinter seinem Gefährten zurück. Neuere Versuche von A ron (9) an Ratten in derselben Ricbtung haben gezeigt, dass das Wachstum dieser Tiere im frühen Alter durch Unterfütterung während längerer Zeit verzögert wird und dass doch eine Fähigkeit für späteres kräftiges Wachstum beibehalten werden kann. Dieser Forscher bemerkt jedoch: „Allerdings scheinen die Tiere weder in Gewicht noch in Grösse ihre normalen Brudertiere völlig zu erreichen und das Versäumte nicht ganz nachholen zu können." Wenn wir daher die Versuche im ganzen betrachten, lassen sie immer noch die Frage offen über die Beziehung des Alters zu der Fähigkeit nicht erledigtes Wachstum wieder aufzunehmen.

Obgleich Rubner (y8) vor kurzem behauptet hat, dass die Wachstumsfähigkeit schliesslich verschwindet, selbst wenn sie nicht ausgenützt wird, hat Aron (9a) in einer späteren Übersicht des Wachstumsthemas gezeigt, dass der experimentelle Beweis gegen diese Annahme spricht (104a). Er bezieht sich besonders auf die von uns veröffentlichten Beobachtungen $(83,83 \mathrm{a})$, in welchen gezeigt wurde, dass die Fähigkeit zu wachsen im Alter von 314 Tagen nach einer Hemmung von 276 Tagen fortdauern kann. Es werden Tatsachen angeführt um die Annahme zu unterstützen, dass dje schliessliche ausgewachsene Körpergrösse durch se h $\mathrm{r}$ l̇an g an da u ernde Unterernährung während des Jünglingsalters merklich beeinflusst werden kann. Bei der Besprechung des Wachstums von Kindern bemerkt Boas (12), dass, obgleich Verzögerung des frühen Wachstums durch anormal rasche Entwickelung in einer späteren Periode ausgeglichen werden kann, eine ungebührlich lang andauernde Verzögerung nicht ganz kompensiert werden kann; infolgedessen kann eine übermässig frühe Hemmung des Wachstums für das Individuum verhängnisvoll werden. Obgleich das Wachstum des Körpers bei der Erholung sehr rasch ist bei Kindern, deren Entwickelung vorübergehend durch Krankheit oder andere ungünstige Bedingungen gestört worden ist, so muss das, was in den letzten Zeiten der Lebensspanne mit ibnen geschieht, noch bestimmt werden, um die Frage zu beantworten, ob teilweiser Hunger im frühen Lebensalter irgend einen Einfluss entweder auf die Langlebigkeit oder auf den Eintritt des Alters hat (42). Aron weist darauf hin, dass die meisten der spärlichen, experimentellen Tatsachen, welche über diesen Gegenstand gesammelt worden sind, sich auf Individuen beziehen, die durch Unterernährung in ihrem Wachstum gehemmt worden sind, und er wirft die Frage auf, ob sich die aus einer solchen Art der Hemmung gezogenen Schlüsse ebensogut auf andere Bedingungen verzögerten Wachstums anwenden lassen. 
Die Wachstumsfähigkeit, und die Intensität des Wachstumstriebes kann sach den Erfahrungen der beschriebenen Versuche nicht mehr vornehmlich als eine Funktion des Alters, d. h. der nach dem Befruchtungsvorgang verstrichenen Zeitspanne oder der im Körper abgelaufenen Zahl der Zellteilungen betrachtet werden, und auch nicht von der umgesetzten Kalorienzahl abhängig sein. Massgebender als das Alter scheint die endgültige Grösse des Individuums zu sein, wie die folgende Beobachtung dartun soll: Weibliche Ratten erreichen ausgewachsen nur ein erheblich geringeres Gewicht als männliche Geschwistertiere; ihre Wachstumskurve verflacht sich früher und ihr Wachstum stockt vor dem der Brudertiere gänzlich. Hemmt man nun eine junge männliche Ratte im Wachstum so lange bis ein Schwestertier ausgewachsen ist und das gehemmte Brudertier erheblich an Gewicht übertrifft, und füttert jetzt erst das gehemmte Brudertier auf, so erreicht endgültig doch das männliche Tier trotz der Wachstumshemmung noch ein beträchtlich höheres Gewicht als das Schwestertier, ein Ausdruck der überragenden Wirkung der kongenitalen Anlage (des Wachstumstriebes) auf den Ablauf der Wachstumsvorgänge gegenüber sekundären Momenten (9a).

Bei der Untersuchung der Fähigkeit der Albinoratten ihr Wachstum fortzusetzen nach mehr oder weniger lang andauernder Hemmung dieser Funktion, haben wir die Unterbrechung des Wachstums vermittelst verschiedener Verfahren versucht (83). Anstatt der Methode der Unterernährung mit Rationen von geeigneter qualitativer Zusammensetzung, haben wir wirksame Verkrüppelung auf verschiedenen anderen Wegen herbeigeführt, wie z. B. der Anwendung von Diäten, welche ein geeignetes Eiweiss enthielten und die anorganischen Salze in der Form einer Mischung reiner Chemikalien, wie sie Röhmann benutzte, zusammen mit Rohrzucker und Stärke als Kohlehydratbestandteil (Tafel IV); durch Einschränkung des Eiweissgehaltes in der Nabrung unter dem für das Wachstum erforderlichen Minimum; durch Lieferung, als ausschliesslicher Quelle für die Stickstoffaufnahme von Eiweisskörpern, welchen eine für das Wachstum unentbehrliche Aminosäuregruppe fehlte (Tafél III und IV Fig. 4 und 5 [172a]). In all diesen Versuchen ist Sorge getragen worden, um jede andauernde Körpergewichtsabnabme bei dem angewandten Diätregime zu verhüten. Da manche von ihnen selbst für kurze Erhaltung ailein ungeeignet sind, wäre es notwendig, die Ratten von Zeit zu Zeit. durch Einführung eines vollkommenen Nahrungsmittels wie unsere Milchnährgemische es sind, wieder zu beleben. Sobald die Tiere auf diese Weise wieder auf ihr früberes maximales Gewicht gebracht worden waren, oder sogar etwas darüber, wurde die Hemmungsdiät wieder erneut (s. Tafel III und IV).

Die Resultate mancher dieser Versuche sind graphisch auf den beigegrebenen Tafeln angegeben. Bei der Erklärung derselben ist es notwendig, an die gewöhnliche Dauer der normalen Wachstumsperiode zu denken. Diese 
ist ausserordentlich variabel; sie überschreitet aber seiten 335 Tage. Strenge Grenzen in bezug auf die Dauer des Wachstums und die erreichte maximale Grösse können nicht angegeben werden. Die Männchen werden immer grösser als die Weibchen. Nur vier von 110 Ratten, alles Weibchen, nahmen nach einem Jahre an Gewicht zu; von 38 Männchen nahmen nur vier nach 300 Tagen an Gewicht zu. Unter dem angegebenen Alter ist die Zunahme an Körpergewicht ausserordentlich langsam, wenn sie überhaupt vorkommt; und wahrscheinlich stellt sie eher Ablagerung von Reservestoffen, wie Fett dar, als Wachstum im Sinne von Entwickelungsveränderungen.

Bei manchen der verkrüppelten Tiere lag das momentane Körpergewicht an dem Tage, an welchem eine wirksame Kost für das Wachstum wieder aufgenommen wurde, unter demjenjgen, welchøs sie in einer früheren Zeit erreicht hatten. Eine Gewichtszunahme bis zu der Zahl des früheren Maximums, kann in Wirklichkeit nicht als neues Wachstum angesehen werden, insofern, als es bloss etwas der Wiederherstellung Analoges darstellt. Daher haben wir auf einer "Grundlinie" in manchen Kurven den Punkt vermerkt, an welchem das Gewicht anfing über das frühere Maximum hinaus zuzunehmen, und wir haben diesen als den Anfang des neuen Wachstums betrachtet.

Bei Ratte 531 q, Fig. II, Tafel II, war die Wachstumsfähigkeit im Alter von 532 Tagen nicht verloren, oder bei noch inehr als der Hälfte der Lebensspanne der meisten Ratten, welche wir unter unseren Bedingungen einstellten und im Käfig bielten ${ }^{1}$ ). Dieses Tier war, wie bemerkt werden muss, schon bis auf eine Grösse von $170 \mathrm{~g}$ gewachsen, ehe die Hemmungsperiode mit Kornglutennahrung (80) weitere Gewichtszunahme hemmte. Ratte 569, Fig. III, Tafel I/II, auf ähnliche Weise bei $160 \mathrm{~g}$ Körpergewicht gehemmt, zeigte eine energische Wachstumsreaktion im Alter von 480 Tagen. Fig. IV, Tafel III/IV stellt die Wiederaufnahme des Wachstums im Alter von 417 Tagen dar nach einer Periode sehr lang andauernder Wachstumshemmung mit Hilfe der Methode von Fütterung mit unvollkommenen und vollkom. menen Futtergemischen (angegeben durch die geraden bzw. unterbrochenen Linien). Ein ähnlicher Versuch ist auf Fig." V, Tafel III/IV gezeigt, in welchem die Hemmung des Wachstums und der Ernährungsverminderung von dem unterbrochenen Gebrauch von Gelatine, als einziger Stickstoffquelle in der Nahrung herrührte.

Die anschaulichen experimentellen hier beleuchteten Resultate verleihen der weitverbreiteten Ansicht keine Stütze, dass der Wachstumstrieb, die Wachstumsfähigkeit, oder der Wachstumsimpuls, wie er häufig genannt wurde, mit dem Alter verloren geht, gleichgültig ob er während der gewöhnlich mit der Grössenzunahme verknüpften Periode funktioniert hat oder nicht. Die

1) Slonaker (106) hat Albinoratten lebendig mehr als 1000 Tage in seinem Laboratorium gehalten. 
Schwierigkeiten, Versuche dieser Art eher wäbrend Jahren, als während Monaten fortzusetzen, sind gross, so dass wir nicht in der Lage sind zu sagen, dass der Wachstumsimpuls bei unerwachsenen Tieren niemals im Laufe der Zeit erschöpft wird. Aber es scheint, als ob die Wachstumsfähigkeit durch die Ausübung dieser fundamentalen Eigenschaft der tierischen Organismen verloren wird.

Diese Schlüsse sind nicht durch ein einziges Verfahren erreicht worden, denn wir verhinderten unsere Tiere vermittelst vieler Methoden am Wachstum. Ob die Lebensspanne durch Verzögerung der Wachstumsvollendung verlängert werden kann, ist noch nicht unter Bedingungen festgestellt worden, die Krankheit oder Emährungsanomalien ausschliessen.

\section{Der normale Vorgang des Wachstums.}

„Dass die Fähigkeit zu wachsen eng mit der Lebenslänge bei den verschiedenen Tieren in Beziehung steht, ist fraglos, aber eine geeignete Formulierung dieser Beziehung ist schwierig. Sicherlich existiert bis jetzt noch keine geeignete Erklärung der Tatsache, dass manche Tiere länger als andere leben; wir finden im allgemeinen, dass grössere Tiere diejenigen sind, die länger leben, und so muss die Lebenslänge mit der Grösse assoziiert sein; aber wenn man diese Beziehung prüft, scheint es, dass die Grösse von zwei Faktoren abhängt - der Geschwindigkeit des Wachstums und von der Zeitlänge, welche das Wachstum andauert; und Tiere, welche einen grossen Umfang erreichen, wachsen sowohl rasch wie während einer langen Zeit" (22, S. 33). Obgleich wir ein wenden können, dass die Wachstumsmöglichkeit, soweit sie geht, ein Schutz gegen beginnende Entartung ist, ergibt doch eine Untersuchung der Einzelheiten wegen unserer geringen Einsicht in bezug auf die Lebensdauer bei Tieren nicht viel. Im allgemeinen nimmt man an, dass Vögel, Reptilien, Batrachier und Fische fähig sind, viele Jahre lang zu leben. Es scheint ferner, dass viele Reptilien und manche Fische fast ebensolang wachsen wie sie leben, aber im späteren Leben ist ihr Wachstum sicherlich sehr langsam. Bei Vögeln konnte man an vielen Beispielen zeigen, dass sie mehr als hundert Jahre alt werden und dabei lang andauernd wachsen. Bei ihnen kann man daher weder von beständigem Wachstum noch von erheblicher Grösse reden, um ihr langes Leben zu erklären, so dass also in Wirklichkeit die eigentlichen Bedingungen, welche die Langlebigkeit bestimmen, noch unerkannt sind" (22, S. 35). Das Phänomen des natürlichen Aufhörens des Wachstums ist bekannt. „Wenn das Wachstum fortschreitet und die natürliche Reife eintritt, wird die Fähigkeit des Individuums, zu wachsen, rasch geringer. Dies ist eine eigenartige und hochinteressante Tatsache, welche noch nicht erklärt worden ist" $(50$, S. 926).

Minot $(50,60,61)$ hat insbesondere die Ansicht vertreten, basiert auf seine Untersuchungen der prozentualen Gewichtszunahmen, welche schon er- 
wähnt worden sind, dass es bezüglich der Wachstumsmöglichkeit schon von einem sehr frühen Zeitpunkt an ein deutliches Versagen gibt. Der Abfall in der Wachstumsfähigkeit, gemessen an der Änderung in der Wachstumsgeschwindigkeit, ist zuerst ausserordentlich rasch und später langsam. Er rührt von Vorgängen im tierischen Körper selbst her. Nach Minot beruht das raschere Wachstum daher auf der Jugend des Individuums - seiner kleinen zeitlichen Entfernung seit s ei n er Erzeugung. Das Aufhören des Wachstums ist so mit dem Alter verknüpft. Nach dem ,Gesetz der genetischen Einschränkung" ist das Schicksal einer Zelle, nachdem sie vorgeschritten und bis zu einer bestimmten Grenze differenziert ist, damit auch bestimmt. „Sie kann von da an weiter gehen nach einer oder der anderen Richtung, immer fortschreitend, in ihrer Zytomorphose weitergehend, aber die allgemeine Richtung ist vorgeschrieben worden, und die Möglichkeiten jener Zelle werden, wenn sie in ihrer Entwickelung fortschreitet, immer eingeschränkter" (63). Das Aufhören des Wachstums ist ferner nach dieser Ansicht nur ein Eingriff in die Zytomorphose, welche das Altwerden bestimmt. Minot hat zwar früher angenommen, dass das Wachstum bis zum Nullpunkt binabsiukt, ,weil es einen bestimmten zur Zeit der Befruchtung gegebenen Impuls gibt, welcher allmählich verschwindet, so dass von Anfang des neuen Wachstums an eine Herabsetzung der Wachstumsgeschwindigkeit eintritt". Da ven port, welcher sich von dem konstanten Wachstum der Pflanzen leiten liess, lehnte Minots Theorie ab. Er nimmt an, dass das endgültige Aufhören eine spezielle Eigenschaft bostimmter Organismen ist, die gleich strukturellen Eigenschaften auf Grund besonderer Qualitäten zu erklären sind. „Der Grund, warum das Tier endlich aufhört zu wachsen, ist derselbe, warum das differenzierte Gewebe unter der Spitze des Epicotylen zu wachsen aufhört, nicht weil eine notwendige Grenze für die Wachstumskraft in einem gewissen Zeitraum von der Befruchtung an eintritt, sondern weil es in der. Natur der Art liegt, dass das Individuum an diesem Punkte aufhören muss zu wachsen. Das unbegrenzte Wachstum dieses Teiles, das beschränkte Wachstum jenes, sind ebensosebr Eigenschaften einer Gruppe, wie irgend eine strukturelle Eigenschaft" (2, S. 290).

Morgan (67, S.211) hat gemeinsam mit anderen gezeigt, dass das Aufhören des Wachstums nicht notwendigerweis e von einem Verlust der Fähigkeit weiteren Wachstums abhängt. Die Fähigkeit mancher Tiere, Teile zu regenerieren - ein Vorgang, der nahe verwandt ist mit dem Wachstum - gebietet für die verschiedenen Perioden des Lebens Vorsicht beim Ziehen von Schlüssen in bezug auf den Verlust der Wachstumsmöglichkeit. Es kann etwas das Wachstum hemmen, wenn das Alter fortschreitet. Morgan hat festgestellt, dass wir aus den 'Tatsachen der Regeneration schliessen müssen, dass tierische Gewebe nicht leicht ihre Fähigkeit weiter zu wachsen verlieren. Es ist manchmal angenommen worden, dass das Wachstum verzögert oder gehemmt 
wird, weil das Tier nur eine bestimmte Menge von Nahrung verdauen kann, und dass die ausgewachsene Grösse das Gleichgewichtsstadium zwischen der verdauten Menge von Nahrung und der verbrauchten Menge ist. Die experimentellen Versuche führten Morgan jedoch zu dem Schluss, dass das Aufhören nicht primär von dem Problem der Nahrungsversorgung herrührt (68, S. 219). Die Natur der Hemmung, welche die Entwickelung hindert, wenn die Grösse sich der Norm nähert, ist für das Tier noch unbekannt.

Wenn wir beim Suchen nach etwas mehr Spezifischem in bezug auf die Abnahme oder das Aufhören des Wachstums unsere Aufmerksamkeit auf die Einheit der biologischen Tätigkeit, auf die Zelle, lenken, können gewisse allgemeine Prinzipien in Betracht gezogen werden. In einem einzelligen Organismus übertrifft unter günstigen Ernährungsbedingungen der Prozess des Aufbaus denjenigen des Abbaus, so dass der Körper an Umfang bis zu einer Grenze zunimmt, wo Spaltung stattfindet. „Was die Grenze bestimmt, ist unbekannt, aber die Ursache ist vielleicht auf irgend eine Weise mit dem geometrischen Prinzip verknüpft, dass das Volumen der Zelle wie der Kubus ihres Durchmessers zunimmt, während die Oberfläche, durch welche sie die Nahrung resorbiert und auf andere Weise in Beziehungen zur Aussenwelt tritt, nur im Quadrat ihres Durchmessers zunimmt" (105). Da die Tätigkeit eine Funktion der Oberfäche ist, muss, je grösser die Einheit ist, um so geringer ihre Tätigkeit sein. Ein Organismus kann auf dieser Basis nur einen grossen Umfang durch eine Vervielfältigung von Einheiten erreichen, wobei jede dieselbe Menge an Oberfläche zeigt wie ein einzelner zellulärer Organismus, obgleich sie eher einem inneren als einem äusseren Medium ausgesetzt ist. Eines der Geheimnisse des Wachstumsstillstandes bei höheren Arten liegt in der Einschränkung dieser Zellteilung. Nach Minot. „hängt die Wachstumsgeschwindigkeit von dem Grade des Altwerdens $a b$ ", wobei das letztere aus der Struktur erklärt wird; das Altwerden hängt von der Zunahme des Protoplasmas und von der Differenzierung der Zellen ab. Bei der Kritik dieser kurzgefassten Auffassung betont Donaldson, dass sie einen wichtigen Faktor vernachlässigt, der die Wachstumsgeschwindigkeit modifiziert. Es ist die Akkumulation von Zellen. ;Wenn wir die Bedingungen analysieren, welche zur Verminderung der Geschwindigkeit führen, stellen sich die allgemeinen Prozesse folgendermassen dar: Die aufbauenden Zellen des Körpers vergrössern sich, teilen sich und vergrössern sich wiederum, zur selben Zeit, wo manche von ihnen aufhören sich zu teilen. Die Anzahl dieser letzteren Zellen nimmt rasch zu, während die relative Anzahl der sich teilenden Zellen abnimmt. In bezug auf die absolute Zahl der sich mit zunehmendem Alter teilenden Zellen ist unser Wissen sehr gering. Der Körper nimmt solange an Gewicht $\mathrm{zu}$, als die sich teilenden Zellen fortfahren sich zu vervielfältigen und die anderen sich zu vergrössern. Wachstum ist $\mathrm{Zu}$ nahme an Gewicht. Die Wachstumsgeschwindigkeit sinkt, wie gezeigt worden 
ist, rasch, besonders während der früheren Stadien. Ausser anderen Umständen, welche zu diesem Resultat beitragen, scheint das grösstenteils von der Anhäufung von Zellen herzurühren, welche zu irgend einer gegebenen Zeit mehr oder weniger ihre volle Grösse erreicht haben und bei denen weiteres Wachstum tatsächlich aufgehört hat. Gleichzeitig hiermit schreiten die zytomorphen Veränderungen, welche die Seneszenz bedingen, fort, aber natürlich schliesst die Seneszenz, so wie sie in dem obenstehenden zweiten Altersgesetz definiert worden ist, diese Idee der Akkumulation von Wachstumsprodukten nicht in sich ein. Daher wird, wenn die Wachstumsgeschwindigkeit abnimmt und der Zustand des Altwerdens fortschreitet, die Wachstumsgeschwindigkeit auch grösstenteils durch den Faktor modifiziert, auf welchen wir soeben die Aufmerksamkeit gelenkt haben. Gleichzeitig wird der Vergleich zwischen Wachstumsgeschwindigkeit und Seneszenz weiter dadurch erschwert, dass, während sich die Verminderung der Wachstumsgeschwindigkeit kurvenmässig darstellen lässt, es nicht ebenso möglich ist, eine graphische Darstellung des Fortschreitens des Altwerdens herzustellen. Die Übereinstimmung zwischen den beiden Serien der Ereignisse ist daher allgemeiner und weniger vollständig als die Fassung des Gesetzes es zeigen würde" (26, S. 376).

Eine weitere Erörterung des Wachstumsstillstandes gilt den Beziehungen des Kerns zum Zytoplasma in den wachsenden Zellmassen. Die Ernährung und das Wachstum in den Zellen beruhen auf der Gegenwart eines Kernes. Zellen, welche einen sehr grossen Umfang erreichen, können viele Kerne entbalten. Der Prozess der Zellteilung wird durch das Verbältnis der Masse des Kernchromatinmaterials zu dem des Protoplasmas der Zelle bestimmt (13). Loeb hat gezeigt, dass nach der Befruchtung eine ungeheure Synthese von Kernmaterial statthat. Er nimmt die Möglichkeit an, dass die Zellteilung durch die Gesetze der Massenwirkung und des chemischen Gleichgewichtes bestimmt wird $(51$, S. 61). Diese Synthese der Kernverbindungen aus den protoplasmatischen Bestandteilen ist nach Loeb ein reversibler Prozess. Da beständig Neuanpassungen stattfinden, um das Missverhältnis zwischen Kern und Protoplasmamaterial zu stören, kann das Aufhören des Wachstums irgendwie mit der Herstellung des Gleichgewichts nach bestimmten chemischen Gesetzen verknüpft sein $(89$, S. 581).

\section{Wachstum und Seneszenz.}

Seneszenz ist als eine Eigenschaft der meisten lebenden Materie definiert worden, die ihren auffallendsten Ausdruck in dem allmählichen Verlust der funktionellen Fähigkeiten des Organismus, ihr Ende im Tode findet. Nach dieser, von Minot vertretenen Ansicht, kann das Altwerden als ein Verlust der Wachstumsmöglichkeit angesehen werden - das berechtigt dessen Erwähnung in diesem Essay. Da nach der Definition von Minot die Wachstumsmöglichkeit von der Geburt an allmählich abnimmt, beginnt die 
Seneszenz sehr frühe. Sie. ist nicht ganz synonym mit dem, was wir im gewöhnlichen Sprachgebrauche mit Verfall bezeichnen. Wenn wir das zugestehen, müsste die nächste Grundlage der so definierten Seneszenz, den Schlüssel zur Erklärung des Wachstumsstillstandes in sich schliessen. „Das Protoplasma ist die physikalische Basis der fortschreitenden Gebrechlichkeit." Dieses Diktum lenkt die Aufmerksamkeit auf die morphologische Betrachtung der Zellen. Es sieht das hohe Alter nicht als eine Krankheit an, bei welcher abwendbare Zustände des Verdauungskanals zu unzeitiger Vergiftung des Organismus mit dem Produkt anormaler Fäulnisveränderungen führen (Metchnik off). Die Zunahme des Protoplasmas in den Zellen ist, nach Minot, sowohl das Zeichen für fortschreitende Organisation wie für vorgerücktes Alter. Er hat die etwas paradoxe Ansicht, dass die Zunahme des Protoplasmas - die physikalische Grundlage des Lebens - ein Zeichen hohen Alters ist, in folgenden Worten ausgesprochen: „Ich betrachte den Verlust der Wachstumsmöglichkeit des Körpers als von der Zunahme und der Differenzierung des Protoplasmas in der einzelnen Zelle herrührend. Natürlich geht diese Zunahme in den Zellen nicht in allen gleichmässig vor sich. In manchen ist sie frühzeitig stark, in anderen ist sie lange verzögert. Ein wichtiger Teil unserer Körperfunktionen hängt von der lebenslänglichen Erhaltung gewisser Zellen in einem mehr oder weniger embryonalen Zustand $a b$, die deshalb konstanter Vervielfältigung fähig sind. Solche Zellen bedingen das Wachstum der Haare und der Nägel. Solche Zellen dienen zur Erneuerung des Blutes usw. Aber im weiteren Sinne gesprochen, ist es natürlich richtig, dass die Menge des. Protoplasmas im Verhältnis zu den Kernen zunimmt, und dass, wenn sie zunimmt, die Wachstumsfähigkeit abnimmt. Sind wir daher nicht berechtigt zu sagen, dass die Zunahme und die Differenzierung des Protoplasmas die Ursache der Abnahme der Wachs. tumsmöglicbkeit ist?. Altwerden besteht in anderen Worten primär in einer relativen Zunahme des Protoplasmas. Wir besitzen so ein zytologisches Zeichen, durch welches das hohe Alter erkannt werden kann, und wir sind imstande, Seneszenz mit sichtbaren Veränderungen in den Zellen zu verknüpfen, wir sind imstande, zu behaupten, es gibt eine histologische Grundlage oder Ursache des hohen Alters".(60, S. 247). Die Verjüngung müsste nach dieser Grundlage in einer Überproduktion von Kernmaterial bestehen.

Diese morphologischen Kriterien der Seneszenz sind nicht unangefochten geblieben. Child $(16,17)$ hat eine physiologische Erklärung formuliert, nach welcher die Seneszenz wesentlich nicht, wie Minot es postuliert hat, in Zytomorphose besteht, sondern in einer Verminderung der Geschwindigkeit des Stoffwechsels infolge der Zunahme der strukturellen Hindernisse für den Stoffwechsel. Die Zelle wird weniger erregbar, weniger reizfähig, und wenn der Prozess weit genug geht, ist Tod oder Stillstand die Folge. Die beiden Ansichten haben viel Gemeinsames, denn die Anhäufung von strukturellen 
Substanzen bedeutet gewöhnlich Zunahme des Zytoplasmas; aber es kann eine Zelle oder ein Organismus alt werden ohne irgend eine derartige Zunahme des Umfanges des Zytoplasmas zu zeigen, nur infolge Zunahme an Dichtigkeit und Undurchlässigkeit ihrer Membranen oder infolge Wasserverlustes (10). Äbnlich hat Conklin gesagt: „Meine Beobachtungen stützen nicht die Ansicht, dass Seneszenz herrührt von einer Abnahme (Minot) oder einer Zunahme (Hertwig) des Kernes im Verhältnis zum Protoplasma; noch dass die Verjüngung während der Spaltung durch die grosse Zunahme des Kernstoffes, relativ zu dem Protoplasma geschieht. Andrerseits scheint die Seneszenz mit einer Abnahme, die Verjüngung mit einer Steigerung des Stoffwechsels verknüpft zu sein (Child). Alles was den Austausch zwischen Kern und Zytoplasma vermindert, wie Differenzierungs- und Stoffwechselprodukte innerhalb der Zelle oder dichte Kernmembran, setzt den Stoffwechsel herab und führt zur Seneszenz; alles, was diesen Austausch erleichtert, vermehrt den Stoffwechsel und führt zur Verjüngung. Es ist anzunehmen, dass in früher Entwickelung gesteigerte Oxydation mit Befruchtung und Mitose verknüpft ist (Loeb, Lyon, Warburg)" (9). Schliesslich hat Robertson von ganz anderen Betrachtungen aus den Gedanken kritisiert; ein allmähliches Fortschreiten der Seneszenz wurde dureh die Tatsache dokumentiert, dass die tägliche oder jährliche Gewichtszunahme von dem Augenblick des erreichten Maximums beständig abnimmt. „Im Gegenteil", schreibt er, ,sehen wir, dass die Betrachtung des Wachstumsverlaufs selbst zu keinem derartigen Schlusse führt; es folgt aus unserer Formel, dass die allmähliche Abnahme in der jährlichen oder täglichen Steigerung in der zweiten Hälfte eines Zyklus ebenso notwendig ist, wie seine allmähliche Zunahme während der ersten Hälfte; aus der Gewichtszunahme kanu man mit der Zeit eine nachfolgende Gewichtsabnahme ableiten. Daher ist die absolute Abnahme an Gewicht und Volumen, welche beim Altern ein sehr allgemeines Phänomen ist, von einem ganz sekundären Vorgang abhängig, welcher auf das Wachstumsphänomen selbst superponiert ist. Das gesamte Wachstum der Säugetiere scheint im allgemeinen das Resultat von drei Wachstumszyklen zu sein, deren relative Grössen und Zeitverhältnisse jedoch bei den verschiedenen Arten, Geschlechtern oder selbst Rassen, sehr verschieden sein können. Die Zeit der maximalen Steigerung in einer Zeiteinheit, welche von dém dritten Zyklus herrührt, scheint im allgemeinen mit dem Auftreten der Pubertät übereinzustimmen" (89, S. 613). Wieweit das Altern mit Änderungen der Struktur, des Stoffwechsels, mit Krankheit oder speziellen Typen des chemischen Gleichgewichtes zu erklären ist, diese Frage bleibt noch zu lösen. „Das Geheimnis des Ablaufs der tierischen Maschine erwartet noch eine Erklärung, obgleich natürlich die mechanischen Hindernisse gegen die Nahrung, welche auf Zunahme an Umfang folgen und die grössere Anstrengung, welche notwendig ist um nach der Trennung von der Mutter 
Nahrung zu erhalten, seit langem erkannt worden sind. Es gibt jedoch noch etwas anderes als diese Mechanismen in dem Problem. Man kann in der Tat annehmen, dass jedes Tier einen bestimmten beschränkten Vorrat von potentieller Energie besitzt, mit welcher es durchs Leben gehen muss, aber die verwickelte Art und Weise, wie diese Energie abgegeben werden kann, ist so gross, und die Kombinationen ihrer Erscheinungsweise so mannigfach, dass es bis jetzt nur auf die aller allgemeinste Weise möglich ist, die Kapazität eines gegebenen Individuums zu erschliessen. Wir geben zu, dass Krankheit fundamental erschöpfend ist, dass übermässige Anstrengung und Entbehrung ihr unverlöschliches Zeichen auf dem körperlichen Organismus zurücklassen, und doch ist so viel Kunst dabei in der Art und Weise, Anstrengung zu verausgaben, dass wir gegenwärtig ganz ohne Hilfsmittel sind, ihre Verausgabung aufzuzeichnen oder zu erklären, wie strukturelle Mängel verdeckt werden können" (204, S. 64). Wenn der Versuch, das Leben zu verlängern, biologisch vergebens ist, dann können wir mit v. Feuchtersleben übereinstimmen: „Das ganze Geheimnis sein Leben zu verlängern, besteht darin, es nicht zu verkürzen."

\section{Anormalitäten des Wachstums. - Die Pathologie des Wachs- tums.}

Unsere Auffassung von dem, was als eine Anomalie oder Abnormität des Wachstums angesehen werden soll, hängt von der Definition ab, welche wir für den normalen Vorgang angenommen haben. Wenn wir uns die Erklärung von Schloss über normales Wachstum in die „artspezifische korrelative Vermelırung der Körpermasse in bestimmten Zeitabschnitten “ ins Gedächtnis zurückrufen, wird es wahrscheinlich, dass die Abweichungen das Zeitelement in sich schliessen ("Anomalien der zeitlichen Entwickelung“) oder die Verteilung und die Beziehungen der verschiedenen Teile und Bestandteile des Körpers („Anomalien der korrelativen Entwickelung“). So können die in einer Zeiteinheit erreichten Gewinne nicht der durchschnittlichen Reihe der Körpergewichtszunahmen in einem gegebenen Alter oder in einer Entwickelungsperiode entsprechen; sie können kleiner oder sogar entschieden grösser sein. Abweichungen in diesen Zeitverhältnissen des Wachstums sind die häufigeren Anomalien. Korrelationsstörungen der wachsenden Teile können ganz unabhängig vorkommen, so dass einzelne Organe und Gewebe ihre gewöhnliche Struktur oder normale Funktion nicht erreichen können. „Das in einem bestimmten Zeitmoment bestehende Verhältnis der einzelnen Körperteile ist nicht das für den betreffenden Moment in der Artentwickelung vorgesehene" (104, S. 31). Solche Anomalien brauchen sich nicht auf einmal in der Wachstumskurve für den ganzen Körper zu offenbaren.

Die Ursachen für die Abnormitäten des Wachstums sind mannigfacher Art: konstitutionelle Defekte, unzutreffende Ernährung und verschiedene Faktoren 
der Umgebung können mehr oder weniger verantwortlich dafür sein. Es ist dementsprechend schwer, auf einer ätiologischen Grundlage die Zeichen zu klassifizieren, welche sie bedingen. Es kommen Abweichungen vor, die sich vermutlich noch im Bereich des Normalen befinden. Dies bezieht sich z. B. auf die Variationen im Wachstum der einzelnen Wesen eines Wurfes oder zwischen verschiedenen Würfen. Die Gewinne sind jedoch nicht zufällig. Bei Ratten hat Miss Dunn (28) gefunden, dass die einzelnen Tiere eines Wurfes ihre ursprüngliche Reihenfolge in bezug auf ihr Gewicht beizubehalten suchen, wobei besonders schwere Ratten ihre Überlegenheit bewahren. Weite und etwas fixierte Verhältnisse, wie diese, werfen die Frage auf, ob die Unterschiede eine pränatale oder postnatale Erklärung haben. Pfaundler (37) hat gezeigt, dass die Gewichtskurve nicht immer die Wachstumsmöglichkeit — "Lebenspotential" — in geeigneter Weise ausdrückt. Die prozentuale Gewichtszunahme - "Zuwachskoeffizient" - eines langsam wachsenden Kindes kann sogar grösser sein als die eines normal wachsenden Kindes. Wenn das erstere zu früh geboren worden ist, wird dies dadurch erklärlich, dass in früheren Perioden, wie im intrauterinen Leben, die Wachstumsgeschwindigkeit grösser ist. Wir haben es hier mit einem Individuum in einem absolut frühen Alter zu tun. Diese Zwischenfälle beim Wachstum sind daher nicht besonders pathologisch. Obgleich die Gewichtskurve ungewöhnlich sein kann, ist die Wachstumsmöglichkeit klar. Da ist keine absolute Lebensschwäche vorhanden wie bei den kongenitalen Defekten, wo das Lebenspotential gering ist. Offenbar können hier zwei Typen der kongenitalen Kraftlosigkeit unterschieden werden. Die obenstehenden Ausführungen können zur Erläuterung der Behauptung dienen, dass es oft schwierig ist die Linie zwischen dem normalen und dem anormalen Wachstum zu ziehen.

\section{Beschleunigung des Wachstums.}

Anomalien des Wachstums, durch eine übermässige Geschwindigkeit kenntlich, gehören $\mathrm{zu}$ den Seltenheiten in der Physiologie. Beispiele von frühem Riesenwuchs, welche in diese Kategorie passen könnten, sind beschrieben worden. Die häufigeren Fälle von schnellem Wachstum stellen gewöhnlich Erholung oder die Reaktion auf unterdrücktes Wachstum dar, viel eher als wirkliches Wachstum de novo. So sagt Schloss, indem er sich auf solche Beispiele in der Pathologie der Kinderjahre bezieht:

„Was von exzessiver Massenzunahme dem Kliniker häufiger vor Augen kommt, sind die Fälle, bei denen nach vorausgegangenem längeren Gewichtsstillstand, sei es durch Inanition, sei es durch Störungen der Entwickelung infolge von äusseren Schädigungen, das versäumte Wachstum schnell nachgeholt wird. Aber hier ist es fraglich, ob es sich um wirkliches Neuwachstum, also um eine enorme Beschleunigung der Zellteilung und Massenablagerung handelt; wahrscheinlich ist während des vorausgegangenen Ent 
wickelungsstillstandes ein grosser Teil der Wachstumsarbeit schon getan, so dass nur noch die stoffliche Ausfüllung des Vorgebildeten übrig bliebe. Zu dem letzteren wahrscheinlicheren Fall gehörte diese Art „Nachwachstum" zu den progressiven Korrelationsstörungen" (104, S. 35).

Mit anderen Worten, sobald das Wachstum eines ganzen Organismus sowie dasjenige einzelner Organe im Sinne der Beschleunigung modifiziert wird, schliesst das gewöhnlich die Umkehr oder die Rückkehr eines krankhaften in den normalen Zustand in sich.

\section{Hemmung des Wachstums.}

Hemmende Eigenschaften können sich durch abnorm vermindertes Wachstum, frühzeitigen Wachstumsstillstand oder sogar in der Abnahme an Grösse offenbaren. Langsames Wachstum (Hypoplasie), die erste Kategorie, ist eine bekannte menschliche Erfahrung, die erklärt werden kann, sowohl durch äussere wie durch innere Faktoren, welche in Verbindung mit den angenommenen Ursachen des Wachstums erörtert worden sind. Fehler in der Ernährung sind gewöhnliche Ursachen; aber selbst bei richtiger Diät kann ein Zustand der Erhaltung ohne Wachstum entstehen. Hier kommen wir zu den zwerghaften oder verkümmerten Individuen. Aron $(7,6)$ und W a ters $(116,117,118)$ haben interessante Beispiele für andauerndes Stationärbleiben des Gewichts während des Jünglingsalters geliefert. Durch Unterdrückung des Wachstums infolge Einschränkung der Nabrung, hat Aron die Zunahme des Körpergewichts verhindert, ohne gleichzeitig die Veränderung der Statur vollständig zu verhindern. Er unterscheidet zwei Perioden in seinen Versuchen: „Erste Periode. So lange sich eine Reserve an Energie im Körper befindet, entnimmt das Tier davon, während hungernde Körperteile weiter wachsen. Dieser Hunger erzeugt keinen Gewichtsverlust, so wie er es bei erwachsenen Tieren tun würde, sondern er wird durch eine Gewichtszunahme des Skeletts und durch eine Zunahme der Verwässerung des Körpers kompensiert oder sogar überkompensiert. Zweite Periode. Dieselbe beginnt, wenn das Tier die letzte Phase der Abmagerung erreicht hat, wobei, wenn die Aufnahme an Energie nur der zur Erhaltung erforderlichen Anforderung entspricht, kein Wachstum stattfindet, und sowohl Gewicht wie Wachstum stillstehen. Während der ersten Periode weisen Konstanz oder leichte Gewichtszunahme auf Hunger hin, während der zweiten Periode auf Aufhören des Wachstumstillstandes. Es ist nur möglich das Wachstum durch Einschränkung der Nabrung vollständig zu unterdrücken, wenn ein Tier so abgemagert ist, dass es keine weiteren Reservestoffe zu verbrauchen hat. Vom biologischen Standpunkt aus gibt es zwei Kräfte in einem wachsenden Tiere, welche in gewissem Sinne einander entgegengesetzt sind, der Trieb zu wachsen und der Erhaltungstrieb. In den ersten Perioden des Versuches scheint es, dass der Wachstumstrieb in einem jungen Tiere grösser ist als der Erhaltungstrieb. Der weitere Verlauf der Versuche zeigt, dass der Erhaltungstrieb 
schliesslich die Oberhand gewinnt. Daher scheint der Erhaltungstrieb die grössere biologische Kraft zu sein" (8). Wir zitieren weiter: „Es ist möglich, einen Hund, wenn man ihn mit den geeigneten Nahrungsmengen versorgt, in einem abgemagerten Zustand, scheinbar bei guter Gesundheit und beim Gewicht eines jungen Hundes fast ein Jahr lang zu erhalten, während sein Gewicht am Ende des Jahres fast 3 mal so gross sein sollte. Wenn ein solches Tier danach reichlich gefüttert wird, wird es fett und rund, erreicht aber nicht die Grösse eines Kontrolltieres, das von Anfang an normal gefüttert worden ist. Es ist nicht imstande das Wachstum wieder gut zu machen, das durch lang andauernde Nahrungsbeschränkung suspendiert worden ist. Das Wachstum beruht hauptsächlich auf dem Wachstumstrieb, welchen das Skelett besitzt. Das Skelett verliert in vorgerücktem Alter die Fähigkeit zu wachsen, ohne Rücksicht auf die Grösse, welche das Tier erreicht hat" (9, S. 43-44). Die Darstellung einer vollkommenen Erhaltung ohne Wachstum ist ziemlich eingehend im Zusammenhang mit unseren eigenen Versuchen an Albinoratten und Mäusen erörtert worden (82, 83, 120).

Allmähliche Gewichtsabnahme, negatives Wachstum (Kataplasie), ist ein ausgesprochen pathologisches Anzeichen. Wie die meisten Anormalitäten des Jünglingsalters, sind ihre klinischen Anzeichen von entscheidender Bedeutung.

Auf Unregelmässigkeiten des Wachstums beim Individuum folgt kompensierende Unregelmässigkeit. Minot hat gezeigt, dass es eines erstaunlich lang andauernden Eingreifens bedarf, um ein Meerschweinchen für immer zwerghaft klein zu machen. Verluste von einem Drittel des Körpergewichtes können wieder eingebracht werden (59, S. 134). Dies ist vermutlich auch beim Menschen der Fall, so dass ernste Krankheit in der Jugend auf die Grösse des Erwachsenen keinen starken Ejnfluss hat.

Schapiro (103) fand in Bestätigung des scheinbar festen und bestimmten Strebens nach gleichmässigem Wachstum, dass, wenn junge Kätzchen zweimal am Tag chloroformiert wurden, ihr Wachstum im Vergleich mit normalen Kontrolltieren verzögert wurde. Jedoch kompensierte nach dem Aufhören der Chloroformbehandlung die grössere Geschwindigkeit während einer Nachperiode völlig die frühere Verzögerung in der Entwickelung. Statistische Untersuchungen von Boas (12) an Kindern zeigen, dass Verzögerung im frühen Wachstum später durch abnorm rasches Wachstum wieder eingebracht wird. Ungebührlich lange Verzögerung kann auf diese Weise nicht kompensiert werden; deshalb ist, nach $\mathrm{B}$ o as, die übermässige Unterdrückung des Wachstums für das Individuum ungünstig. $\mathrm{Ob}$ alles Wachstum in solchen Fällen aufhört, oder ob unsere Messungen nicht hloss einen Verlust besonderer Körpersubstanzen, wie der angesammelten Nährstoffe anzeigen, muss festgestellt werden. Die Antwort gilt auch für die bereits aufgeworfene Frage mit, ob wir es bei dem Erholungsprozess mit neuem 
Wachstum oder mit dem Wiederaufbau der heruntergekommenen Gewebe zu tun haben.

Versuche, das Wachstum durch Mittel wie Alkohol, Nikotin, Kaffein usw. zu beeinflussen, sind in der Literatur verzeichnet (57). Sie brauchen in diesem Zusammenhang nicht näher besprochen zu werden. Man sollte daran denken, dass die sichtbaren Wirkungen nicht die einzigen sind, die in die Pathologie des Wachstums eingreifen können; Fehler können versteckt in den Kurven oder äusseren Erscheinungen vorkommen, ohne sich jedoch in den feineren Strukturen des Organismus, welche dem blossen Auge verborgen sind, zu erkennen zu geben.

\section{Die mit dem Wachstum verwandten Prozesse.}

Ehe wir weiter im einzelnen die Agenzien oder Ursachen des Wachstums untersuchen, ist es wünschenswert, wiederum auf gewisse Unterscheidungen in der Nomenklatur hinzuweisen, welche sowobl zur Verwirrung sowie zur Klärung des Verständnisses des Gegenstandes beigetragen haben. Auf die Nachteile der Anwendung des Ausdrucks Wachstum mit seinen vielen Nebenbedeutungen ist schon hingewiesen worden. Wachstum, Differenzierung und Entwickelung haben zu den verschiedenen Zeiten spezifische charakteristische Definitionen in bezug auf die allmähliche Zunahme bei lebendigen Wesen durch natürliche Vorgänge erhalten. Morphologische Betrachtungen sind hauptsächlich schuld an den von manchen Forschern gemachten Unterscheidungen gewesen. Z. B. die Veränderungen in der Zahl und Grösse oder Masse der Zellen werden als Wachstumsveränderungen beschrieben; adaptive Veränderungen im Aufbau oder in der Anwendung und die chemische Konstitution der Bestandteile dieser morphologischen Einheiten werden Veränderungen bei der Entwickelung zugeschrieben. Sie sind qualitativ zum Unterschied zu den rein quantitativen Veränderungen (22, S. 46). Die von Daven port gemachte Unterscheidung wird in folgenden Worten ausgedrückt: „Die Entwickelung besteht aus Wachstum und Differenzierung, die bei den grösseren Organismen von Kern- und Zellteilung begleitet werden"(20. Einleitung). In diesem Sinne kann sich das Wachstum entweder im ganzen Organismus verteilen, oder lokal, indem es einen Faktor der Differenzierung bildet. Tatsächlich gehen diese beiden Prozesse Hand in Hand und sind in der letzten Analyse schwer von einander zu trennen. Für unseren vorliegenden Zweck muss es genügen, auf diese feinen Unterscheidungen hinzuweisen. Dasselbe gilt für die Ausdrücke Hypertrophie und Hyperplasie, wobei der letztere Typus der Vergrösserung von der Bildung neuer Zellen abhängig ist. Bei Säugetieren gibt es z. B. kein hyperplastisches Wachstum in den nervösen Elementen nach der Geburt. Andere Gewebe, wie Binde- und epitheliales Gewebe zeigen reichliche Hyperplasie.

Die Zunahme an Grösse und Gewicht, welche im a usgewachsenen 
Leben beobachtet wird, ist in Beziehung zum Wachstum gebracht worden. Die Vorgänge sind vermutlich anderer Art. Dieser Zusatz zu dem Organismus oder Ablagerung von neuem Material - der "Körperansatz" oder "Mast" - spielt eine wichtige Rolle bei dem „Bereitmachen“ des Viehs für den Markt.

"Massenzunahme des Körpers nennt man beim Ausgewachsenen „Ansatz". So entstand die Frage, ob Ansatz und Wachstum, ersteres beim Erwachsenen, letzteres beim Säugling, genau in der gleichen Weise verliefen, wenn dieselbe Kost gegeben wird. Man glaubte einen Gegensatz zwischen Wachstum und Ansatz weniger, was doch naheliegend gewesen wäre, in dem morphologischen Unterschied als vielmehr darin zu sehen, dass Ansatz beim Erwachsenen nur unter grossem Eiweissüberschuss zustande komme und ausserdem nur. kurze Zeit währe. Ich kann nur zugeben, dass Fälle dieser Art nicht selten sind, aber eine allgemeine Gültigkeit kann man dieser Annahme nicht mehr zusprechen. Man darf nicht vergessen, dass das Nährstoffverhältnis zwischen Eiweiss- und N-freien Stotfen bei Wachsenden ynd Ausgewachsenen ganz wechselnd sein kann. Ich habe gesehen, dass aber unter ähnlichen Nährstoffverhältnissen wie es beim jungen Tier die Regel ist, auch beim ausgewachsenen länger dauernder Ansatz erzielt wird, aber eines versteht sich von selbst, die Variante des Erfolges der Aufspeicherung von Eiweiss ist verschieden. Dass der Ansatz beim Ausgewachsenen eher zum Stillstand kommt als das Wachstum ist etwas ganz Selbstverständliches. Beim Wachstum wird eben von der Zelle immer wieder Platz für die Eiweissablagerung geschaffen, weil neue Zellen gebildet werden und bei der Rekonstruktion füllen sich nur solche Zellen, in denen ein Mangel vorhanden ist. Das wachsende Tier vermehrt allmählich sein Gewicht auf das 20- bis 30fache des Neugeborenen, die sich rekonstruierende Zelle kommt selten über die Verdoppelung der Masse hinaus. Damit wird aber kein neuer Gesichtspunkt gewonnen, denn dass nur junge Tiere wachsen und alte nicht, bedarf keiner weiteren Erläuterung" (103, S. 61).

Der "Ansatz" kann einen beständigeren Typus haben, derart, wie er die Ablagerung vou Fett, Glykogen oder sogar von Eiweiss in den Zellen charakterisiert; oder er kann deutlich „unbeständig" sein, indem er eher reichlich Wasser als feste Elemente, welche in geeigneten Verhältnissen assimiliert werden, umfasst. Dieses letztere Bild der Vorratsablagerung im Körper, bei welchem Wasser in übertriebenen Mengen vorhanden ist, trifft man nicht selten in der Pathologie.

"Wenn wir zuerst das Zustandekommen des Körperansatzes in pathologischen Fällen untersuchen wollen, so haben wir zu unterscheiden zwischen der Wirkung der wasserlöslichen resp. gelösten Stoffe und der der unlöslichen resp. ungelösten Stoffe. Für die ersteren lässt sich die oben geforderte und begründete rein physikalisch-chemische Betrachtungsweise wenigstens theo- 
retisch mühelos durchfübren: für die letztere ist sie ebenfalls möglich, für unsere $Z$ wecke hier aber führt sie uns nicht viel weiter. Die Frage, die uns hier zunächst interessiert, ist die, woher es kommt, dass nicht nur die zugeführten Nährstoffe, sondern auch noch meist ein entsprechend Vielfaches, das sich bei näherer Untersuchung als Wasser herausstellt, im Körper zum Ansatz kommt. Mit der einfachen Antwort, es handle sich hier um Neuaufbau von Geweben, und dazu gebrauche der Organismus eine entsprechende Menge Wasser, kann man sich nicht zufrieden geben, da doch diese Wasserretention auch ohne wirklichen Neuaufbau eintreten kann" (104, S. 14).

Diese anormale Wasserretention, welche dem wahren Ansatz ähnelt, kann wenigstens auf zwei Weisen erklärt werden. Für die gelösten Substanzen kann die Theorie des osmotischen Druckes in Frage kommen. Ausser dieser wohlbekannten Hypothese verdienen die neueren Auffassungen der Kolloidchemie, welche die Imbibition und andere Faktoren, die gewöhnlich in Verbindung mit Ödem, Totenstarre usw. erörtert werden, zur Erklärung der ungebührlichen Wasserretention im Organismus herangezogen zu werden. Nur wenn diese Formen des Pseudowachstums, bei welchem das Wasser den wesentlichen Anteil bildet, anerkannt werden, kann man die plötzliche Umkehr - die in quantitativer Hinsicht oft enorm ist - verstehen.

Wahrer "Ansatz" muss daher von Regeneration (Ersatz, Auffütterung, Rekonvaleszenz, Erholung) unterschieden werden, welche stattfindet, wenu durch Hunger, Krankheit oder Unterernährung oder alles vereint das Wacbs. tum im Jünglingsalter oder durch Körpergewichtsverlust beim Erwachsenen gehemmt worden ist. Die Zunahme an Grösse, welche die Wiederernährung begleitet, ist nicht selten mit echtem Wachstum verwechselt worden. Sie können und dürften vermutlich zwei verschiedene Prozesse sein. Bei dem einen werden entleerte Teile wieder hergestellt, teilweise nur durch Ablage und Restitution der Vorräte; beim Wachstum kommen ausserdem neue Veränderungen hinzu.

„Wenn wir überhaupt jede Vermehrung, sei es der gesamten Körpermasse, sei es auch nur eines Organs oder eines Körperstoffes (Fett, ja sogar auch Wasser) mit dem nichts präjudizierenden Terminus Ansatz belegen, so wollen wir davon als Wachstumsansatz oder schlechthin Wachstum nur die Zunahme über das Mass des schon einmal Erreichten hinaus, als Regenerationsansatz die Zunahme bis zu diesem Mass nach vorausgegangenem Verlust bezeichnen" (104, S. 5).

"Die Mehrung der lebenden Substanz kanu ebensowohl durch Ansatz wie auch durch Wachstum zustande kommen, die in beiden Fällen eintretende Mehrung der Masse sollte aber an sich keinen Grund, beide Vorgänge für identisch zu halten, wie es bisher immer geschehen ist, abgeben, im Gegenteil schon die morphologisch ungleichartigen Vorgänge müssen uns veranlassen, Regeneration und Wachstum zu trennen oder wenigstens eine 
solche Verschiedenheit bei Prüfung der physiologischen Vorbedingungen des Zustandekommens beider im Auge zu behalten. Dass man aus praktischer Erfahrung heraus etwas zur Klärung dieser Frage beitragen könnte, hatte ich gehofft, es ist mir nach mehrfacher Rückfrage bei Fachleuten aber nichts bekannt geworden, was darauf schliessen lässt, dass in der Ernährung normal wachsender einerseits und rekonvaleszenter, aufzufütternder Säuglinge anderseits spezifische Unterschiede gemacht werden. Während man beim Wachstum annehmen darf, dass der Bedarf an Stoffen gemeinhin gleichbleibend der Qualität nach sich gestaltet, haben wir bei der Regeneration zweifellos materiell sehr verschiedene Vorgänge der Anlagerung von Eiweisssubstanzen, weil ja die einen Eiweissverlust bedingenden Vorgänge mannigfaltige, dem Umfang wie der Qualität der ergriffenen Organe entsprechend, verschiedene sind. Die konsumierenden Wirkungen der Infektionskrankheiten sind anders wie die der allgemeinen Inanition. Gestatten uns die heutigen Kenntnisse auch nicht zwischen den verschiedenen Formen der Rekonstruktion zu trennen, so ist es doch zum mindesten nötig, zwischen letzteren und dem Wachstum zu scheiden. Sehe ich also vorläufig davon ab, den eigentlichen Chemismus beider Prozesse weiter zu behandeln, so, glaube ich, lassen sich die Unterschiede beider und die Notwendigkeit einer Scheidung aus ernährungsphysiologischen Tatsachen heraus erbringen. Die treibenden Kräfte sind einmal das Wachstumsgesetz der Spezies, begründet in der Geschwindigkeit der Kernteilung und Zellmassemehrung, ein unveränderliches Erbe, beim Ansatz baben wir einen Vorgang, der in allen Alterszuständen vorkommt, und zwar täglich in die Erscheinung tritt, in dem Wiederersatz des durch die "Abnutzungsquote" des Stoffwechsels bedingten Stoffverlustes. In dieser Art und diesem Umfang betrachtet, hängt der Ansatz direkt mit dem jeweiligen Stoffwechsel und seiner Intensität zusammen, schnelle Rekonstruktion, wo rascher Aufbrauch gegeben ist" (100, S. 118).

"Wachstum und Rekonstruktion sind verschiedene Dinge, weil ersteres vom Wachstumstrieb, letzteres von der Stoffwechselintensität abhängig ist. Erstere Behauptung bedarf keines besonderen Beweises, letztere ist leicht einzusehen. Je intensiver der Stoffwechsel, um so grösser der Zerfall im Hunger, die Körpergrösse bzw. das Oberflächengesetz entscheidet hierüber. Schon a priori muss man annehmen, dass bei verschiedenen Individuen demnach auch der Aufbau um so rascher sein muss, je bedrohlicher die Verluste sind. Ich habe in der Tat gefunden, dass die Tiere auch schneller ihren Aufbau betreiben, wenn sie Verluste gehabt haben. Auch der Säugling kann von diesem Gesetze keine Ausnahme machen" (100, S. 120).

Es ist vielleicht der Betonung wert, dass die Wiederberstellung ein Phänomen ist, welches sowohl in den Wachstumsperioden wie in den späteren (erwachsenen) Altersperioden zu beobachten ist. Die Kurve der Wiederherstellung ist etwas, was für die Untersuchung ebenso leitsam ist wie 
die Wachstumskurve. Es sind schon brauchbare Angaben dafür vorhanden, dass der chemische oder Stoffwechselprozess der Regeneration keineswegs identisch ist mit jenem des Wachstums.

"Wachstụm und Regeneration werden meist in ganz verschiedenen Kapiteln der Biologie abgehandelt; auch ihre Forschungsmethode ist eine verschiedene; während das reine Wachstum nur der blossen Beobachtung und der theoretischen Spekulation unterliegt, ist die Lehre von der Regeneration durchaus experimentell begründet. Daher sind auch die Gesetze der Regeneration viel fester begründet als die des Wachstums. Wachstum und Regeneration sind aber durchaus verwandte Gebiete, so nahe verwandt, dass sie von mancher Seite miteinander identifiziert werden. Hierbei wurde aber nicht, wie man a priori annehmen sollte, die Regeneration in die Lehre vom Wachstum aufgenommen, sondern das Wachstum wurde der Regeneration zugeteilt; so von Weigert, der alles Wachstum als regeneratives auffasste oder von Roux, der das Wachstum als, Überkompensation im Ersatz des Verbrauchten' definierte. Einfacher und sinngemässer betrachtet Morgan die Regeneration als die Wiederaufnahme eines temporär sistierten Wachstums" (104, S. 112).

Wie Wachstum ist das Wort Regeneration in den verschiedensten Bedeutungen angewandt worden. „Das Wort „Regeneration“ soll, nach dem allgemeinen Sprachgebrauch, nicbt nur den Ersatz eines verlorenen Teiles bedeuten, sondern auch die Entwickelung eines neuen ganzen Organismus, oder sogar die eines Teiles eines Organismus aus einem Stück eines Erwachsenen, oder eines Embryos oder eines Eies. Wir müssen auch jene Fälle ejnschliessen, bei welchen der ersetzte Teil kleiner ist als der entfernte Teil, oder sogar in der Art verschieden. . . . Den Ausdruck ,physiologische Regeneration" werde ich im gewöhnlichen Sinne anwenden, um solche Veränderungen wie das Mausern und das Ersetzen von Federn usw. mit einzubegreifen - Veränderungen, welche mit dem Lebenszyklus des Individuums nahe verwandt sind" $(69)$.

Die Fähigkeit der Regeneration im allgemeinen Sinne nimmt ab, wenn wir die Skala der Wirbeltiere hinaufsteigen. Es ist die Frage erhoben worden warum dies der Fall sei, besonders wenn die Fähigkeit der Regeneration nahe mit der dem Protoplasma anhaftenden Wachstumsfähigkeit verwandt ist. Morgan glaubt, dass wenigstens ein Grund in dem Mangel einer koordinierten Regeneration bei den höheren Wirbeltieren liegt, $d . h$. in der Langsamkeit gewisser Gewebe zu gleicher Zeit mit anderen Geweben zu regenerieren. Insofern so ein indirekter Einfluss auf die möglichen Ursachen des nicht korrelierten Wachstums zu erkennen ist, welches sich zeitweise als ein pathologisches Phänomen darstellt, sei Morgans Ansicht etwas genauer ausgeführt. Er schreibt: „Die Erfahrung zeigt, glaube ich, mit einiger Wahrscheinlichkeit, dass der Fehler von der Tatsache herrührt, dass die ver- 
schiedenen Gewebe sehr verschiedene Geschwindigkeiten der Regeneration haben. Mit anderen Worten, scheint jedes Gewebe beim Menschen die Fähigkeit zu haben, seine Art zu regenerieren, aber nicht alle mit der gleichen Geschwindigkeit, daher können sie nicht zur geeigneten Zeit zusammenwirken, um eine neue Struktur zu bilden. Beim Menschen regeneriert die Haut; die Muskeln regenerieren, obgleich vielleicht weniger gut; die Nerven und die Blutgefässe regenerieren, und die Knochen haben sogar eine nicht unbeträchtliche Fähigkeit zu heilen und sogar in gewissem Umfange zu regenerieren. Daher scheint, wie ich gesagt habe, die mangelnde Entwickelung des neuen Gliedes nicht von der Unfähigkeit der einzelnen Elemente zu regenerieren abzuhängen, sondern von ihrer Unfähigkeit gleichmässig zu regenerieren. Die Knochen, oder die Nerven, oder die Muskeln können die Hauptursache der Störung sein, denn sie erzeugen mit grosser Langsamkeit neues Material" (68, S. 228).

Die „physiologische Regeneration" dauert während des ganzen Lebens, sogar bei den höheren Tieren an. Sie ist enger mit der restaurierenden Regeneration, welche wir "Wiederherstellung“ genannt haben, verwandt, deren Ursache der Verlust an Körpersubstanz ist. Der Ausdruck ist sogar von manchen Forschern noch weiter ausgedehnt worden, um die Abnutzung des Körpers (Rubner's „Abnutzungsquote"), die im täglichen Leben eintritt, mit einzubegreifen. So schreibt Schloss:

„Nach unserer Definition, die also nicht nur in der Zellneubildung eine Regeneration sieht, findet an jedem Organ und zu allen Zeiten eine physiologische Regeneration statt als Folge der jeder lebenden Substanz notwendigen Abnutzung. Man kann also in diesem Sinne den Stoffwechsel, der doch jedem lebenden Organteil zukommt, als Ausdruck der beständigen Regeneration auffassen, wie es schon Lotze getan. Was hier von der physiologischen Regeneration gesagt ist, gilt in noch höherem Grade auch von der pathologischen, d. h. der Regeneration nach pathologischem Verbrauch oder Verlust. Was wir klinisch unter Reparation oder Regeneration verstehen, das betrifft in den seltensten Fällen zelliges Material oder Organteile; in der Regel sind es alle möglichen festen und flüssigen Körperbestandteile, die ersetzt werden müssen, und es ist oft unmöglich, den Anteil der einzelnen festzustellen. Man wird sich also zunächst einmal an die rohe Masse halten und zusehen, wieweit sich im einzelnen Feststellungen machen lassen" (104, S. 113).

Das ganze Gebiet der Physiologie der Regeneration ist bis jetzt noch sehr wenig erforscht. Verluste, welche von einfachem Hunger herrühren, können offenbar rasch wieder gedeckt werden. Ob das Endresultat in bezug auf die Zusammensetzung der ersetzten Gewebe dasselbe ist, wie dasjenige, welches sich beim normalen Wachstum ergibt, bleibt zu erforschen. Hatai (43) hat gefunden, dass „,soweit wie das Körpergewicht und das Zentralnervensystem 
in Betracht kommen, die Wirkung eines einundzwanzigtägigen, teilweisen Hungers bei dreissig Tagen alten Albinoratten eventuell vollständig kompensiert wird. Die chemische Zusammensetzung des Gehirns und des Rückenmarks bleibt jedoch nicht ganz frei von der Wirkung, wie durch den höheren Prozentgehalt an Wasser und dem niedereren Prozentgehalt an Äther-Alkoholextrakt bei den Versuchsratten, im Vergleich zu den Kontrolltieren, angedeutet wird." Morguli s (70, S. 169) histologische Untersuchungen an Salamandern, welche nach einer Hungerperiode wieder gefüttert wurden, geben eine Idee von dern, was in zytologiseher Hinsicht von der Regeneration erwartet werden darf. „Das Volumen sowohl der Zellen wie der Kerne nimmt ab, wenn die Salamander unter dem Einfluss des Hungers kleiner werden, und das Volumen nimmt wieder $\mathrm{zu}$, wenn die ausgehungerten. Tiere gefüttert werden. Sowohl die Zunahme wie die Abnahme der Volumina der Zellen und der Kerne der untersuchten Gewebe sind grösser als die Zunahme und Abnahme des gesamten Körpergewichts während der entsprechenden Zeitperioden. Überdies ist die Geschwindigkeit der Verminderung des Zellvolumens bei Hunger grösser als die der Kerne, ebenso auch die Geschwindigkeit der Zunahme unter dem Einfluss der Rückkehr zur normalen Diät. Infolgedessen wird der Kern im Verhältnis zur ganzen Zelle grösser, wenn der Hunger andauert; wenn aber die Fütterung wieder aufgenommen wird, werden die normalen Verhältnisse rasch wieder hergestellt. Die Kerne bei ausgebungerten Tieren zeigen eine deutliche Tendenz sich zu strecken, wenn aber die ausgehungerten Tiere wieder gefüttert werden, nehmen sie sehr bald wieder die normale Form an, - sogar ehe sie das normale Volumen erreicht haben. Während die Zunahme im Umfang der Zellen ein Faktor von höchster Bedeutung ist, um ein ausgehungertes Tier zu seiner normalen Grösse zurückzubringen, spielt die Bildung neuer Zellen eine wichtige Rolle bei der Restauration der Gewebe in ihren normalen Zustand. Der Prozess der Wiederherstellung wird mit einer wunderbaren Geschwindigkeit ausgeführt."

Gewisse Eigenschaften des Stoffwechsels des Regenerationsprozesses sind von Me Collum (53) untersucht worden, welcher sie als in der Art verschieden von den Wachstumsvorgängen betrachtet. Er nimmt an, dass die Prozesse des zellulären Katabolismus und der Regeneration nicht die Zerstörung und den Wiederaưbau eines ganzen Eiweissmoleküls umfassen.

Wenn es wahr ist, dass die Fäbigkeit zur Regeneration eine latente Jugendlichkeit erfordert, kann der Umfang, bis zu welchem Gewichtsverlust mit Fortdauer des Lebens verträglich ist, ebenso von der latenten Wachstumsmöglichkeit wie von der Regeneration herrühren. „Ich glaube, sofern überhaupt das Gewicht noch einmal zum Stehen kommt, auf welcher Stufe es auch sei, ist eine Erholung denkbar, sofern die Causa peccans aufhört zu wirken, und alle Hilfsmittel der Therapie zur Verfügung stehen. . . . Der 
längere Stillstand nach einem Sturz auf einer bestimmten Stufe ist immer ein Zeichen der Widerstandsfähigkeit des Organismus und gibt Hoffnung auf Erhaltung" (104, S. 71). Genau so wie oben die Beziehung des Alters zu der Wachstumsmöglichkeit erörtert worden ist, muss die Fähigkeit wieder herzustellen in bezug auf das Alter betrachtet werden. Tatsächlich findet das seinen Ausdruck in Schlüssen, wie z. B., dass je jünger ein Kind sei, um so leichter sich die Wiederherstellung vollzieht. Es scheint eine Erfahrungstatsache zu sein, dass durch Unterernährung im Wachstum zurückgebliebene Tiere, ebenso wie junge Kinder, die sich von langer Krankheit erholen, bei Rückkehr zu normaler Kost und Gesundheitsbedingungen mit mehr als normaler Kraft zu wachsen beginnen und am Ende der Wachstumsperiode ebenso schwer sein können, und ein ebenso schweres Gehirn haben wie ihre normalen Gefährten. Trotzdem berechtigt uns das noch nicht zu dem Schlusse, dass die wiederhergestellten Individuen in jeder Hinsicht normal sind. Qualitative Veränderungen, welche durch die kursorischen Untersuchungen nicht bestimmt werden, können eingetreten sein (vgl. 25, S. 251). Bezüglich solcher Faktoren wie Diät,,typen" (z. B. vegetarianische oder gemischte Kost), Tätigkeit, Temperatur, Klima, Schwangerschaft usw. in ihrer Bedeutung für das Wachstum sind heute nur wenige breite Verallge. meinerungen gestattet $(106,107)$.

\section{Die Ursache des Wachstums.}

In der ganzen vorangehenden Beschreibung des Wachstumsphänomens seinen verschiedenen Eigenschaften, Kriterien, den modifizierenden Faktoren und verwandten Phänomenen, ist wenig von dem Ursprung dieser grundlegenden Äusserung der lebendigen Organismen gesagt worden. Welches ist die dem Wachstum zugrunde liegende Ursache? Wie andere biologische Vorgänge kann dieser auch nur in seinen Erscheinungen befriedigend dargelegt werden. Die Ursache der Regeneration ist Verlust an Körpersubstanz. Wir können gleich im Anfang offen zugestehen, dass wir in bezug auf das, was im Protoplasma während des Wachstums vor sich geht, fast nichts wissen, und sehr wenig in bezug auf die Ursachen, welche ihn hervorrufen oder hemmen. Die einzige Rechtfertigung, diese Unwissenheit unter einer vagen Terminologie zu verschleiern, liegt in der Hilfe, welche eine formulierte Hypothese oft für die Lösung dunkler Probleme bringt. Mit dieser einleitenden Behauptung kann das Wachstum als das Resultat eines angestammten Wachstumsimpulses - eines inneren Faktors - und geeigneter Umgebung, wobei letztere die Nahrungsversorgung einschliesst - eines äusseren Faktors definiert werden. Bei diesen sind beteiligt gewisse typische biologische Kräfte, der Stoffwechsel und Energiewechsel, sowie gewisse physiko-chemische Reaktionen. Die Bedingungen, welche das Wachstum bestimmen, liegen hauptsächlich in den Zellen. Wie wir heute nicht imstande sind, den inneren 
Faktor auf geeignete Weise zu erklären, ebenso unmöglich ist es, alle äusseren Faktoren anzuführen, wie wir es für Pflanzen tun. Luft, Licht, Wärme, Nahrung usw. haben ihre Aufgaben. Jedoch wie wesentlich die Nahrung für das Wachstum sein kann - und niemand kann ihrer vorherrschenden Bedeutung widersprechen - sie kann doch in keiner Richtung als die wichtigste Ursache des Wachstums angesehen werden. Die Nahrung kann nur dem Wachstumsimpuls freien Spielraum geben. „Die ungemeine Wichtigkeit der Imponderabilien für das Wachstum lernt man erst dann richtig würdigen, wenn Störungen der Entwickelung eintreten, die nicht auf die bekannten Ursachen zurückgeführt werden können" (104, S. 105).

Der Nachdruck, welcher auf die verschiedenen angenommenen ursächlichen Faktoren beim Wachstum gelegt wird, variiert mit dem Standpunkt und der Erfahrung jedes Forschers über den Gegenstand. So hat Rubner seine Ansicht in folgenden Worten ausgedrückt: „Zum Verständnis des Wachstums gehört die Darlegung der Funktion der einzelnen Nährstoffe (natürlich auch der anorganischen), der Stoffwechsel, es gehört aber weiter dazu die Kenntnis des Kraftwechsels, da die reine Betrachtung des Stoffwechsels über eine rein empirische Feststellung nie hinauskommt, und die Erkenntnis des Wachstums ohne die energetische Kritik ganz unmöglich ist. Die eine grosse Unbekannte auf dem Gebiete der Wachstumspbysiologie ist der Wachstumstrieb, der in gesetzmässiger Weise don Gang der Entwickelung, Massenzunahme, durch die Regelung der Ernährung leitet. Den Urgrund hat dieser Wachstumstrieb in der Geschwindigkeit der Kernteilung; wie wir noch sehen werden, leitet sich hieraus der ganze Prozess des Stoffumsatzes ab. Die Kernteilungsgeschwindigkeit ist offenbar etwas der Spezies Eigentümliches, somit sind wir nicht in der Lage, vorläufig tiefer in dieses Problem vorzudringen. Die endliche Begrenzung des Wachstums mit Erreichung der durcbschnittlichen Grösse und ähnliches werde ich in der nächstfolgenden Abhandlung eingehender besprechen. Dem Wachstumstrieb gegenüber steht die Nahrung, welche aber nur einen temperierenden Einfluss auf die Möglichkeit des Grades des Wachstums ausübt“ (99, 100, S. 86).

Von dem, was wir den inneren Faktor beim Wachstum - den „Wachstumstrieb, die „Wachstumsfähigkeit", die „Wachstumsmöglichleit" - genannt haben, von dem Faktor, welcher in seinem Ursprung vererblich ist und dem Wachstum seine Grenzen setzt, welche die Ernährung nicht fundamental ändern kann, ist weiter wenig zu sagen. Ob er als ein ,,artspezifischer Rhythmus der Zeilteilung, wie Friedenthal (35) es genannt hat, oder in anderen Ausdrücken beschrieben wird, um die Individualität des Vorgangs bei den verschiedenen Arten zu bezeichnen, das fügt unserem wahren Verständnis wenig Bestimmtes hinzu.

„Die Natur des Wachstumstrieb ist dunkel" (Aron). Friedenthal hat die Tatsachen folgendermassen beschrieben: „Der Rhythmus der Zell- 
teilungen strebt eine mnemische Wiederholung der homologen energetischen Situation der Vorfahrenreihen an. Wo eine solche nicht möglich ist, schlägt das Wachstum originale Bahnen ein. Der Zellteilungsrhythmus ist in hohem Masse abhängig von der Wirkung von Hormonen, Produkten der inneren Sekretion und des Zellzerfalles, welche uns Mittel an die Hand geben werden, den exakten Zellteilungsrhythmus in weitgehender Weise nach unserem Willen zu verändern." Ob sich der letztere Teil dieser Behauptung als richtig erweisen wird, muss noch abgewartet werden. Einstweilen wird keinerlei Vorteil aus dieser Behauptung erreicht. „Die natürliche Einrichtung, welche in der lebenden Substanz diejenigen Affinitäten weckt, welche die Neubildung der Substanz als Wachstum, d. h. als eine Mehrung von Protoplasma und Zellkern bis zur Bildung einer zweiten Zelle hervorruft, nenne ich den Wachstumstrieb. Der Wachstumstrieb bezeichnet die Grenze dessen, was ein Tier in der gedachten Periode der Körpergewichtsverdopplung leisten kann. Ernährungsphysiologisch drückt er sich in dem Verhältnis der Ansatzgrösse zum Stoffwechsel aus. Der Wachstumstrieb liegt von Geburt in der Zelle, er kann bei bestimmtem Nahrungsangebot die Zellteilung in bestimmt begrenztem Umfang durchführen, die eine Spezies schnell, die andere langsam. Diejenige, welche schnell arbeitet im Wachstum, arbeitet auch schnell im Stoffwechsel" (100, 101, S. 192). Die innere Natur des Wachstums aufzudecken, heisst in das Geheimnis der verschiedenen Charakteristica der lebendigen Substanz eindringen. Hier herrschen die Hypothesen unumschränkt.

„Im Akt des Wachstums liegt ein wesentlicher Teil des ganzen Lebens. geheimnisses begründet, es ist die Erschaffung des Lebens im vollsten Sinne des Wortes. Wenn aus der befruchteten Eizelle der im Verhältnis zu dieser ungeheure Organismus eines Säugers sich aufbaut, so hat die ganze spätere Körpermasse das Leben aus der Eizelle empfangen, nicht nur die Durchschnittseigenschaften, sondern alle die besonderen Eigenschaften des Individuums bis hinab ins kleinste ..... Manche behaupten, dass die Zeugung des Lebens nur durch die Aufnahme besonders grosser Energiemassen in das vorher tote Eiweissmolekül erklärt werden könne. Niemand wird behaupten wollen, dass der Energieinhalt der lebenden Substanz nicht ein anderer sein kann, als der des unbelebten Eiweisses. Da der Aufbau ein anderer ist, muss sich dies auch in dem Energieinhalt zeigen. Ob dabei aber eine $\mathrm{Zu}-$ nahme oder Abnahme eintreten wird, kann a priori nicht gesagt werden, da wir ja gar nicht wissen, welche Atomgruppen des Nahrungseiweisses in den neuen Verband übergehen. Pflüger meinte, dass die Cyangruppe im Eiweiss dominierend vertreten sei, wodurch der labile Charakter desselben eine Erklärung finde, nach $O$. Löw liegen labile Plasmaproteine mit Aldebyd- und Aminogruppen vor. Wie dem auch sei, diese Anschauungen sind beachtenswerte Hypothesen, aber zurzeit nicht näher prüfbar. . . . Der Annahme, 
die lebende Substanz müsse einen sehr bedeutenden Energieinhalt besitzen, liegt, wie ich sehe, zumeist die irrige Anschauung zugrunde, dass diese Lebenssubstanz später besondere Kraftleistungen zu bieten hätte; dies trifft aber gar nicht zu, denn man wird doch z. B. den Fermenten, welche ungeheure Umsetzungen herbeiführen können und trotzdem unbelebt sind, nicht einen ungeheuren Energievorrat zuschreiben wollen. Im übrigen aber haben wir gesehen, wie die auftretenden Kräfte eben aus der Nahrung stammen. Auch der komplizierteste Aufbau der lebenden Substanz rechtfertigt diese Anschauung nicht; sehen wir doch beim Abbau des toten Eiweisses durch Pepsin und Pankreassaft sozusagen einen thermisch indifferenten Prozess vor uns.

Manche wollen die Anhäufung von Energie auch nur auf bestimmte Zellgruppen beschränkt sehen; dahin gehört die Meinung Bechterews (Psyche und Leben, Wiesbaden 1908, S. 93 und 188), die dahin geht, dass eine besondere Reserveenergie in den Nervenzentren sich findet. Die Gehirnund Nervensubstanz soll ausserordentliche Energievorräte schon aus der Nahrung anhäufen. Ausserdem sollen elektrische Ströme, die sich bei Molekularvorgängen äussern, auch für diese Anhäufung von Energie in Betracht kommen. Die Nervenzellen seien besondere Aufnahmeapparate von Energie, die längs der "Nervenbahnen" ins Zentralorgan gelangen, „wo unerschöpfliche Energievorräte sich in Gestalt komplizierter, chemischer, insbesondere Eiweiss. verbindungen" ansammeln. Die psychischen Erscheinungen mit ihrem Bewusstseinsinhalt sollen ein Ausdruck der Reserveenergiemengen der Zentren sein. Die völlig hypotbetische Natur derartiger Annahmen brauche ich kaum besonders $\mathrm{zu}$ charakterisieren; nichts spricht für sie, alles, was uns an experimentell erreichbarem Material zur Verfügung steht, dagegen. Ich erwähne nur folgendes: Es ist in hohem Masse wahrscheinlich, wenn nicht gewiss, wie schon oben erwähnt, dass beim Wachstum nicht das Nahrungseiweiss direkt als solches aufgenommen, dem übrigen angefügt und belebt wird, sondern dass der materielle Akt in zwei Phasen sich vollzieht; einmal in der Vorbereitung des Materials. Dieser Akt verläuft, ohne dass dabei die Wachstumseigenschaft irgend etwas zu tun hat, vermutlich überhaupt nach Art fermentativer Vorgänge. . . . E. Erst aus diesem, dem Körper schon angepassten Material wird das Biogen erzeugt, woraus sich ergibt, dass der Belebung selbst eine zwar biologisch höchst bedeutsame, energetisch aber wohl ganz beschränkte Arbeit zugewiesen ist" (98, S. 100).

So hervorragend die Rolle der Zelle beim Wachstum sein mag, so kann doch das Entwickelungsproblem nicht nur vom Standpunkt der Zellularphysiologie aus untersucht werden. Wir geben zu, dass die Nahrung nur eine begrenzte Bedeutung für die Erklärung sowohl des Wachstumstriebes, wie der Wachstumsmöglichkeiten liefern kann; aber auf jeden Fall steht der Nahrungsfaktor beim Wachstum der experimentellen Untersuchung.offen. Die grösste Hoffnung auf einen Fortschritt bei der Lösung der dunklen Wachs- 
tumsfragen scheint daher in dieser Richtung zu liegen. Vorhandene Versuche können z. B. die Unhaltbarkeit der Anschauungen, wie sie Morgan in nachfolgendem Zitat geäussert hat, klar machen. „Bis zu einem gewissen Umfang hängt die Wachstumsgeschwindigkeit von der Nahrungsmenge ab. Es ist klar, dass, wenn weniger Nahrung aufgenommen wird, als nötig ist, um neues Gewebe aufzubauen, die Wachstumsgeschwindigkeit nachlassen muss. Wenn andererseits mehr Nahrung aufgenommen wird als assimiliert werden kann, wird die Wachstumsgeschwindigkeit nicht dadurch erhöht. Dies ist jedoch keineswegs die ganze Frage, denn die Tiere zeigen eine merkwürdige, regulierende Fähigkeit und speichern gewöhnlich in der Form von Fetten Reservematerial auf, wenn ein Übermass an Nahrung aufgenommen worden ist ..... Wir können die Tatsachen durch die Annahme erklären, dass, wenn weniger als das Maximum gegeben wird, mehr Substanz aus der Nahrung verdaut wird, und wenn mehr als das Maximum genommen wird, verhältnismässig weniger resorbiert und assimiliert wird. Der Appetit des Tieres liefert ein Mass für die Menge, welche für das Wachstum und die Regeneration notwendig ist, aber eines, auf welches man sich nicht ganz verlassen kann“ (67, S. 2õ3). Zur Aufklärung der Ernährungsprobleme haben wir anderswo versucht, einige experimentelle Beiträge hinzuzufügen $(83,52)^{1}$ ).

Ein weiterer Faktor, der eng mit dem Ernährungsproblem verbunden ist, verdient hier besondere Erwähnung. Er betrifft die Möglichkeit des Vorhandenseins spezifischer Nebenfaktoren, die für die Darstellung des erfolgreichen Wachstums unumgänglich sind. Ein schwerwiegendes Beweismaterial lässt vermuten, dass "Hormone“ oder „Vitamine" oder ähnliche Reizmittel des Wachstums wesentlich sind $(46,49)$. Friedenthal (34) hat sie als "Mitosone"produkte der inneren Sekretion bezeichnet, welche den Rhythmus der Zeilteilung beschleunigen.

Bei den niedereren Formen besonders behauptet Davenport, dass "Wachstum als eine Reaktion auf chemische Agenzien aufgefasst werden muss, welche das Protoplasma dazu reizen, entweder sie selbst zu absorbieren und zu assimilieren ... . , oder andere Substanzen zu resorbieren" (20, S. 335). Ob solche bestimmenden Faktoren (Wachstumsreize, Zellvermehrungsreize, Auslösungsursachen des Wachstums) (104, S. 104) als solche in der Nahrung gefunden werden, wird gegenwärtig noch untersucht. Da das Ergebnis noch aussteht, erübrigt es sich, hier darauf einzugehen. Auf jeden Fall ist jedoch ihre Rolle unter den äusseren Wachstumsursachen nicht die eines einfachen Nährmittels im Sinne der Abgabe von Energie oder Stoffen zur Entwickelung.

Die Analyse des Wachstums als eines kontrollierbaren Ernährungsfaktors und als eines angeborenen Wachstumsimpulses hat ihre Bedeutung für die Pathologie des Wachstums und das Verständnis der dort vorkommenden

1) Zahlen über das Nahrungsbedürfnis beim Wachstum sind von Lusk (52, S. 228) zusammengestellt worden. 
Probleme. Es wird klar, dass anormales Wachstum nicht immer durch Regulation der äusseren Faktoren der Diät usw. verbessert werden kann. Der Diätotherapie oder anderen therapeutischen Massregeln wird häufig durch das unveränderliche Vorhandensein einer unvollkommenen Konstitution, die sonst die Grundlage einer passenden Wachstumsfähigkeit ist, eine Grenze gesetzt.

\section{Die Wachstumsgesetze.}

Von dem Versuch, Gesetze aus Tatsachen zu formulieren, welche nicht überreichlich vorhanden sind, und welche eine beträchtliche Anzabl von Variablen in sich schliessen, kann kaum erwartet werden, dass er Verallgemeinerungen sehr exakter Natur ergibt. Trotzdem sind Versuche, wahrscheinliche Wachstumsgesetze aufzustellen, gemacht worden. Auf frühere Beobachtungen gestützt, betrachtet Lu s k (52, S. 249) es als feststehend, dass „während der normalen Entwickelung von Jungen desselben Alters und derselben Art ein bestimmter Prozentsatz der Nahrung für das Wachstum zurückbehalten wird, ohne Beziehung zu der Grösse des Individuums". Dieses Wachstumsgesetz ist auf Beobachtungen gegründet, die an wachsenden Tieren, besonders in Lusks Laboratorium angestellt wurden. Rubner hat unabhängig davon ein ganz ähnliches Wachstumsgesetz für alle Arten, ausser dem Menschen, aufgestellt, als Ausdruck der Annahme, dass derselbe Energieaufwand nötig ist, um eine Einheit von neuer Substanz bei jungen Tieren aufzubauen: „Die zur Verdoppelung eines Tieres aufgewendete Kräftesumme (Kal.) ist mit Ausnahme des Menschen bei den verschiedenen Tierspezies, ob sie schnell wachsen oder lange zur Verdoppelung brauchen, dieselbe; man kann dies also das Gesetz des konstanten Energieaufwandes beissen" (99, S. 160).

Danach scheint es, dass Lebendiges immer dieselbe Energiemenge für vergleichbare biologische Umbildungen beim Wachstum verbraucht. Die Bildung von $1 \mathrm{~kg}$ Körpersubstanz, die $30 \mathrm{~g}$ Stickstoff und $1722 \mathrm{Kal}$. enthält, verlangt bei wachsenden Tieren $4804 \mathrm{Kal}$; nur beim Menschen ist das Bedürfnis sechsmal so gross.

„Der Anwuchs auf natürlichem Wege kostet also bei allen Tieren genau das gleiche. Die Natur arbeitet bei den verschiedenen Spezies der Tiere nach einem ökonomischen Prinzip, wie wir deren viele kennen, z. B. das Gesetz der isodynamen Vertretung der Nahrungsstoffe, die Ausnutzung der im Stoffwechsel erzeugten Wärme bei der chemischen Wärmeregulation usw." $(99,101$, S. 160). Der folgende Schluss ist von weiterem Interesse: „Jugendperiode wie Grösse sind also Verhältnisse, die sich energetisch begrenzt erweisen; damit füllen sich die Grenzen, die zwischen den möglichen Extremen der Warmblütergrösse liegen, völlig aus und die einzelnen spezifischen Tiergrössen ordnen sich als bekannte Grössen ein. Hat die lebende Substanz der Tiere nach ibrer Geburt eine energetisch bestimmte Summe des Nahrungsverbrauches erlangt, so ist die Speziesgrösse erreicht" (98, S. 141). 
Weitere von Rubner stammende Betrachtungen in bezug auf die Lebensdauer der einzelnen Arten in Beziehung zu der Anzahl der während des Lebens umgesetzten Kalorien, brauchen uns bier nicht zu beschäftigen.

Rubners Theorie, dass der Mensch eine besondere Stellung einnimmt, und er eine Ausnahme unter den Säugetieren bezüglich der Wachstumsgesetze bildet, ist von Friedenthal heftig angegriffen worden, welcher das Gesetz des konstanten Energieverbrauchs für ähnliches Wachstum für unhaltbar ansieht. So schreibt er: „Die von Rubner berechnete und so lebhaft betonte Sonderstellung des Menschen, welche ihn dazu führte, den Bionten im menschlichen Protoplasma andere Eigenschaften zuzuschreiben als denen der übrigen Lebewesen, die Tiere auf Grund des behaupteten konstanten Energieaufwandes für unter sich verwandt zu erklären, den Menschen mit den anderen Tieren für nicht verwandt zu halten, ist nach der experimentellen Nachprüfung nicht aufrecht zu halten." Friedenthal (35) zeigt, dass die Fähigkeit der Tiere zu wachsen mit der teilungsfähigen Substanz, nicht mit der ganzen Grösse oder Körperoberfläche, welche den Stoffwechsel in anderer Hinsicht reguliert, zusammenhängt. Nur das Protoplasma wächst aktiv, nicht die Vorratsprodukte - der Ballast. Und man muss dabei daran denken, dass in diesem Sinne ein Tier wachsen kann (auf Kosten der Reservestoffe), während sein Gewicht stationär ist, oder sogar abnehmen kann. Daher kann kein passendes "Gesetz" gebildet werden, bis wir die Masse der lebendigen Substanz im Körper kennen.

Roberts on $(89,91)$ bat auch versucht, einen mathematischen Ausdruck für gewisse Wachstumseigenschaften zu finden. Er glaubt, dass Tatsachen in der Form von grossen Messungen, die sowohl für Menschen wie für Pflanzen gelten, Beziehungen ergeben, wie man sie erwarten würde, wenn das Wachstum der Ausdruck einer autokatalytischen chemischen Reaktion wäre. Von der Zellteilung ist festgestellt worden, dass sie der Ausdruck einer autokatalytischen Synthese des Kernmaterials ist und eine ähnliche Reaktion soll sich auf das Zellwachstum oder die Synthese des Zytoplasmas anwenden lassen. Damit übereinstimmend folgt jeder Wachstumszyklus der Formel:

$$
\log \frac{\mathrm{x}}{\mathrm{A}-\mathrm{x}}=\mathrm{K}\left(\mathrm{t}-\mathrm{t}_{1}\right)
$$

wo $\mathrm{x}$ die Menge (in Gewicht oder Volumen) des Wachstums ist, welche zur Zeit $t$ erreicht worden ist; $A$ ist die während des Zyklus erreichte Gesamtmenge, $\mathrm{K}$ ist eine Konstante und $t_{1}$ ist die Zeit, zu welcher das Wachstum, infolge des Zyklus, halb vollendet ist. Das Wachstum irgend eines besonderen Gewebes oder Organs steht mit dem eines anderen Gewebes oder Organs, oder des ganzen Körpers in Beziehung, nach der Formel:

$$
\log \frac{x^{\prime}}{A_{1}-x^{\prime}}=a \log \frac{x^{\prime \prime}}{A_{2}-x^{\prime \prime}}+b
$$

wo $x^{\prime}$ das Gewicht oder Volumen des einen Organs, $x^{\prime \prime}$ das des anderen 
Organs, $A_{1}$ das Endgewicht oder Volumen des ersten Organs, $A_{2}$ das des zweiten ist, und a und $\mathrm{b}$ sind Konstanten.

Diese Schlussfolgerungen von Robertson sind auch von Friedenthal kritisiert worden: „Gegenüber diesen Versuchen, gleich beim ersten Eiuarbeiten in die Physiologie des Wachstums grundlegende, allgemein gültige, mathematisch formulierte Gesetze alles Wachstums aufzufinden, ist zu bedenken, dass wir über die Geschwindigkeit der Nukleinsynthese doch nur durch Nukleinbestimmungen einigen Aufschluss erhalten können, nicht aber durch Bestimmung von Gesamtgewichten von Volumina oder gar von Längenmassen. Wir können wohl nicht voraussetzen, dass die Ablagerung von Skeletteilen, von Reservenährstoff und von festen oder flüssigen Sekreten parallel der Nukleinsynthese verlaufen wird, und werden daher nicht erwarten, Wachstumsgesetze aus Rohgewichtsbestimmungen ableiten zu können. Durch Bestimmung des organisch gebundenen Phosphors, welcher nicht in Alkoholäther löslich ist, könnte man wohl über die Nukleinmengen im Protoplasma Aufschluss erbalten. Solche Versuche sind aber bisher nicht veröffentlicht worden" (35).

Man kann, nach unserer etwas zerfahrenen Kenntnis der Wachstumsphänomene die Schlussworte von Friedenthals Kritik der bisher vorgeschlagenen „Wachstumsgesetze“ nur hervorheben. „Zum Schlusse sei betont, dass man besser tut, in der Biologie das Wort Gesetz zu vermeiden, welches Wort die Suggestion der absoluten Verbindlichkeit nabelegt, während wir in der Biologie uns mit Regeln begnügen müssen, welche Ausnahmen erleiden and niemals die Gesamtheit der Lebensvorgänge umfassen. Die moderne Auffassung des biogenetischen Grundgesetzes gibt eine gute Illustration für die Nichtanwendbarkeit des Wortes Gesetz in der Biologie. Wenn die Wachstumsvorgänge genauer verfolgt und studiert sein werden, werden sich zweifellos gewisse Regelmässigkeiten aufstellen lassen. Die experimentelle Nachprüfung der bisher aufgestellten Wachstumsgesetze lehrte, dass wir heute selbst von der Aufstellung allgemeiner Wachstumsregeln noch weit. entfernt sind. Der Weg, welchen die Naturwissenschaften bisher mit Erfolg gegangen sind, führte nicht von aufgestellten Grundgesetzen zu Tatsachen, sondern von der Sammlung von Tatsachen zu Gesetzmässigkeiten. Es ist anzunehmen, dass die Physiologie des Wachstums darin keine Ausnahme machen wird" (35).

\section{Einige das Wachstum betreffende Probleme.}

Es ist fast unmöglich, die hervorragenden Charakteristika der Physiologie des Wachstums zu überblicken, ohne die Aufmerksamkeit auf die offenbaren Lücken in unserer Kenntnis zu richten. Probleme erwarten uns jeden Augenblick - manche davon deutlich bestimmt und der experimentellen Untersuchung zugänglich, andere durch das Gewirr der sich widersprechenden 
Tatsachen verdunkelt, oder durch die mannigfachen Faktoren, welche in die Entwickelungsfragen eingreifen, kompliziert. Kein Überblick irgend eines Bildes einer sich entwickelnden und wachsenden Wissenschaft ist vollständig oder klärend, wenn er nicht ebenso gut Probleme aufwirft, wie er sie beantwortet. Manche von diesen, welche sich auf diesem Gebiete zeigen, mögen flüchtig mit kurzen Kommentaren entwickelt werden.

\section{Statistiken des Wachstums. Die Histologie des Wachstums.}

Die Statistiken des Wachstums, welche Veränderungen im Gewicht und in der Grösse in sich schliessen, sind, da sie am leichtesten zu erhalten sind, in grösster Anzahl gesammelt worden. Es gibt aber zahlreiche statistische Einzelheiten, welche das Wachstum der einzelnen Teile der Organe umfassen, welche ebenso wesentlich für das Verständnis der Korrelation der am Wachs. tum beteiligten Organe sind. Hat nicht Morgan an diese Eigenschaft eine mögliche Erklärung geknüpft, warum das Wachstum aufbört? Donaldson und seine Mitarbeiter haben unter den neueren Forschern diese Fragen der relativen Grösse des Organs wieder aufgegriffen.

Mehr als je taucht gegenwärtig die Notwendigkeit weiterer Untersuchungen der Histologie der wachsenden Gewebe bei Säugetieren auf. Sie sind grundlegend für jede Untersuchung des morphologischen Hintergrundes, der Wachstumsfunktionen. Die Popularität, deren sich die histologische Untersuchung in der Embryologie in den letzten Jahren erfreut hat, sollte auf die postnatalen Phasen des Lebens ausgedehnt werden. Im allgemeinen lehrt man uns, dass verschiedene Gewebe ungleiche Wachstumsfähigkeit im Sinne der Zellvervielfältigung haben. Manche von ihnen, wie die Hoden, vervielfältigen ihre Zellen während des ganzen Lebens; andere, wie die Muskeln und das Nervensystem nur in der embryonalen Periode; andere wieder, wie die Drüsen während einer variablen Periode nach der. Geburt. Solange ein solcher Nachdruck auf die Zelle beim Wachstum gelegt wird, sollten wir mehr über ihre morphologische Geschichte während dieser Periode wissen; und dies gilt vor allem für jene Gewebe, die sogenannten Drüsen ohne Ausführungsgang, wie Hypophyse und Thymus, welche gewöhnlich auf irgend eine Weise mit dem Wachstum in Verbindung gebracht werden. Bis vor ganz kurzem hat sich das Interesse der Histologen entweder auf die embryonalen oder ausgewachsenen Gewebe der Säugetiere, mit nur geringer Beach-

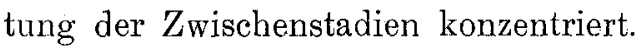

\section{Ernährung und Wachstum.}

Trotz der Wichtigkeit der Wärmebedürfnisse und des Kraftwechsels für den sich entwickelnden Organismus darf man nicht zulassen, dass man deswegen die Rolle vernachlässigt, welche die einzelnen Nährmittel beim Wachstum spielen. Die chemischen Seiten der Ernährung sind ebenso bedeutend 
wie das Energiebedürfnis. Erst in den letzten Jahren hat die Wissenschaft angefangen, bestimmte Tatsachen über die chemischen und biologischen Beziehungen der Nahrung zu den Geweben der Tiere zu liefern. Wir zitieren aus einer neueren Rede von T. B. Osborne folgendes: „Es ist klar, dass strukturelle Unterschiede zwischen sehr ähnlichen Proteïnen verschiedenen Ursprungs existieren, und es ist interessant zu beobachten, dass chemisch identische Eiweisskörper bei Tieren oder Pflanzen verschiedener Arten offenbar nicht vorkommen, wenn dieselben nicht biologisch sehr nahe verwandt sind. In dieser Hinsicht stehen die Eiweisskörper in scharfem Gegensatz zu den anderen Bestandteilen der Pflanzen und Tiere, denn es kommen nicht nur genau dieselben Zucker- und Fettarten bei vielen Arten von Pflanzen und Tieren vor, sondern viele von diesen sind beiden Lebensformen gemeinsam. Es scheint daher, dass die chemische Konstitution der Eiweisskörper eng mit deu biologischen Verhältnissen der Lebensformen, welche sie erzeugen, verknüpft sind, und dass die morphologischen Unterschiede zwischen den Arten ihr Gegenstück in den Eiweissbestandteilen ibrer Gewebe finden" (81).

Die widersprechenden Ansichten, welche seit Liebig, in bezug aut die Bedeutung des Eiweisses bei der Ernährung, vertreten worden sind, haben ihr Gegenstück in der Erklärung des Wachstums gefunden. Voit nahm an, dass der Eiweissstoffwechsel des wachsenden Organismus von dem des ausgewachsenen verschieden ist. „Es steht fest", schreibt er, "dass im noch wachsenden Organismus die Bedingungen für den Eiweisszerfall ungleich ungünstiger sind als beim ausgewachsenen, womit eben das rasche Wachstum der Organe zusammenhängt" (115). Rubner hat die Hinfälligkeit der Theorien, welche das Wachstum mit einer verminderten Kraft des Eiweissstoffwechsels im Körper verknüpfte, gebührend betont. Er hat es ferner durch seine wohlbekannten Untersuchungen, besonders mit $\mathrm{Heubner,} \mathrm{klar-}$ gestellt, dass die Kost des Kindes im allgemeinen eher eiweissarm als das Umgekehrte, wie gewöhnlich angenommen wurde, ist. Wie niedrig die Eiweissaufnahme sein kann, sei durch folgende Zahlen an einem Beispiel erläutert:

Für das Wachstum $7 \%$ der gesamten Energieaufnahme Für die Erhaltung 5\% , , , , "Gibt man aber grössere Eiweissmengen in der Kost des Säuglings, so folgt das Wachstum nicht der Eiweissmenge; das Wachstum ist eine Funktion der Zelle, es kann durch unzureichende Eiweisszufuhr latent werden, aber Eiweiss vermag nicht die Wachstumsschnelligkeit über die von der Natur gesteckten Grenzen zu heben“ (100, S. 110).

Die wohlbekannten Analysen von Bunge (14) und Abderhalden (1), welche den engen Parallelismus zwischen der Geschwindigkeit des Wachstums und der Konzentration von Eiweiss und Asche in der Milcb von verschiedenen 
Arten zeigen, sind als Beispiele einer kausalen Beziehung zwischen Eiweisskörpern und Wachstum zitiert worden. Über diese interessanten Untersuchungen sagt Minot: „Es ist klar, dass je weniger Eiweiss in ibrer Milch ist, die Spezies um so länger brauchen, um ihr Gewicht zu verdoppeln. Das. sieht im ersten Augenblick so aus, als wenn es eine Beziehung zwischen der Zusammensetzung der Milch und der Wachstumsperiode des Tieres darstelle; aber man weiss sehr gut, dass wenn man Kuhmilch, die sehr reich an Eiweiss ist, einem Säugling, einem menschlichen Säugling, verfüttert, dieser Säugling nicht mit derselben Geschwindigkeit wie die junge Kuh wächst, sondern mit der des Menschen. Es ist daher klar, dass es nicht bloss eine Frage der Nabruigszufuhr ist. Wir haben hier in der Tat eines der wundervollen Beispiele für den teleologischen Mechanismus des Körpers. Die verschiedenen Arten haben ihre charakteristischen Wachstumsgeschwindigkeiten und durch eine kunstvolle Anpassung ist die Zusammensetzung der Muttermilch derart geworden, dass sie das Junge jeder Art mit dem geeigneten Quantum von Eiweissstoff versorgt, das für die Wachstumsgeschwindigkeit, deren das Junge fähig ist, erforderlich ist. Es ist eine wunderbare Anpassung, aber keine kausale Beziehung zwischen dem Eiweissgehalt der Muttermileh und der Wachstumsgeschwindigkeit des Jungen. Es ist ein Beispiel von Korrelation, nicht von Kausalität" (62, S. 108).

Niemand wird heute dem widersprechen, dass deutliche chemische und biologische Unterschiede zwischen Eiweisskörpern aus verschiedenen Quellen existieren. Diese Ungleichheiten sind, bis vor ganz kurzem, nicht in bezug auf ihre mögliche Bedeutung für die Ernährung untersucht worden. Es ist hier und da angedeutet worden, dass die vermutete chemische Ungleichheit der Milcheiweisskörper der verschiedenen Arten ihren Wert bei der künstlichen Kinderernährung beeinflussen könnte. Manche von den Ansichter haben ihre Berechtigung dadurch verloren, dass neuerdings nachgewiesen wurde, bis zu welchem Umfang die Eiweisskörper vor der Resorption und der späteren Rekonstruktion im Organismus aufgespalten werden. Die bis vor kurzem gültigen Tatsachen rechtfertigen jedoch keinen endgültigen Entscheid.

Ein genauer Vergleich der Eiweisskörper ungleichen Ursprungs oder ungleicher Eigenschaften war unmöglich, solange die Kenntnis der „Bausteine", welche sie liefern können, fehlte.

In der ganzen erwähnten Literatur wird man vergeblich nach irgendwelchen Angaben über die neueren Auffassungen des Stoffwechsels suchen, für deren Entwicklung Abderhalden in so reichem Masse massgebend gewesen ist. „Wir müssen annehmen", sagt Rubner, „dass das Nährmaterial über den Schwellenwert hinausgehen muss, ehe das Wachstum fortschreiten kann. - Ob es der Konzentrationsgrad des Eiweisses in den Gewebsflüssigkeiten ist, welcher der bestimmende Faktor ist, oder ob der Körper Stoffe aufstapelt und sie für seine Zwecke behält, kann heute nicht 
festgestellt werden" (99, S. 113). Rubner wagte im Jahre 1908 die Behauptung nicht, dass ,beim Wachstum alle Eiweissbestandteile, welche für den Zellaufbau wesentlich sind, aufgenommen werden" (S. 111) und er fügt binzu, dass es nicht sicher ist, ob derselbe Prozess für die Wiederherstellung des Gewebes wesentlich ist. Unterdessen ist eine neue Auffassung aufgekommen, welche nicht mehr die Nahrungsprodukte unverändert oder höchstens nur unbedeutend verändert in die Stoffwechselvorgänge eintreten lässt. Die Bedeutung der Nahrungseinheiten - der „Bausteine“ - ist in den Vordergrund gerückt. Die Gewebe sind unabhängig von den groben Eigenheiten der aufgenommenen Nahrung; sie wählen ihre Bausteine für das Wachstum und die Wiederherstellung und ihr Heizmaterial aus den abgebauten Resten des Darminhaltes aus. „Der einzelne Baustein verrät nicht, welche Rolle seine Muttersubstanz dereinst im Zellgetriebe gespielt hat. So wird die einzelne Körperzelle in weiten Grenzen unabhängig von äusseren Einflüssen" (A bderbalden, 1912).

Ein sorgfältiger Vergleich der verschiedenen Eiweisskörper, welche als Nahrungseiweisse dienen, und deren biologische Eigenschaften und chemischer Aufbau heute ziemlich im Detail bekannt sind, schliesst sogleich die Wahrscheinlichkeit einer direkten Beziehung zwischen denselben und den Körpereiweissen aus, von welchen man annehmen muss, dass sie dieselben ersetzen oder vermehren. Die Unterschiede sind zu auffallend.

Quantitativer Vergleich der Aminosäuren, welche man dureh Hydrolyse aus Proteinen erhältt ${ }^{1}$.

(Zusammengestellt von T. B. Osborne, 1914).

\begin{tabular}{|c|c|c|c|c|c|c|}
\hline & Casein & Ovalbumin & Gliadin & Zein & Edestin & Legumin (Erbse) \\
\hline Glycocoll & 0,00 & 0,00 & 0,00 & 0,00 & 3,80 & 0,38 \\
\hline Alanin & 1,50 & $2, \varepsilon 2$ & 2,00 & 13,39 & 3,60 & 2,08 \\
\hline Valin & 7,20 & 2,50 & 3,34 & 1,88 & 6,20 & $?$ \\
\hline Leucin & 9,85 & 10,71 & 6,62 & 19,55 & 14,50 & 8,00 \\
\hline Prolin & 6,70 & 3.56 & 13.22 & 9,04 & 4,10 & 3,22 \\
\hline Oxyprolin & 0,23 & $?$ & $?$ & $?$ & ? & $?$ \\
\hline Phenylalanin & 3,20 & 5,07 & 2,35 & 6,55 & 3,09 & 3,75 \\
\hline \multirow[t]{2}{*}{ Glutaminsäure } & 15,55 & 9,10 & 43,66 & 26,17 & 18,74 & 13,80 \\
\hline & 1,39 & 2,20 & 0,58 & 1,71 & 4,50 & 5,30 \\
\hline Serin & 0,50 & $?$ & 0,13 & 1,02 & 0,33 & 0,53 \\
\hline Tyrosin & 4,50 & 1,77 & 1,61 & 3,55 & 2,13 & 1,55 \\
\hline Cystin & $?$ & $?$ & 0,45 & $?$ & 1,00 & $?$ \\
\hline Histiain & 2,50 & 1,71 & 1,49 & $0,8 \cdot 2$ & 2,19 & 2,42 \\
\hline Arginin & 3,81 & 4,91 & 2,91 & 1,55 & 14,17 & 10,12 \\
\hline Inysin & 5,95 & 3,76 & 0.15 & 0,00 & 1,65 & 4,29 \\
\hline Tryptophan, ungefahr & 1,50 & vorhanden & 1,00 & 0,00 & vorbanden & vorhanden \\
\hline \multirow[t]{2}{*}{ Aminoniak } & 1,61 & 1,34 & 5,22 & 3,64 & 2,28 & 1,99 \\
\hline & $65, \overline{49}$ & 48,85 & 84,73 & $\overline{88,87}$ & 82,28 & 57,43 \\
\hline
\end{tabular}

1) Diese Analysen sind Kombinationen aus den besten Bestimmungen der verschiodenen Chemiker. 
Niemand würde dem entgegentreten, dass wenn Calcium oder Eisen für das Wachstum unumgänglich nötig wäre, sie in der Nahrung geliefert werden müssten. Aber es hat nicht geringer Forschung bedurft, und es bedarf ihrer noch viel mehr, um eine gleichwertig überzeugende Feststellung in bezug auf die einzelnen Eiweissbausteine, die Aminosäuren, zu machen. Die Gründe für diese Ungewissheit sind nicht schwer zu finden. Die Ungleichheiten der Eiweisskörper vom Aminosäurestandpunkt aus sind erst vor ganz kurzer Zeit aufgedeckt worden; und, was noch wichtiger ist, es ist nicht möglich gewesen zu sagen, welche Fähigkeit der tierische Organismus haben kann, um die verschiedenen Aminosäuren - achtzehn oder mehr an der Zahl - von neuem aufzubauen, welche einen Platz im Bau und in den Funktionen des Körpers haben.

Es ist klar, dass wir wissen müssen, welche Nahrungselemente irgend einer Art unentbehrlich sind, und ferner, ob ein vollständiges Fehlen oder Mangeln derselben in der Aufnahme durch direkte Synthese gut gemacht werden kann. So ist schon gezeigt worden, dass Glykokoll $\mathrm{CH}_{2}$. COOH von<smiles>N</smiles>

neuem im Körper gebildet werden kann. Fehlen desselben in der Nahrung würde deshalb nicht notwendigerweise sich in irgend einer Ernährungsstörung zeigen. Das Tryptophan

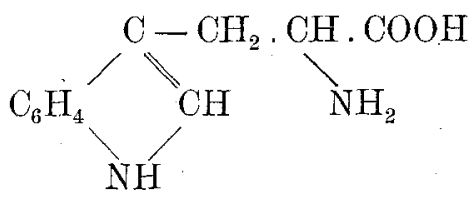

andererseits kann offenbar nicht von Säugetieren (wenigstens nicht in genügender Menge) de novo erzeugt werden, wenn man nach den verhängnisvollen Folgen, welche auf eine tryptophanfreie Kost folgen und die rasche Erholung, welche durch den Ersatz von fehlenden Aminosäuren herbeigeführt wird, urteilen darf. Die Situation wird weiter durch die Wahrscheinlichkeit kompliziert, dass neuer Gewebsaufbau, sowie ihn das Wachstum in sich schliesst, Bausteine erfordert, welche entweder bei der Abnutzung im gewöhnlichen Erhaltungsumsatz ohne Wachstum erhalten bleiben, oder deren es für den Erhaltungsstoffwechsel nicht bedarf, oder die dabei nicht zerstört werden.

Wenn wir unsere Betrachtungen für den Augenblick auf das Eiweissbedürfnis beschränken, werden wir nicht irregehen, wenn wir dabei heute als von den spezifischen Aminosäurebedürfnissen des wachsenden Organismus sprechen. Ein direkter Weg, dies zu untersuchen, besteht darin, die stickstoffhaltigen Bestandteile der Nahrung (insofern sie in gewöhnlicher Weise durch die Eiweisse geliefert werden) in der. Form von Mischungen der bekannten Aminosäurederivate einzuführen. Die technischen Schwierigkeiten 
eines derartigen Verfahrens sind heute fast unüberwindlich. Abderhalden (Abderhalden 1912; auch Abderbalden und Hirsch 1912) allein hat das mit einem gewissen Grad von Erfolg an jungen Hunden versucht, die er mit vorverdauter Nahrung fütterte. In manchen seiner Versuche ergaben sich beträchtliche Gewichtszunahmen - in einem Falle $1000 \mathrm{~g}$, in einem anderen Falle $1200 \mathrm{~g}$. Andauerndes Wachstum ist ein wunderbares Zeichen der Eiweisssynthese und der geeigneten Diät. Aber.keine zeitweise oder vorübergehende Gewichtszunahme, auch keine, welche auf den Körperverfall durch vorangehende ungeeignete Ernährungsbedingungen folgt, kann als ein Beweis für wahres Wachstum angesehen werden, denn die Wiederherstellung kann zustande kommen, ohne notwendigerweise wirkliche, synthetische Prozesse in dem beabsichtigten Sinne in sich zu schliessen. Wahres, beständig fortdauerndes Wachstum äussert sich in charakteristischen Zunahmen an Gewicht und Grösse, wie sie auf typischen Wachstumskurven dargestellt worden sind.

Ein anderer Weg, um sich dem Problem zu nähern, warum Stickstoffelemente für das Wachstum wesentlich sind, besteht darin, die Wirksamkeit der einzelnen Eiweisskörper, und besonders jener, von welchen bekannt ist, dass sie sich von dem typischen Gewebseiweiss des Tieres in ihrem strukturellen Aufbau weit unterscheiden, zu vergleichen. Offenbar kann das nicht durch Zusätze zur gewöhnlichen gemischten Kost geschehen, welche gewöhnlich eine Reihe von Eiweisskörpern enthält. Sogar Milch, die als eine verhältnismässig einfache Nahrung angesehen wird, enthält wenigstens zwei Eiweisskörper - Kasein und Laktalbumin - die in Struktur und Aminosäuren entschieden ungleich sind, und in ganz verschiedenen Verhältnissen in die Brustdrüsen Sekrete von verschiedenen Arten abgeben. Es wurde daher notwendig, eine Kost vorzuschlagen, in welcher alle wesentlichen Nahrungsbestandteile, ausser Eiweisskörpern oder Aminosäuren, reichlich vorhanden waren, und zu welchen diese stickstoffhaltigen Nahrungssubstanzen eine nach der anderen zugesetzt und untersucht werden konnten. Auf diese Weise wird der Eiweissfaktor die einzige Variable in der Diät.

Trotz zahlreicher früherer Fehler ist die Möglichkeit Tiere mit Gemischen von isolierten Nahrungssubstanzen zu erhalten und dabei Wachstum. herbeizuführen, endlich nachgewiesen worden ${ }^{x}$. Röhmann ist ein Pionier auf diesem Gebiet gewesen. (Röhmann 1912.)

T. B. Osborne und ich (Osborne und Mendel 82, S. 80) waren imstande, das Studium der Rolle der einzelnen Eiweisskörper und Aminosäuren beim Wachstum zu erleichtern, indem wir die Anwendung der sogenannten "eiweissfreien Milch" genannt haben, in die künstliche Ernährung einführten. Diese besteht aus getrockneten Resten von Milch nach Entfernung der Fette und der Eiweisskörper. Sie enthält, abgesehen von unbe-

\footnotetext{
$\left.{ }^{1}\right)$ Die frühere Literatur ist bei $O$ sborne and M e n del (82) angegeben.
} 
deutenden Spuren von nicht entferntem Eiweiss, allen Milchzucker und alle anorganischen Elemente zusammen mit kleinen Mengen gelegentlicher Bestandteile, von denen die meisten unbekannt sind, jedoch offenbar einen wesentlichen Nicht-Eiweissfaktor der Nahrung liefern. Bei Mischungen von "eiweissfreier Milch“, Zucker, Stärke und gereinigten Fetten, zusammen mit ausgewählten isolierten Eiweisskörperu, sind junge weisse Ratten (und in manchen Fällen Mäuse, Wheeler 1913, 130) bis zur Reife gewachsen und haben ihrerseits Junge erzeugt. Die Reibe der einzelnen Eiweisskörper, mit welchen in geeigneter Konzentration das Wachstum gesichert worden ist, wenigstens während längerer Beobachtungszeiten, wenn nicht bis zur vollständigen Reife, umfasst folgende:

Eiweisskörper

Tierischen Ursprungs

Kasein (Mileh)

Laktalbumin (Milch)

Ovalbumin (Hühnerei)

Orovitellin (Hühnerei)

\author{
Pflanzlichen Ursprungs \\ Edestin (Hanfsam $\Theta$ ) \\ Globulin (Schotensame) \\ Exceslin (Brasilianische Nuss) \\ Glutelin (Mais) \\ Globulin (Baumwollsamen) \\ Glutenin (Waizen) \\ Glycinin (Saubohne) \\ Cannabin (Hanfsame)
}

Unsere Versuche, das Wachstum herbeizuführen, misslangen mit:

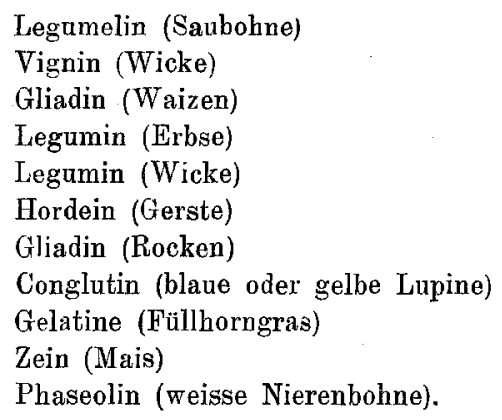

Bei einigen dieser Eiweisskörper, besonders Gelatine, Zein, Gliadinen und Hordein wurde die Wachstumshemmung sofort durch die bekannten Mängel jeder dieser Substanzen in bezug auf eine oder mehrere Aminosäuren erklärt, von welchen bereits festgestellt wurde, dass sie von den adäquaten Eiweisskörpern geliefert werden.

Die Tryptophangruppe (mit ihrem Indolkern) fehlt in Gelatine und Zein; die Diaminosäuregruppe (Lysin) fehlt ganz oder fast in Zein, in Gliadinen und Hordein. Andere Mängel sind das Fehlen der Tyrosingruppe in Gelatine und der Glykokollgruppe in Zein. Dass Glykokoll entweder nicht unentbehrlich ist, oder dass es durch direkte Synthese dem Organismus geliefert werden kann, wird durch das ausgezeichnete Wachstum gezeigt, das den Gebrauch von glykokollfreiem Kasein begleitet. 
Wenn wir die Situation analysieren, so wie sie in den Kurven mancher aktueller Versuche dargestellt wird, sehen wir, dass sowobl Lysin wie Tryptophan ohne Frage als Bausteine beim Wachstum notwendig sind. Der durch die Zeinnahrung herbeigeführte Abfall kann durch Zusatz von Tryptophan, als solches, zu der Kost gehemmt werden. Darauf erfolgt Stillstand; aber es wird kein Wachstum erzeugt, bis nicht Lysin hinzugefügt wird: Die Bedeutung anderer von Eiweisskörpern abgeleiteten Aminosäuren mussauf vergleichenden Wegen untersucht werden. Experimentell werden solche Untersuchungen durch die Tatsache kompliziert, dass die meisten brauch-

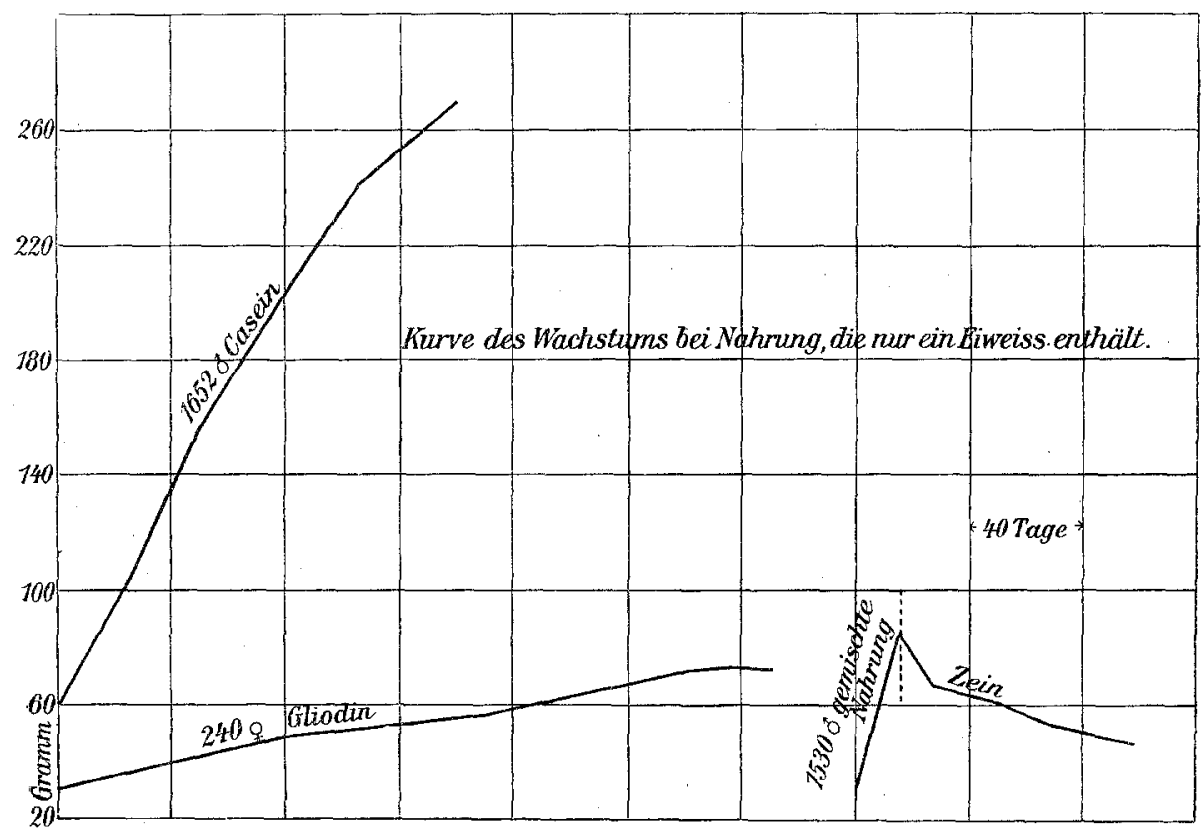

Figur 3.

Fig. 3 zeigt typische Wachstumskurven von Ratten, die mit Nahrung, die nur ein Eiweiss enthielt, erhalten wurden. Bei der Kaseinnahrung (glykokollfrei) wird befriedigendes Wachstum erreicht; bei der Gliadinnahrung (Mangel an Lysin) ist etwas mehr als Erhaltung des Körpergewichts möglich; bei Zeinnahrung (frei von Glykokoll, Lysin und Tryptophan) ist sogar Erhaltung des Körpergewichts unmöglich.

baren Eiweisskörper nicht ganz frei von den wichtigen Aminosäurekernen sind. Die Versorgung der fehlenden Aminosäuren muss nicht in der Form der isolierten Verbindung geschehen. Geeignete Eiweisskörper, welche sie abgeben, reagieren auf dieselbe Weise.

In diesen Beispielen war die Versorgung mit verschiedenen Eiweisskörpern eine ergiebige. Wenn jedoch das Eiweiss in beschränkteren Mengen gereicht wird, kann sich die Unentbehrlichkeit gewisser Aminosäuren auf die überraschendsten Weisen geltend machen. Kasein liefert z. B. verhältnismässig wenig von der schwefelhaltigen Aminosäure Cystin. Wo die 


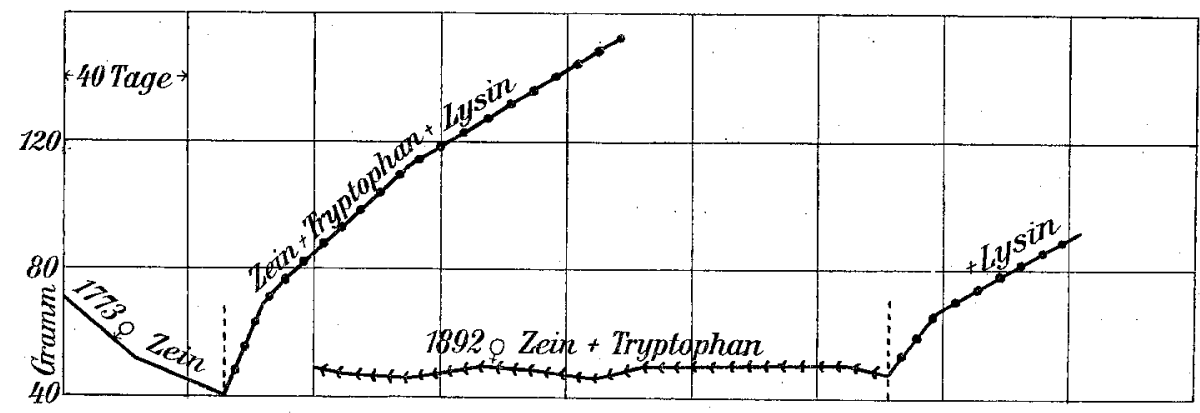

Figur 4.

Fig. 4 zeigt die Wirkung der Addition der Aminosäuren Tryptophan und Lysin zu Zein, welches sie nicht entbält. Mit Zein allein (Ratte 1773) zeigt sich Ernährungsabfall. Der Zusatz von Tryptophan (Ratte 1892) führt zu Erhaltung ohne Wachstum mit Nahrung, welche Zein als einziges Eiweiss enthält. Der Zusatz von Tryptophan und Lysin zu Zein setzt die Tiere instand beträchtlich zu wachsen.

Es ist interessant in bezug auf Ratte $1892 \mathrm{zu}$ beobachten, dass das Wachstum dieses Tieres während sechs Monaten, ohne materielle Veränderung in ihrem Körpergewicht, gehemmt war. Dass die Wachstumsfähigkeit durch andauerndes Kleinerwerden infolge unzureichender Nahrung nicht verloren ist, wird durch das spätere Wachstum des Tieres gezeigt, als Lysin der Zein und Tryptophan enthaltenden Nahrung zugesetzt wurde.

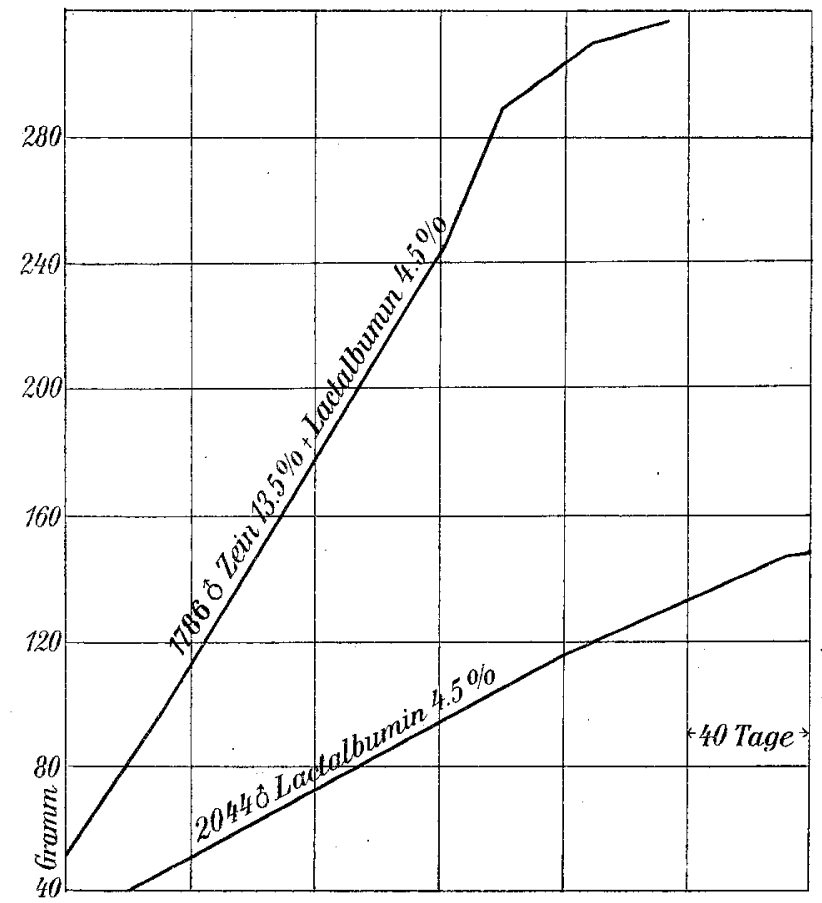

Figur 5.

Fig. 5 zeigt die günstige Wirkung auf das Wachstum durch Ergänztng eines Eiweisses (Zein), das, wenn es das einzige in der Nahrung ist, unfähig ist, Tiere zu erhalten durch ein "vollkommeneres" Eiweiss (Laktalbumin). Das Verhältnis des angewandten Laktalbumins $-4_{12}^{1 / 2} \%$ - genügte an sich nicht, das Wachstum gut zu fördern. Es liefert offenbar die im Zein fehlenden Aminosäuregruppen. 
Kaseinmenge in der Nahrung reichlich ist, werden offenbar alle Aminosäuren in hinreichender Menge gereicht, um die geeignete Synthese des (Cystin enthaltenden) Gewebes, welches von der Wachstumsmöglichkeit - dem Vererbungsfaktor - umschlossen wird, zu gestatten. Wenn aber die Kaseinversorgung eingeschränkt wird, ist die Wachstumskurve verändert.

Das bedeutet nicht, dass das Wachstum durch das Feblen von genügendem Eiweiss per se beschränkt wird; denn der Zusatz von Cystin hebt sofort die ernährende Wirksamkeit der Kost. Das Wachstum ist durch die Versorgung in der (relativ) am wenigsten reichlich vorhandenen wesentlichen Aminosäure - in diesem Falle Cystin - eingeschränkt worden.

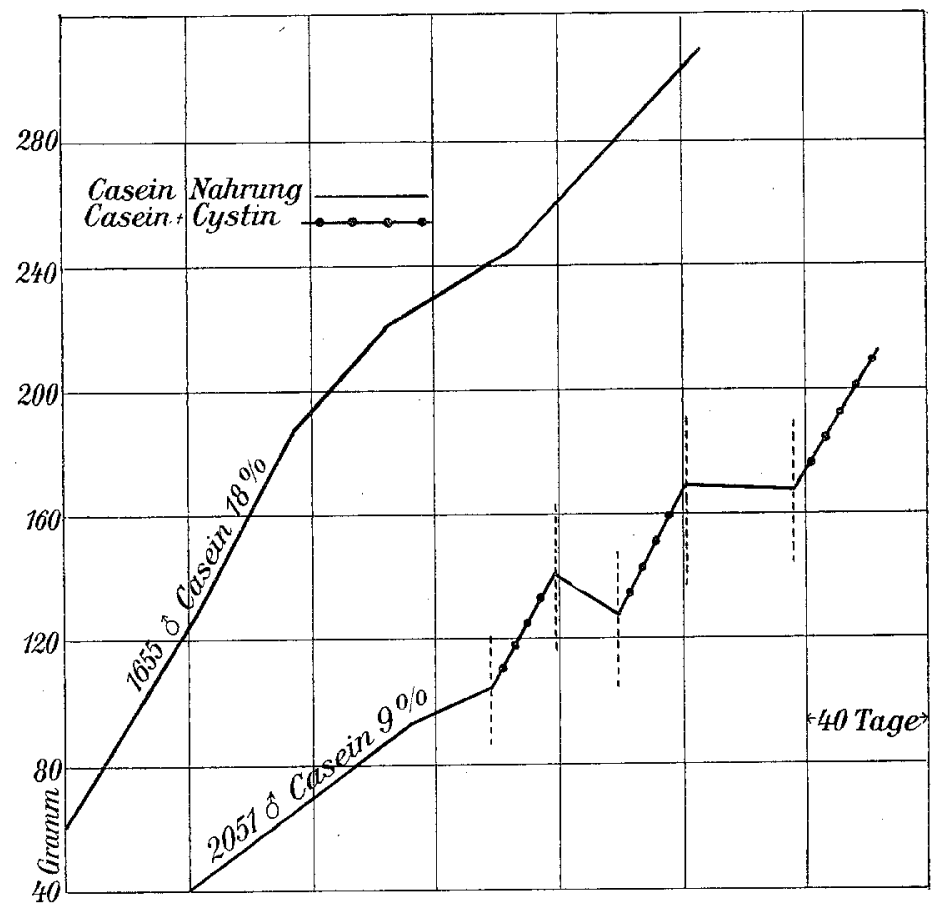

Figur 6.

Die Kurve für die Ratte 1655 zeigt das befriedigende Wachstum, welches man erhalt, wenn $18 \%$ Kasein in der Nahrung als einziges Eiweiss vorhanden war. Mit einer geringeren Menge von Kasein (Ratte 2051) - 9\% - erfolgte viel weniger rasches Wachstum. Dass die Unzulänglichkeit der kleineren Kaseinmengen wesentlich von ihrem Mangel an Cystin liefernden Gruppen herrührt, wird durch den ausgesprochen beschleunigenden Einfluss auf das Wachstum gezeigt, welcher durch den Zusatz der Aminosäure Cystin zu der Nahrung, welche $9 \%$ \% Kasein enthält und durch die rasche Gegenwirkung, als das Cystin der Nahrung entzogen wurde, zustande gebracht wird.

Dasselbe wird bei Edestin berichtet, einem Eiweiss, das adäquat für das Wachstum ist, wenn es reichlich verfüttert wird, das aber seine verhältnismässige Armut an Lysingruppen offenbart, sobald die Aufnahme beschränkt wird. Hier ermöglicht der Zusatz von Lysin, anstatt Cystin, 
dem Organismus, die übrig bleibenden reichlicheren Aminosäuren wirksam für das Wachstum zu verwenden, selbst wenn die gesamte Eiweissversorgung nicht gross ist. Die Grenzen der Möglichkeit des Wachstums und der Umfang, bis zu welchem es vollendet wird, werden durch die Versorgung mit jeder einzelnen wesentlichen Aminosäure gegeben. Es tut dabei nichts zur Sache, ob diese als solche oder in Form von Eiweiss geliefert wird; in jedem Fall tritt das "Minimumgesetz" in Erscheinung. Das Aminosäuredefizit eines Eiweisses kann dadurch gut gemacht werden, dass man es durch ein anderes Eiweiss, in welchem es nicht im selben Grade mangelt, ergänzt.

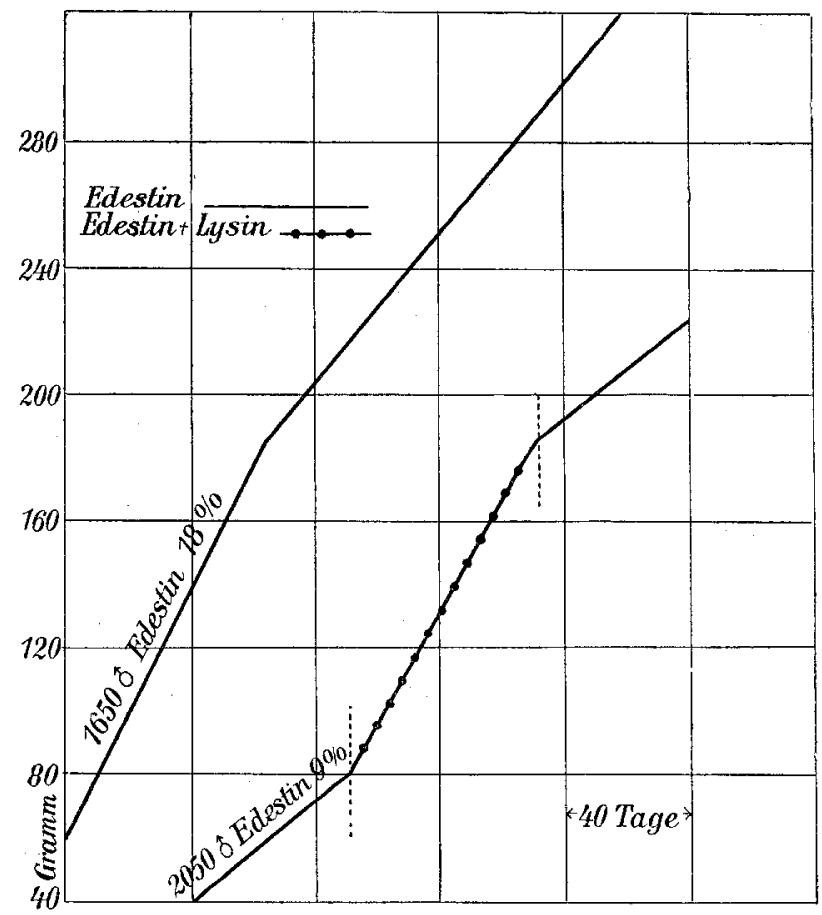

Figur 7.

Die Kurve für Ratte 1650 zeigt das befriedigende Wachstum, welches man erhält, wènn $18 \%$ Edestin als einziges Eiweiss in der Nahrung vorhanden war. Mit einer geringeren Menge von Edestin (Ratte 2050) - 9\% - erfolgte viel weniger rasches Wachstum. Dass die Unzulänglichkeit der geringeren Menge von Edestin wesentlich von seinem relativen Mangel an Lysin liefernden Gruppen herrührt, wird durch den deutlich beschleunigenden Einfluss gezeigt, welcher zustande kommt durch den Zusatz der Aminosäure Lysin zu der Nahrung, welche $9^{0}: 0$ Edestin enthält, und durch das langsamere Wachstum, wenn das zugesetzte Lysin der Nahrang entzogen wird.

Wir wollen nun betrachten, was diese neuen Beobachtungen für das Problem des Eiweissminimums bedeuten; man kann jetzt vorziehen, von Aminosäureminima zu sprechen. Die Unterschiede zwischen den Eiweisskörpern erscheinen in einem neuen Lichte. Das Vorhandensein von Laktalbumin zusammen mit Kasein in der Milch liefert eine Mischung von 
Eiweisskörpern, welche Gramm für Gramm Kasein allein vorzuziehen ist. Das relative Aminosäuredefizit der letzteren, wie es sich in dem niedrigen Gehalt an Cystin zeigt, wird durch Laktalbumin beseitigt. Daher ist es vom Standpunkt der Ökonomie aus vorteilhaft, den Aminosäureaufbau aller verfügbaren Nahrungseiweisse zu kennen, so dass sie in Verhältnissen dargøreicht werden können, welche einen ausgeglichenen Gesamt-Aminosäureaufbau, der fast annähernd ideal ist, liefern. Dies hat praktisch eine viel grössere Bedeutung für die Tierproduktion in der Landwirtschaft, wo die Ökonomie der Kost von grösserer ökonomischer Bedeutung ist als für die menschliche Ernährung, wo wir grössere Hilfsquellen haben. Die Eiweisse des Maiskerns bestehen z. B. grösstenteils aus Zein, welches selbst kein Ernährungsgleichgewicht aufrecht erhalten kann (Osborne und Mendel 1913a, 1914 b, 51). Korn und die Nebenprodukte des Kornes sind besonders ungenügend für gute Fütterungsresultate, wenn sie nicht durch andere eiweissenthaltende Nabrungsstoffe ergänzt werden. Osborne und ich baben gefunden, dass verschiedene Eiweisskörper wie Kasein, Laktalbumin und Edestin, oder selbst das Maisglutenin, das begleitende Eiweiss des Zeins im Maiskern, ungleiche Wirksamkeit als Eiweisssupplement zeigen, um Wachstum mit Zein enthaltenden Diäten zu fördern. Wie wir andernorts geschrieben haben „Die vorangehenden Versuche rücken gewisse Probleme, welche mit der Ökonomie der Nahrungsmittel und dem kommerziellen Futter zusammenhängen, in ein neues Licht". Korn bildet die billigste Basis zur Fütterung von Farmtieren bei der Nahrungserzeugung. Insofern als die Geschwindigkeit des Wachstums mehr durch vererbte, als durch Ernährungsbedingungen bestimmt ist, ist es fruchtlos, mehr Energie, und besonders mehr Eiweiss zu liefern, als für die normale Entwickelung wesentlich ist. Ein ungeeignetes, aber billiges Eiweiss kann vorteilhaft durch ein solches ergänzt werden, welches die nötigen Faktoren, nämlich die Aminosäuren, liefert. Der relative ökonomische Wert dieser Zusätze supplementärer Eiweisskörper zu einer unwirksamen, aber billigen Kost hängt nicht nur von ihrer Quantität, sondern ebenfalls von ihrem Aminosäureaufbau ab. Ein sehr kleiner Zusatz eines Eiweisses, wie Lactalbumin, kann viel vorteilhafter sein, wenn der Preis pro Einheit des Gewinnes betrachtet wird, als grössere Mengen von billigeren Eiweissen, welche das Aminosäuredefizit der Standarddiät weniger vollkommen ergänzen. Es gehört vielleicht keine allzu utopistische Hoffiung dazu, zu erwarten, dass der Tag kommen wird, wo Aminosäurekonzentrate dazu dienen werden, die Eiweissmischungen in einem Futter wie Mais oder seiner Handelsnebenprodukte zu vervollkommnen. (Osborne und Mendel 1914b, S. 10.)

Kornmais ist nicht nur ganz arm an Eiweiss, dessen grösster Teil bestimmte wichtige Aminosäuren nicht zu liefern vermag, sondern es fehlt ihm merklich an Calcium, das offenbar reichlich für den Umfang des Wachstums 
erforderlich ist. Evvard, Dox und Guernsey (1914) haben kürzlich gefunden, dass der Zusatz von Calciumcarbonat und Bluteiweiss zu einer Grundnahrung von Korn und Salz, an trächtige Ferkel verfüttert, ein grösseres Wachstum ergab, nämlich, dass neu geborene Schweine einen grösseren Umfang, stärkere dickere Knochen, vermehrte bessere Hautfarbe hatten und sich in einem besseren Zustand befanden. Es bedarf geringer wissenschaftlicher Phantasie, um derartige Versuche mit Mais auch mit der menschlichen Ernährung in Beziehung zu bringen, in Gesichtspunkte umzusetzen, welche auf die menschliche Ernährung anwendbar sind.

Ohne Kohlehydrat in der Kost sind die Nahrungsfunktionen eines wachsenden Individuums ebenso leicht und sogar noch rascher bedroht, wie sie es während des erwachsenen Lebens sind. Das isolierte Vorkommen von Laktose, einem besonders in der Milch vorkommenden Kohlehydrat in der Nahrung, welche die Natur für wachsende Säugetiere vorgesehen hat, hat ganz natürlich auf Grund teleologischen Nachdenkens die Annahme entstehen lassen, dass Milchzucker ein besonderes Vermögen bei der Ernährung im Wachstumsstadium hat. Andererseits haben Rohrzucker, Maltose, Glukose und sogar Stärke und Dextrine Verfechter, besonders unter den Pädiatern gefunden, welche mehr als alle anderen interessiert waren festzustellen, welches, wenn möglich, das beste Kohlehydrat ist, um es wachsenden Kindern zu verabfolgen. Es sind auf rationelle Experimente gegründete Anzeichen von Ungleichheiten in dem Werte der verschiedenen erwähnten Substanzen vorhanden. Vielleicht müssen diese mit der relativen Tätigkeit des Darmtraktus in den verschiedenen Lebensaltern (oder bei den verschiedenen Arten) die verschiedenen Kohlehydrate vor ibrer Resorption zu verdauen, assoziiert werden. Angaben über diese Ungleichbeiten fehlen nicht ganz (z. B. Mendel und Mitchell 1907). Aber der genaue Vergleich des Wertes der bekannten Zuckerarten kann nur unter experimentellen Bedingungen gemacht werden, bei welchen die Zahl der anderen Variablen auf ein Minimum reduziert wird. Trotz der grossen Literatur über diesen Gegenstand hinterlässt eine kritische Untersuchung desselben den Eindruck, dass das zur Verfügung stehende Beweismaterial zu keinem definitiven Schluss berechtigt, welcher mit absoluter Bestimmtheit für oder gegen die bekannten Zuckerarten der Nahrung entscheiden könnte (siehe Calvary 1913).

Es gibt augenblicklich eine Unmenge von Angaben, ob echte Fette ein wirkliches Bedürfnis zur Erhaltung eines gesunden, normalen Organismus sind. Fette werden natürlich gewöhnlich in grösserem oder geringerem Masse in jeder Nahrung gefunden; aber bis zu welchem Umfange sie ein unentbehrliches Bedürfnis des Tieres darstellen, muss noch festgestellt werden. Wie anderen Ortes gezeigt worden ist (O sb or ne und Mendel, 1912), ist der Grund, warum diese offenbar grundlegende Ernährungsfrage nicht früher beantwortet worden ist, vermutlich den experimentellen Schwierig- 
keiten zuzuschreiben, welche ihrer Lösung anhạften. Fette oder fettähnliche Substanzen sind in gewissem Umfange in der Mehrzahl der bekannten Nahrungsstoffe vorhanden, aus welchen sie nur mit Aufwand von beträchtlicher Mühe und Sorgfalt entfernt werden können; und die Versuche Tiere mit künstlich präparierten Mischungen von isolierten Nahrungssubstanzen zu erhalten, haben bis vor kurzem nur geringen Erfolg erzielt ${ }^{1}$ ).

Es gibt noch einen weiteren Grund, warum es praktisch unmöglich gewesen ist, die Frage der Entbehrlichkeit wahrer Fette zu beantworten. In Nahrungsstoffen sind diese Glyzeride fast immer von Substanzen von ähnlicher Löslichkeit und physikalischen Eigenschaften begleitet: Phosphatide, Cholesterol, Pigmente usw., für welche die heterogene Bezeichnung "Lipoide" vorgeschlagen worden ist $\left.{ }^{2}\right)$. Diese werden in bestimmter Menge in jeder aktiven Zelle gefunden; aber obgleich diese Tatsache vermuten lässt, dass wenigstens manche dieser sogenannten ,Lipoide“ eine hervorragende biochemische Bedeutung haben, folgt keineswegs daraus, dass sie während des Wachstums oder zu anderen Zeiten wesentlich für die Ernährung sind. Sie werden durch Pflanzenzellen aufgebaut, und es ist nicht unstatthaft, von ihnen anzunehmen, dass sie ähnlich auch im tierischen Organismus gebildet werden. Me Collum 1909 (Me Collum und Halpin 1912, auch Fingerling 1912) hat gezeigt, dass der von einem Tier zur Phosphatidbildung erforderliche Phosphor aus anorganischen Phosphaten bezogen werden kann, und dass Phosphatide von neuem im tierischen Körper aufgebaut werden können. Röhmann (1908 und 1914) stellt die Möglichkeit der Lecithinsynthese bei Mäusen fest, welche bis in die zweite Generation mit lecithinfreier Nahrung erhalten wurden.

Ein neues Interesse ist für die Frage der Rolle der Fette, als unentbehrlicher Faktoren in der Nahrung durch die Beobachtung von Stepp geweckt worden (1909, 1911a, 1911b, 1912a, 1912b). Bei dem Versuche, festzustellen, ob Tiere von ihrer Nahrungsversorgung an Lipoiden abhängig sind, oder ob sie dieselben durch Synthese wie Pflanzen liefern können, fütterte er mit Äther und Alkohol extrahierte Stoffe an Mäuse und beobachtete die Wirkung auf das Ernährungsgleichgewicht der Tiere. Offenbar schied diese Zubereitungsmethode der Nahrung gleichzeitig die wahren Fette aus der Diät aus. Stepps Beobachtungen und Schlüsse verdienen im $\mathrm{Zu}-$ sammenhang mit dem vorliegenden Problem sorgfältig in Retracht gezogen zu werden. Er bemerkte, dass seine Mäuse ausnahmslos in wenigen Wochen zugrunde gingen, wenn man ihnen sonst geeignete Nahrungsgemische, welche gründlich extrahiert worden waren, darreichte. Es wird daraus gefolgert,

1) Eine Besprechung der früheren Versuche in dieser Richtung findet man bei Osborne und Mendel 1911 a, 82 .

2) Für eine allgemeine Beschreibung der sogenannten Lipoide, ihr Vorkommen und ihre mögliche biochemische Bedeutung, siehe Bang 1907, 1909. 
dass die mangelhafte Ernährung von dem Fehlen gewisser „Lipoid"substanzen herrührt, weil der Zusatz von Alkohol-Ätherextrakten von Stoffen, von welchen man weiss, dass sie reich an diesem Typus von Verbindungen sind, genügte, um die Tiere am Leben zu erhalten. Es wird angenommen, dass die fehlende Substanz nicht anorganisch ist, da der Zusatz der Asche der Lipoidextrakte, die aus dem Nahrungsstoff gemacht wurden, die Mäuse nicht am Leben erhalten konnte. Ferner - und dies muss hier hervorgehoben werden - wird festgestellt, dass der erhaltende Bestandteil nicht gewöhnliches Fett ist, insofern als der Zusatz eines so typischen Fettes wie Butter den fehlenden lebenserhaltenden Faktor nicht ersetzen konnte. Vor ganz kurzem hat Stepp (1913) wiederholt seine Anschauung vertreten, dass die Alkohol-Äther-löslicben Nahrungsbestandteile, bei deren Abwesenheit die Mäuse regelmässig zugrunde gehen, nicht Fette sind. Er behauptet, dass sie in Alkohol, aber nicht in Äther löslich sind. (Siehe auch Oseki 1914). Tripalmitin, Tristearin und Triolein belebten Stepps schlecht ernährte Mäuse nicht wieder.

Vor einiger Zeit glaubten Osborne und ich (Osborne und Mendel 1912), dass wir einen Beweis für die Entbehrlichkeit echter Fette für das Wachstum bei Ratten erhalten hatten, obgleich wir mit fettfreier Nahrung bei Mäusen keinen Erfolg hatten. Unsere Nahrungsmittel bei diesen Versuchen können vermutlich als fettfrei bezeichnet werden, selbst wenn es vielleicht nicht zulässig ist, von ihnen als lipoidfrei zu sprechen; denn gemäss der landläufigen Bezeichnung enthalten die sogenannten "Lipoide" in heissem Alkohol lösliche Substanzen, welche sich nicht in Äther aufzulösen brauchen. Keiner unserer isolierten Nabrungsstoffe wurde der Extraktion mit heissem Alkohol unterworfen. Zweifellos würde eine solche Behandlung andere Substanzen ebenso wie Lipoide aus einer derartigen Mischung, wie der „eiweissfreien Milch“ entfernen. Obgleich die Tiere eine Zeitlang bei der so angelegten ,künstlichen“ Nahrung wuchsen, führt uns die spätere Erfahrung zu dem Glauben, dass die Versuche, obgleich sie sich in manchen Fällen über vier Monate ausdebnten, trotzdem von zu kurzèr Dauer waren, um eine endgültige Antwort zu gestatten. Früber oder später konnte keines der Tiere weiter wachsen oder bei solcher fettfreier Nahrung gedeihen.

Dieser Ernährungsverfall schliesst jedoch nicht notwendigerweise das Fehlen wahrer Fette in sich, sondern betrifft vermutlich eine neue und bisher unbeachtete Frage der Ernährung beim Wachstum, welche genauere Betrachtung verdient. Ich verweise auf die Rolle, welche von Substanzen gespielt werden kann, die nicht identisch mit den gewöhnlichen Nahrungsmitteln sind, und welche, trotz der minimalen Mengen, welche davon in der Kost vorhanden sind, trotzdem unentbehrlich für das Wachstum und die Erhaltung des Lebens sein können. Hopkins hat den Ausdruck „akzessorische Diätfaktoren", Hofmeister "akzessorische Nährstoffe", 
(Oseki, S. 160), Funk "Vitamine" für die hierbei beteiligten Faktoren vorgescblagen.

Es würde uns zu weit von unserem unmittelbaren Thema abführen, wollten wir jetzt die Entwickelung des Beweises dafür überblicken, dass es ausser den Nahrungsmitteln im gewöbnlichen Sinne, andere Bestandteile unserer Nahrung gibt, welche von grösster Bedeutung für das Leben sind ${ }^{1}$ ). Die Idee ist grösstenteils das Ergebnis der modernen Untersuchung der sogenannten „deficiency"-Krankheiten, besonders von Beriberi und Skorbut. Es war kaum möglich, das Problem unter idealen Bedingungen zu untersuchen bis befriedigende Methoden für Futtergemische von isolierteu Nahrungssubstanzen mit einem gewissen Erfolge vorgeschlagen wurden. $\mathrm{Zu}$ wie vielen neuen und anregenden Hypothesen hat die Vitamintheorie bereitwillig dienen müssen und ist als Erklärung für alle Arten von pathologischen Bildern, und in manchen Fällen nur auf Grund von Analogien ohne jedem wissenschaftlichen Beweis eigens angewandt worden.

Die Vorstellung der Existenz akzessorischer Faktoren oder spezifischer Bedürfnisse für das Wachstum hat erst vor kurzem eine koukretere Form angenommen. Die Untersuchungen von Röhmann (1902, 1903, 1908a, 1912, 1914), Hopkins (1912), Hopkins und Neville (1913), Mc Collum (1909), Mc Coll um und David (1913a, 1913 b, 1914), Funk (1913a, 1913b, 1914), Funk und Macallum (1914) und von Osborne und Mendel $(1913 b, 1913 c, 1914 a)$ haben insbesondere neue Fragen in bezug auf die mögliche Funktion der akzessorischen Diätfaktoren oder ,Wachstumsvitamine“ beim Wachstum aufgeworfen. Kurz, sie zeigen, dass alle Versuche bei Tieren mit einer Ernährung, die aus sorgfältig gereinigten, isolierten Nahrungsstoflen besteht - nicht den stark komplexen Futtergemischen, wie sie die bekannten Rationen des täglichen Lebens bilden - früher oder später erfolglos waren. Mängel von manchen dieser früher als erfolgreich angesehenen Versuche mit derartig ,,künstlichen“ Diäten, z. B. Mischungen von Kasein, Fett, Zucker, Stärke und anorganischen Salzen, wurden durch die kurze Dauer der Beobachtungen verdeckt. Osborne und ich haben über zahlreiche Beispiele von Wachstum während Perioden von vielen Wochen bei Diäten, welche den soeben skizzierten ähnlich waren, Erfahrungen gesammelt; aber das Wachstum hörte immer auf, wenn die Versuche nicht zu früh unterbrochen wurden; und die Entwickelung wurde wieder aufgenommen, sobald geeignete Diätveränderungen wieder einsetzten. Röhmann, welcher einen ziemlichen Erfolg erzielte, indem er Mäuse sowohl zum $W$ achsen brachte, als er sie mit Mischungen von isolierten Nahrungsstoffen am Leben erhielt, sagt offen: „Diese Futtergemische sind also für die Aufzucht junger Mäuse den natürlichen noch nicht vollkommen gleichwertig .... Worauf diese Unvoll-

1) Für die Literatur dieses Gegenstandes, siehe Funk 1913 a, 1914. 
kommenheit der künstlichen Nahrungsgemische beruht, 'will ich nicht entscheiden. Überaus bequem ist ja die Erklärung mit Hilfe der Vitamine. Aber sind denn wirklich schon einwandfreie Beweise für deren Vorbandensein gebracht? Ich bin vorläufig mehr geneigt anzunehmen,. dass in der von mir verwendeten künstlichen Nahrung zwar alle für die Ernährung und das Wachstum erforderlichen Stoffe vorhanden waren; aber dass das Mischungsverhältnis oder die Form der Nahrungsstoffe nicht derartig war, um die künstliche Nahrung der natürlichen vollkommen gleichwertig erscheinen zu lassen."

Hopkins (1912) fand, dass er das Defizit der "künstlichen“ Gemische decken konnte durch den Zusatz von Milch in Mengen, welche vom Standpunkt ihres Beitrages für die Energie der Ration viel zu klein waren um Bedeutung zu haben. Osborne und ich (Osborne und Mendel 82) fanden in dem, was wir "eiweissfreie Milch" nannten, ein befriedigerendes Ersatzmittel für die weniger wirksamen Salzmischungen oder die Asche der Milch. Dieses Produkt enthält, ausser Laktose und anorganischen Salzen, sehr kleine Mengen von unbekannten Bestandteilen. Unsere Versuche, die „eiweissfreie Milch", auf künstlichem Wege nachzuahmen, wie Röhmann (1903) und von Mc Collum und Davis (1903a, 1913b) mit Salzmischungen es machten, haben im besten Falle beschränktes Wachstum gegeben, obgleich dasselbe gelegentlich in überraschendem Umfang geschah. Für derartige Ausnahmeerfolge kann man die Hypothese aufstellen, dass der junge Organismus manchmal, wenn nicht immer, einen Vorrat der bis jetzt unbekannten "chemischen bestimmenden Faktoren" besitzt, welcher, bei Abwesenheit einer geeigneten Versorgung durch Nahrungsaufnahme, eine Zeitlang genügt. Früher oder später wird dieser erschöpft und das Ernährungsgleichgewicht und das Wachstum hören auf. Der Organismus baut kein "Vitamin" auf, wenn wir es vorziehen, die Situation in Ausdrücken dieser Hypothese auszusprechen.

Mc Collum und Davis (1914) fassen eine reiche Erfahrung mit Ratten, welche mit einer aus gereinigtem Kasein, Dextrin und Salzmischungen (aus Reagenzien) zusammengestellten Nahrung gefüttert wurden, zusammen und lenkten dabei die Aufmerksamkeit auf einen deutlichen Unterschied in der Fähigkeit der einzelnen Tiere, bei einer solchen Nahrung zu wachsen. Sie behaupten, dass normales Wachstum während einer Periode von etwas mehr als hundert Tagen nur ausnahmeweise erreicht werden kann. Manche wachsen überhaupt nicht, andere wachsen entschieden mit subnormaler Geschwindigkeit; und Me Collum und Davis glauben, dass sie in solchen Rationen ein Mittel haben, die Vitalität der Individuen auf eine befriedigendere, als auf die bisher angewandte Weise, zu messen.

Es folgt jedoch nicht direkt daraus, dass die Anormalität der Kost in solchen Fällen von Versagen des Wachstums, wie sie bisher erwähnt wurden 
- ob wir es einen Mangel an „Vitamin“ nennen, das wir als organischen Stoff annehmen (mit Funk), oder es dem Fehlen irgend eines wesentlichen Agens oder einem ungeeigneten Ausgleich der Nahrungsmittel zuschreiben den Mangel eines Wachstumsfaktors in sich schliesst. Adäquates Wachstum setzt einen befriedigenden Zustand der Erhaltung voraus, dass irgendwelche andauernde Gewichtsgewinne gemacht werden können. Man könnte vermuten, dass Milch, „eiweissfreie Milch“ und andere Zusätze zu der unwirksamen ,künstlichen" Nahrung langsam das Wachstum fördern, weil sie etwas Wesentliches für den normalen Stoffwechsel liefern, für die Grundlage, auf welcher Gewebskonstruktion und Zunahme aufgebaut werden. Aber das ist nicht die ganze Geschichte.

Osborne und ich haben Ratten durch zwei Generationen bei einer Diät erhalten, welche nur aus Vollmilchpulver, Speck und Stärke bestand. Als wir versuchten, junge Tiere mit einer ähnlichen Nahrung aus Milcheiweiss, "eiweissfreier Milch", Kohlehydrat und Speck zum Wachsen zu bringen, zeigte sich eine Hemmung des Wachstums, manchmal ganz plötzlich und gewöhnlich allmählicher, ehe die ausgewachsene Grösse erreicht wurde. Der wesentliche Unterschied zwischen der soeben beschriebenen geeigneten und der ungeeigneten Ration liegt in dem Fehlen des Milchfettes oder des Rahmelementes der letzteren. Wir fanden, dass der Zusatz ungesalzener Butter (Osborne und Mendel [1913b]) oder von Butterfett (Osborne und Mendel [1913c]) zu der ungeeigneten Nahrung, in welcher Speck den einzigen Fettbestandteil bildete, die Wachstumshemmung bei nicht gewachsenen Ratten verhinderte, und rasch das Wachstum wiederherstellte, wo es fehlte. Milchfett - das alle in eigentlichen. Fetten lösliche Milchbestandteile ent. hält - enthält daher etwas für das Wachstum Wesentliches ${ }^{1}$.

Vor der Veröffentlichung unserer Resultate zeigten Me Collum und Davis (1913b), dass das Versagen der Ratten weiter zu wachsen, nachdem sie einen kritischen Punkt erreicht hatten bei Mischungen von isolierten Nahrungssubstanzen dadurch geheilt werden könnte, dass man den Ätherextrakt von $\mathrm{Ei}$ oder von Butter lieferte. Sie behaupten, dass Ratten, bei welchen das Wachstum suspendiert wurde, viele Wochen lang in einem scheinbar guten Ernährungszustand bleiben können und doch imstande sind, auf die wachstumsfördernde Wirkung der ätherlöslichen Substanzen sowie

1) Es ist als Kritik solcher Schlüsse behauptet worden, dass die "Akzessorien“ bloss. etwas darstellen, was eine grössere Nahrungsaufnahme mit geeigneterer Erhaltung oder daraus folgendem Wachstum herbeiführt. Offenbar muss Nichtessen verhängnisvoll werden. Wir erkennen die Berechtigung einer solchen Kritik und ihre Anwendbarkeit auf viele Beispiele der Wachstumsabnahme an; aber die sehr umfangreichen Aufzeichnungen, welche wir haben, zeigen zahlreiche Fälle von Abnahme, trotz freier Nahrungsaufnahme. Der ideale Plan, abgemessene Nahrungsmittel zu verfüttern, kann nicht bei vielen Arten während längerer Perioden in befriedigender Weise ausgeführt werden; selbst bei Vögeln, welche gestopft werden können, stösst man auf Grenzen. 
auf die gemischte, natürliche Nahrung zu reagieren. Mc Collum und Davis erbielten in keinem Falle günstige Resultate durch Fütterung von Speck oder Olivenöl. $\mathrm{Zu}$ den Beispielen des günstigen Einflusses von Butterfett und Eierfett haben Osborne und ich die gleichfalls befriedigende Wirkung von Lebertran und vielleicht in geringerem Grade von Ochsenfett hinzugefügt. Die Resultate mit den "wirksamen" Fettmischungen (im Gegensatz zu den unwirksamen) sind so auffallend und so rasch zu erzielen, dass man einen einzigen Nachweis der Vorherrschaft der bisher unvermuteten Diätfaktoren aufbauen kann. Beim Fraktionieren des Butterfettes sind wir nun imstande gewesen, zu zeigen, dass die flüssigeren Teile, oder was wir das Butteröl nennen können, das wirksame Ingredienz enthalten. Dass das nicht allgemein in natürlichen Ölen. vorhanden ist, ist ebenfalls durch die Untersuchungen von $\mathrm{McCollum}$ und $\mathrm{Davis}$ gezeigt worden, und durch unseren eigenen Beweis der Unfähigkeit von Fetten, wie Mandelöl und Olivenöl, das Butteröl in der Förderung der Wachstumsaufnahme zu ersetzen. Die ernährungsfördernden Eigenschaften des Lebertranes wurden auf Grund der weit verbreiteten populären und medizinischen Anwendung dieses Erzeugnisses untersucht. Unsere Versuche liefern, wie wir glauben, den direkten Beweis, dass Lebertran etwas mehr als ein reines Nahrungs. mittel ist. Jetzt im Gange befindliche Versuche, um festzustellen, wieviel Butteröl notwendig ist, um den Ernährungszerfall zu verhüten oder Wiederherstellung herbeizuführen, wo Abfall erfolgt ist, lassen die Mengen überraschend klein erscheinen. Vor ganz kurzem haben $\mathrm{Mc}$ Collum und Davis (1914) gefunden, dass eine Wiederaufnahme des Wachstums bei Ratten, welche so viel als möglich bei fettfreier Nahrung gewachsen waren, durch Olivenöl zustande gebracht werden kânn, indem man letzteres mit einer Seifenlösung schüttelte, welche dadurch hergestellt wurde, dass man Butterfett in einem nicht-wässerigen System mit Kaliumbydroxyd nach der Methode von Henriques verseifte. Die Resultate zeigen, dass die im Butterfett vorhandene Substanz oder Substanzen, welche eine so deutlich anregende Wirkung auf das Wachstum ausüben, stabil genug sind, um den Bedingungen der Verseifung zu widerstehen.

Die günstigen Wirkungen mancher Fettzusätze äussern sich nicht nur in der Wiederaufnahme des Wachstums, sondern auch in dem weiteren Verlaufe gelegentlicher Ernährungsstörungen und Fällen verminderter Immunität gegen Krankheit (Osborne und Mendel, 1913c, S. 43). Versuchstiere erleiden häufig eine Infektion des Auges während der Perioden ihres Ernährungsverfalles. Dies ist von verschiedenen Forschern beobachtet worden und tritt vielleicht in ähnlichen Erscheinungen bei Unterernährung von Kindern zutage. Der einfache Zusatz von Butterfett oder Lebertran zur Kost, obne eine andere Veränderung, fübrt zu einem raschen Verschwinden der Augenkrankheit. 
Keine Mengen von Butterfett oder Lebertran werden Wachstum bei solchen Ernährungen herbeiführen, bei welchen die Proportionen und die Art der anorganischen Salze ungeeignet sind, bei welchen geeignete Kohlehydrate fehlen, oder die Menge oder der Charakter des Eiweisses inadäquat sind. Die Nahrungseinheiten - die Bausteine - dürfen in unserem Enthusiasmus für die neueren Eigenschaften nicht übersehen werden. Die Arbeiten von Stepp, Mc Collum und Osborne und Mendel stimmen darin überein, dass sie darauf binweisen, dass blosses Fehlen von Fett in der Kost nicht die Ursache zur Wachstumshemmung ist: wir sollten vielmehr sagen, dass die gewöhnlichen Fette per se nicht die Träger der wachstumfördernden Wirksamkeit sind. Die natürlich vorkommenden Fette lösen andere Substanzen als Triglyzeride auf. Die Chemie des Problems harrt noch der Lösung.

Es ist nicht unwahrscheinlich - um in hergebrachter Weise sich auszudrücken - dass es wenigstens zwei „bestimmende Faktoren" bei der Ernährung des Wachstums gibt. Einer derselben wird in unserer "eiweissfreien Milch" geliefert, welche richtige Erhaltung selbst bei fehlendem Wachstum sichert. Wir haben vermittelst derselben Ratten obne Wachstum während sehr langer Zeiten erhalten können. Ohne diesen „bestimmenden Faktor" (wie z. B. bei Diäten von isolierten Nahrungssubstanzen, die künstliche Substitute für ,natürliche eiweissfreie Milch" enthalten) führen die besonderen Bestandteile des Butterfettes im besten Falle nur beschränkte Gewinne herbei. Ein anderer, ,bestimmender Faktor" wird demnach von diesen Fetten geliefert (oder kürzlich daraus von Osborne und mir präparierten Teilen): Jeder dieser Faktoren kann ,Acibud" werden; beide sind für das Wachstum wesentlich, wenn der Körpervorrat derselben (wenn es einen solchen gibt) entleert wird (Funk und Macallum 1914). Es ist noch zu früh, einen zu Recht bestehenden Schluss zu versuchen.

Im Bereiche der praktischen Medizin ist es wahrscheinlich, dass diese letzten Untersuchungen fruchtbare Spekulation und wohltätige Anwendungen anregen werden. Die Volkstümlichkeit der Milchfette kann von einem neuen Standpunkt aus wieder belebt werden. Vor ganz kurzem und offenbar ohne Kenntnis der amerikanischen Untersuchungen auf diesem Gebiet hat Niemnnn (1914) den Gebrauch der gewaschenen Butter als ein Hilfsmittel bei der Diät schlecht ernährter Kinàer befürwortet und hat deutliche Erfolge von ihrer Anwendung berichtet. Die diäto-therapeutischen Rechte des Lebertranes erscheinen in einem neuen Lichte. Die Anwendung von Eigelbemulsion bei wachsenden Individuen und die Rechte der Milch oder von Teilen der Milch, sowie Molken usw. auf einen Platz in der Ernährung der jungen Kinder werden so von neuem hervorgehoben, wie sie es immer geworden sind, wenn geeignete Kindernährmittel experimenteller Untersuchung unterworfen worden sind (Wheeler und Beister 1914). Der 
Gegensatz von algerahmter oder rahmfreier Milch mit Vollmilch wird in neue Beziehungen gebracht. Wachstum ist mehr als ein blosses Energieproblem. Unzulänglichkeit der Nahrung und einzelner Nahrungsstoffe können spezifischen Mängeln gegenübergestellt werden. Wir haben noch zu erfahren, wo die wesentlichen Substanzen, abgesehen von den bereits erwähnten wenigen Produkten, zu finden sind. Die mögliche Vorherrschaft der Pflanzenprodukte bleibt noch sicherzustellen. Selbst bei der Frage, ob nicht erwärmte oder erwärmte Milch (und ebenso bei anderen Nahrungsmitteln) könnte die Stabilität der Hilfsfaktoren gegen physikalische Agenzien beteiligt sein.

Vielleicht haben wir es nach allem bei der Verfeinerung der modernen Nahrungszubereitung mit einer herbeigeführten Unterwertjgkeit tatsächlich bekannter Substanzen zu tun. Man denkt leicht an die mögliche Rolle der Spuren von Jod oder Silicum oder Mangan, die bis jetzt unbekannt waren. Mit Aktivatoren und Hormonen, Vitaminen und Nahrungshilfsmitteln, Mitozonen und Produkten der inneren Sekretion, die von Tag zu'Tag unsere Aufmerksamkeit auf sich ziehen, bin ich mir inmitten unserem Enthusias. mus der Warnung bewusst, die in einem anderen Zusammenhang von Rubner gegeben wurde:

„Es ist sehr bedauerlich, dass in der Literatur des letzten Jahrzehnts überhaupt sich an allen Ecken und Enden die Tendenz geltend macht, bei Experimenten, bei denen weder die wirksamen Substanzen, noch die physikalischen Bedingungen genauer bekannt sind, zu sofortiger Namensgebung zu schreiten. Aus den ersten Hypothesen werden weitere Hilfshypothesen mit wieder neuer Nomenklatur. Den Lesern kommt gar nicht mehr zu Bewusstsein, dass die Namen, die er hört, nur hypothetische Körper oder nur Namen für einen Vorgang sind, der vielleicht nur bei gewissen Quantitätsverhältnissen des Stoffes in die Erscheinung tritt, bei anderen nicht. Die allerwenigsten der Leser wissen heute noch die Genesis solcher Worte. Der kleinste Teil kennt die Experimente, auf welche die Namensgebung zurückzuführen ist. Die einfachsten Binsenwahrheiten werden dann in der Form hochtrabender Spezialausdrücke zu neuen Errungenschaften, die Literatur ist heute auf manchen medizinischen Gebieten, man möchte sagen, ohne die Zuhilfenahme besonderer Lexika für Fachausdrücke und Synonyme ungeniessbar. Die Medizin muss hier endlich einmal wieder haltmachen. Hypothesenbau und Theorie haben auch ihr Gutes, sie dürfen aber nicht hypertrophisch werden und das klare durchsichtige Experiment verdrängen. Die Naturwissenschaft darf nicht in ein Spiel mit Worten sich verlieren. Am allerwenigsten ist es aber in der Ernährungslehre angebracht, eine ungesunde Spekulation an Stelle der allerdings mühseligen Experimente zu setzen." (Rubner, 1908, S. 112.)

Annahmen, wie die von Morgan (67, S. 253), nach dem verhältnismässig weniger Nahrung resorbiert und assimiliert wird, wenn von einem wachsenden 
Individuum mehr als das Maximum aufgenommen wird, entbehren noch des experimentellen Beweises. Die Beziehungen zwischen Nahrungsversorgung und Wachstum, die Fragen der Minima und Maxima der verschiedenen Nahrungsmittel, und zahlreiche andere Gegenstände werden in den Arbeiten von Osborne und Mendel über das Wachstum weiter ausführlich behandelt.

Wichtige ökonomische Betrachtungen knüpfen sich an die Geeignetheit, das Wachstum mit geringeren Ausgaben zu modifizieren oder es zu erreichen - eine Möglichkeit, für welche vermutlich Ernährungsfaktoren gegenwärtig die einzige Gelegenheit bieten. Daher die praktische Bedeutung mancher Probleme auf diesem Gebiet. Wie können unwirksame native Nahrungsmittel wirksam gemacht werden und welches ist die relative Ökonomie der verschiedenen Kostarten?

"Die praktische Wichtigkeit der Beherrschung der Wachstumsgeschwindigkeit unserer Haustiere wird klar, wenn man bedenkt, dass für die Fleischproduktion von einigen Tieren ein verschwindend kleiner Bruchteil der gereichten Nahrung als Anwuchs zurückbleibt, bei anderen Tieren, wie den Hausschweinen, bis zu 70\%. Bei den Vogelarten scheinen die Extreme noch weiter auseinander zu liegen als bei den Säugetieren und zwischen der Wachstumsgeschwindigkeit des Kuckucks, welcher nach weniger als 60 Tagen erwachsen ist, und der Langsamkeit des Wachstums der Hühnervögel und Laufvögel zu schwanken" $(34,35)$.

Weitere Betrachtungen dieser Art in bezug auf die verschiedenen Eiweisskörper sind anderen Orts erwähnt (80).

\section{Die Wachstumsmöglichkeit, ihre Daner, der Einfluss des Alters usw.}

Die landläufigen Auffassungen der Wachstumsmöglichkeit, welche in einem früheren Kapitel besprochen worden sind, erwecken den unzweifelhaften Eindruck, dass diese eigenartige Eigenschaft der lebendigen Substanz wesentlich den frühen Lebensperioden angehört, oder jedenfalls für dieselben charakteristisch ist. Wie lange bleibt sie erhalten und in welchem Grade? Wird sie jemals ganz verloren? „In der Regel ist, bei den verschiedenen Tieren verschieden stark, der Wachstumstrieb in der Jugend am stärksten, nimmt allmählich ab und verliert sich im Alter“ (7). In welchem Umfange sind Behauptungen wie die obenstehende richtig, und welches sind ihre Grenzen?

Die bereits in den Versuchen von Osborne und mir, sowie von Aron erworbene Erfahrung zeigt, dass die Wachstumsmöglichkeit keineswegs selbst in einem Alter verloren ist, in welchem das Tier normalerweise ausgewachsene Proportionen erreicht hat. Weitere Arbeit auf diesem Gebiet verspricht wichtige Beiträge zur Kenntnis der Faktoren, welche das Wachstum hemmen oder es erleichtern; ihr Verhalten bei pathologischer Unterdrückung oder Verzögerung des Wachstums ist klar. 
Die Probleme der Wachstumsfähigkeit können auf andere Weisen formuliert werden. Wird das Wachstum, durch die nötigen Einschränkungen in der Diät unterdrückt, auf eine unbestimmte Zeit vollständig aufhören? Was wird aus einem solchen Tier, das an einer solchen Suspension des Wachstums leidet, wenn ihm eine reichliche Kost verabfolgt wird? Welches sind die Gewebsveränderungen, die diese Unterdrückungen und Wiederauffütterungen begleiten, d. h. welches sind die histologischen Begleiterscheinungen?

\section{Die Funktion des Alters}

ist offenbar ein wichtiger Faktor bei der Betrachtung der Wachștumsfragen. Ein Index des Alters ist, abgesehen von der Geburtskurve, sehr wünschenswert. Gewicht und Grösse können im allgemeinen aus vielen, leicht ersichtlichen Gründen inadäquat sein. Was in dieser Richtung sich erreichen lässt, wird durch die Untersuchungen von Donaldson $(23,24)$ und Hatai (42) an Ratten gezeigt. Sie haben gefunden, dass der Prozentgehalt des Zentralnervensystems an Wasser eine Funktion des Alters ist und unter gewöhnlichen Bedingungen, gleichgültig ob das Tier über oder unter der normalen Grösse ist, gut oder schlecht ernährt ist, ein grosses oder ein kleines Gehirn hat, bleibt der Prozentgehalt des Wassers dabei praktisch unverändert. Die Abweichungen bei äusserster Unterernährung sind sogar höchstens sehr gering und verschwinden bei der Wiederkehr normaler Ernährungsbedingungen vollständig. Der Prozentgehalt des Wassers im Zentralnervensystem soll demnach das beste Zeichen für den normalen Prozess des Altwerdens sein. Diese Tatsachen passen zu der menschlichen Erfahrung, dass Unterernährung und Not nicht notwendigerweise die Lebensspanne verkürzen. Es ist von nicht geringem Wert, einen zuverlässigen Index des Alters zu besitzen. Die experimentellen Möglichkeiten und Ziele auf diesem Gebiete sind weit entfernt davon, erschöpft zu sein. Man muss zunächst noch die chemischen Tatsachen und die histologischen und andere Analysen des Alters vervollständigen.

Wenn es in Wahrheit solche Substanzen wie "Mitosone" oder Wachstums, hormone" gibt, welche zu vermehrtem Wachstum führen, wie sie es bei der Entwickelung der Brustdrüse und bei der Entstehung gewisser Sekretionen zu tun scheinen, so ist die Möglichkeit einer wabren Beschleunigung des Wachstums oder der Förderung des Wachstums begreiflich. Könnte Wachstum durch solche Mittel herbeigeführt werden, dann würde es vermutlich zu einem anormalen Resultat führen; denn wie Schloss bemerkt, „eine reine Beschleunigung des individuellen korrelativen Vermehrungsprozesses des gesamten Organismus ist damit noch nicht als möglich erwiesen" (104, S. 99).

Versuche, Wachstum durch Einführung von Drüsen mit innerer Sekretion zu erleichtern, sind vielfach gemacht worden $(6,65)$. In der Regel sind die 
Versuche dürftig geplant und ausgeführt worden. Trotz des durch die Erfahrung gelieferten Gegenbeweises verdienen Versuche in dieser Richtung noch der Fortführung.

\section{Die Unterdrückung des Wachstums; Infantilismus.}

Die Probleme des mangelhaften Wachstums haben in den letzten Jahren neues Interesse erweckt. Es sind verschiedene Typen des Infantilismus beschrieben worden, welche sich zweifellos in ihren morphologischen, physiologischen und ätiologischen Eigenschaften von einander unterscheiden $(45,86)$. Daher mussten diese Zustände, welche durch unglückliche Naturspiele entstehen, grösstenteils so studiert werden, wie die Gelegenheiten sich selbst boten. Mit kontrollierbaren Methoden zur Unterdrückung des Wachstums, so wie wir sie andern Orts beschrieben haben (83), kann $\mathrm{Z}$ wergwuchs unter Bedingungen bewerkstelligt werden, wo die Ursachen und Hilfsmittel experimentell untersucht werden können. Gibt es keine Gewebsveränderungen bei scheinbarem Wachstumsstillstand? Arons Untersuchungen an verkrüppelten Hunden haben gezeigt, wie unerwartet gross die chemischen Veränderungen der Gewebe sein können $(7,8)$. Äussert sich das Alter in dem Aufbau der Zellen trotz des Stillstandes in der Grösse? Werden alle Teile gleichzeitig oder gleichmässig beeinflusst? Welches sind die äusseren, welches die konstitutionellen Faktoren bei dem Zwergwuchs?

Die Bedeutung dieser Probleme für die Klinik der Kinderkrankheiten kommt einem sofort zum Bewusstsein. Sie sind gleich wichtig im Bereich der Ernăhrung des Tieres, wo das Wachstum mit einem Minimum von Kosten bewerkstelligt werden muss und wo ferner der besondere Aufbau des Gewebes der jungen Tiere ihnen einen besonderen Marktwert verleiht. Man denke an den besonderen Wert des jungen Hubnes, des Kalb- und des Lammfleisches. Stationäres Gewicht bei Kindern ist immer eine Sorgenquelle für die, welche für ihr Wohlbefinden zu sorgen haben.

„Es ist eigentlich sonderbar, dass diese Wachstumsanomalie in ihrer biologisch so ungemein interessanten Eigenart noch nie recht gewürdigt worden ist. Stets hat man sie mit den beiden nächststehenden Formen, dem langsamen Anstieg und der allmählichen Abnahme zusammen behandelt, obwohl, wie wir noch sehen werden, sie nur schwer in eine von diesen Formen umzuwandeln ist, eine Tatsache, die allein schon gegen ihre Zusammengehörigkeit spricht. Eine Hauptursache für diese Nichtachtung war der Glaube, diese Umwandlung leicht vornehmen zu können. In manchen Fällen ist das ja auch durch eine bestimmte Nahrungsänderung möglich; wie aber sonst meist diese Erfolge aussehen, werden wir noch bei den Korrelationsstörungen zu schildern haben. Als Hauptcharakteristikum haben wir bei dieser Wachstumsstörung die Tendenz zur absoluten Konstanz der Masse, und zwar geht diese so weit, dass auch bei wochenlanger Beobachtung 
keine, mit der Wage registrierbare bleibende $\mathrm{Zu}$ - oder Abnahme zu beobachten ist" $(104$, S. 38).

Um solchen Situationen zu begegnen, muss man imstande sein, zwischen den kausalen Faktoren $\mathrm{zu}$ unterscheiden, die noch lange nicht hinreichend entwirrt sind.

Sind die Individuen, von Natur aus klein oder klein gehalten durch hemmende Eingriffe, in kleine Erwachsene verwandelt? Ist, mit anderen Worten, das Gewicht eines Individuums in jeder Entwickelungsperiode ein Faktor, der weiteres Wachstum beeinflusst? Die genaue Formulierung solcher Fragen ermöglicht jetzt spezifische Antworten.

Obgleich jedes Individuum bestrebt zu sein scheint, eine bestimmte Grösse zu erreichen, ist es noch strittig, ob die Natur beständiges Wachstum verlangt, oder bis zu welchem Umfang Verminderungen schädlich oder zulässig sind. Es wird immer klarer, dass Wachstum keine ganz unentbehrliche Funktion der lebendigen Substanz ist. Mit anderen Worten, das Ausbleiben weiteren Wachstums ist nicht unverträglich mit dem Leben. Wo sind die Grenzen solcher Situationen? Und vor allem, kann das Leben durch Wachstumsverzögerung verlängert werden. Dies ist eine Seite des weiten Problems der Makrobiotik (das Leben künstlich durch Veränderungen der Bedingungen, unter welchen es weiter geht, zu verlängern). Theoretisch ist es begreiflich, dass Wachstumsprozesse gleich chemischen Reaktionen reversibel sein sollten. Rubner meint: „Nur das Wachstum, die Umformung und neue Mischung der Materie ist der Urquell des Lebens, nur Wachstumsvorgänge können die Folgen einer einseitigen Lebensäusserung, wie der Kraftwechsel eine ist, beseitigen. Bei dem erwachsenen Säugetier ist diese Umformung und Neumischung völlig ausgeschlossen. Nach der Erreichung einer bestimmten Periode der Jugendzeit entwickeln sich die Fortpflanzungsorgane. In diesen findet sich bei derartigen Lebewesen all das deponiert, was zur Erzeugung neuer Organismen und zur Vererbung dient. Die übrigen Zellen des Körpers haben verloren, was die Fortpflanzungsorgane gewonnen haben. Es widerspricht keiner naturwissenschaftlich berechtigten Auffassung, wenn ich annehme, dass aus dem Komplex der jugendlichen noch wachsenden Zelle allmählich solche Stoffgruppen entnommen werden, welche die Potenz des Wachstums darstellen. Von einem bestimmten Zeitintervall ab treten die das Wachstumsprinzip enthaltenden Potenzen an die Geschlechtsorgane, und die übrigen Zellen des Organismus verlieren die Fähigkeit, weiter sich zu entfalten. Die maximale Grösse der Spezies ist erreicht. Es ist aber bei der Wichtigkeit dieses Prozesses klar, dass derselbe in einem Sinne geordnet sein muss, welcher der jeweiligen Lebenswahrscheinlichkeit entspricht. Daraus folgt der Zusammenhang, dass nach dem Umsatz einer gewissen Kraftsumme das Wachstum abschliesst. Ob wir nun diesen Termin als etwas einfach in der Organisation Liegendes betrachten wollen, oder ob die lebende 
Substanz der Zellen des Körpers nach einer gewissen energetischen Leistung das Wachstumsprinzip leichter an die Geschlechtsdrüsen abgibt, mag unentschieden bleiben. Es wird Aufgabe der Zukunft sein, die Gültigkeit dieser Gesetze näher zu erforschen; voraussichtlich werden sich verscbiedene Gruppen gleich konstruierter "lebender Substanzen" ergeben, deren gegenseitiger Vergleich uns vielleicht dann weitere Gesichtspunkte zu erneuter Forschung gibt." $(99$, S. 207.)

\section{Verlust und Regeneration.}

Welches sind die wahren Beziehungen zwischen Regeneration und Wachstum? Wird die Wiedererzeugung eines Verlusts an Grösse rascher bewerkstelligt als das ursprüngliche Wachstum? Sind die Ernährungsbedürfnisse bei der Regeneration verschieden in Qualität oder Quantität von jenen gleich grossen Wachstums? Besteht Regeneration bloss in dem Ersatz von Gewebssubstanz in teilweise entleerten Zellen, oder ist es im weiteren Sinne eine wirkliche Erneuerung? Ist Regeneration leichter beim wachsenden oder beim erwachsenen Individuum möglich? Und da die Regeneration zeitweise bemerkenswert rasch ist, ist man versucht, sich zu fragen, ob ein vorübergehender Verlust und folgende Wiederherstellung auf die Wachstumsfähigkeit als Überreiz wirken, genau so wie das in einen Organismus injizierte Gift eine übermässige Produktion von Antitoxin hervorruft, - ein Beispiel für Weigerts Hypothese der kompensatorischen Überproduktion.

Unterscheidungen zwischen dem, was "Neuwachstum" und "Wiederwachstum" genannt worden ist, verdienen sorgfältig gemacht $\mathrm{zu}$ werden. Wenn man sich an die nahe Verwandtschaft zwischen Wachstum, Wiederherstellung und Regeneration erinnert, ist man versucht, Morgan in die Extreme seiner Spekulation zu folgen. "Ich wünsche nicht zu betonen", schreibt er, ,dass das Fehlen der koordinierten Regeneration die einzige Ursache der mangelhaften Regeneration bei den höheren Wirbeltieren, den Menschen inbegriffen, ist, aber, wie ich schon gesagt babe, gibt es Zeichen dafür, dass die Hauptstörung in der Langsamkeit gewisser Gewebe liegt, gleichzeitig mit anderen Geweben zu regenerieren. Wenn aber die Gewebe beim Menschen noch die Fähigkeit zu regenerieren besitzen, dürfen wir nicht hoffen, mit der Zeit die Geschwindigkeit ihrer Regeneration so anzupassen, dass der Ersatz eines verlorenen Gliedes erreicht werden kann? Ich kann nur glauben, dass sich das eines Tages erfüllen wird" (68, S. 229).

\section{Andere Eigenschaften.}

Man kann von dem genaueren Studium des Wachstums in der Zukunft erwarten, dass es wertvolle Ergebnisse auch über das Wesen pathologischer Neoplasmen, welche die Gesundheit so wesentlich betreffen, bringen wird. Das Wetteifern jugendlicher Zellen, wie dasjenige maligner Tumoren mit den normalen erwachsenen Zellen bringt häufig dem jüngeren Gewebe 
den Sieg. „Junge Zellen sind diejenigen, welche sich am meisten verändern können, bei welchen die genetische Restriktion am wenigsten ins Spiel kommt, und demnach finden wir, dass eine grosse Anzahl von gefährlichen bösartigen Auswüchsen, Tumoren aus Zellen des jungen Typus entstehen, und dass diese Zellen, welche eine grosse Fähigkeit haben, sich zu vervielfältigen rasch wachsen, und dass sie von sich aus einen eigenen Charakter annehmen können; ihre genetische Restriktion ist uicht so weit gegangen, dass alle ihre Veränderungsmöglichkeiten auf dem Wege der Differentiation festgestellt worden sind; es steht denselben noch eine bestimmte Reihe von Möglichkeiten offen, und sie können sich nach der einen oder der anderen Richtung wenden. Daher kann es pathologische Wachstumsarten geben, die normalerweise im Körper nicht vorhanden sind. Es scheint mir, so weit mich meine Kenntnis dieses Gegenstandes zu urteilen befähigt, wahr zu sein, dass alle derartigen pathologischen Wachstumsarten abhängen von der Gegenwart verhältnismässig junger und nichtdifferenzierter Zellen, welche in eine neue Richtung gelenkt worden sind. Das Problem der normalen Entwickelung und der anormalen Struktur ist ein und dasselbe. Sowohl der Embryologe und der Anatom einerseits, wie der Pathologe und Kliniker andererseits, haben es je mit diesen Fragen der Differenzierung, und praktisch mit keiner anderen, zu tun. Alles, was im Körper vorkommt, ist die Folge der verschiedenen Differenzierungen, und ob wir den Zustand jenes Körpers normal oder pathologisch nennen, tut wenig zur Sache; und doch ist die Ursache davon die Differenzierung der Teile" (61).

Mit den besser formulierten Prinzipien des Wachstums wird man möglicherweise auf befriedigendere Weise zwischen wahrer Hyperplasie und blosser Hypertrophie unterscheiden und jeder unerwünschten Wirkung derselben entgegenwirken können. Die Probleme der Immunität, wie sie sich während des Wachstums im Gegensatz zum späteren Leben zeigen, erfordern auch Beachtung. Schloss hat den Ausspruch getan: „Die natürliche Immunität der Säuglinge wird durch die normale, stoffliche Korrelation bedingt. Jede Änderung derselben führt zu einer Herabsetzung der Immunität, die sich sowohl in einer grösseren Anfälligkeit, als in einer verminderten Heilungstendenz äussert" (104, S. 146). Solche Aussprüche müssen noch bewiesen werden, denn es ist nicht immer leicht den Wachstumsfaktor von anderen Elementen, wie unrichtiger Ernäbrung, dem verminderten Widerstand gegen Krankheit, zu unterscheiden.

Andere spezielle Fälle der Wachstumsabänderungen erfordern gesonderte Besprechung. Die Schwangerschaft z. B. liefert verschiedene Probleme gleichzeitigen Vorkommens. Die intrauterinen Geschehnisse sind an sich Wachstumsäusserungen unter der Herrschaft eines ausgewachsenen Organismus. Welche Unterschiede zeigen sich zwischen dem Tragen des Jungen, ehe das mütterliche Wachstum vollendet ist und danach? Wird das 
mütterliche Wachstum durch frühe Empfängnis und Schwangerschaft, ehe das volle Wachstum beim Weibchen vollendet ist, verzögert oder ständig unterdrückt? (119). Solche Fragen haben sowohl eine physiologische wie soziologische Bedeutung.

"Jeder grosse Fortschritt in der Wissenschaft eröffnet unserem Auge Tatsachen, welche wir vorher nicht beobachten konnten, und stellt neue Anforderungen an unsere Interpretationsfähigkeit .... So gross auch der Fortschritt der wissenschaftlichen Erkenntnis gewesen sein mag, er ist nicht grösser gewesen als das Wachstum des zu behandelnden Stoffes. Das Ziel der Wissenschaft ist klar - es ist nichts weniger als die vollständige Erklärung des Universum. Aber das Ziel ist ein ideelles - es zeigt die Richtung, in der wir uns bewegen und streben, aber niemals ein Stadium, welches wir wirklich erreichen werden. Das Universum wird immer grösser, wenn wir lernen mehr von unserem kleinen Erdenwinkel aus davon zu verstehen" (85). 
丞

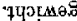

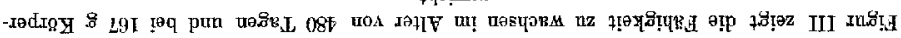

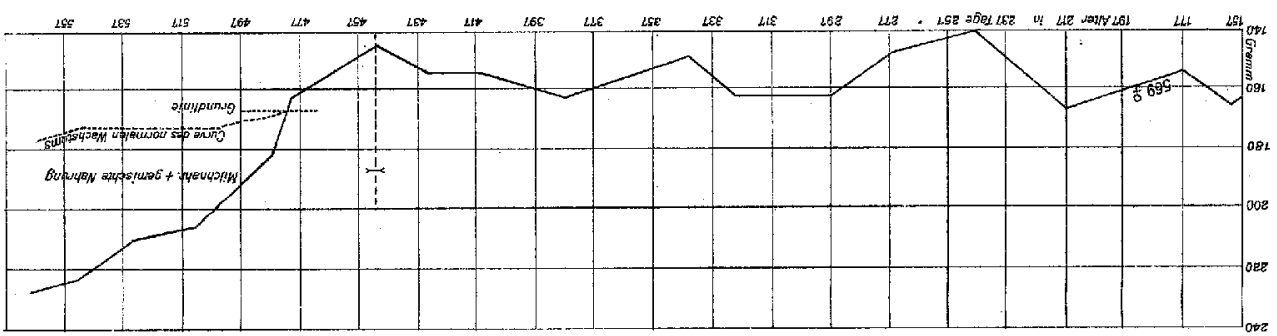

品

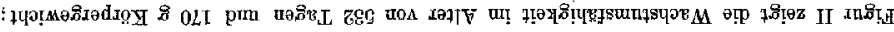

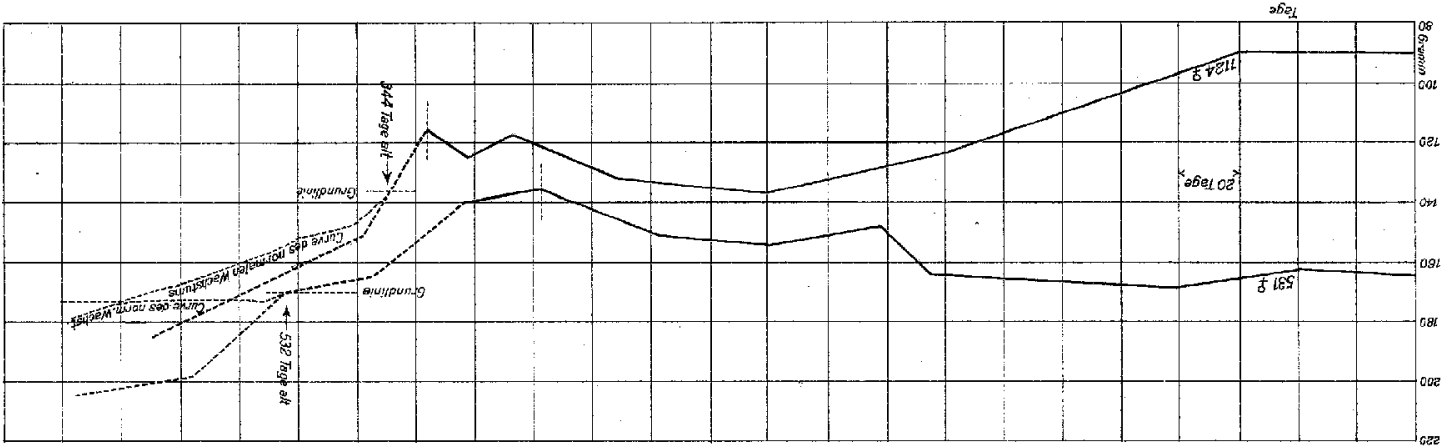



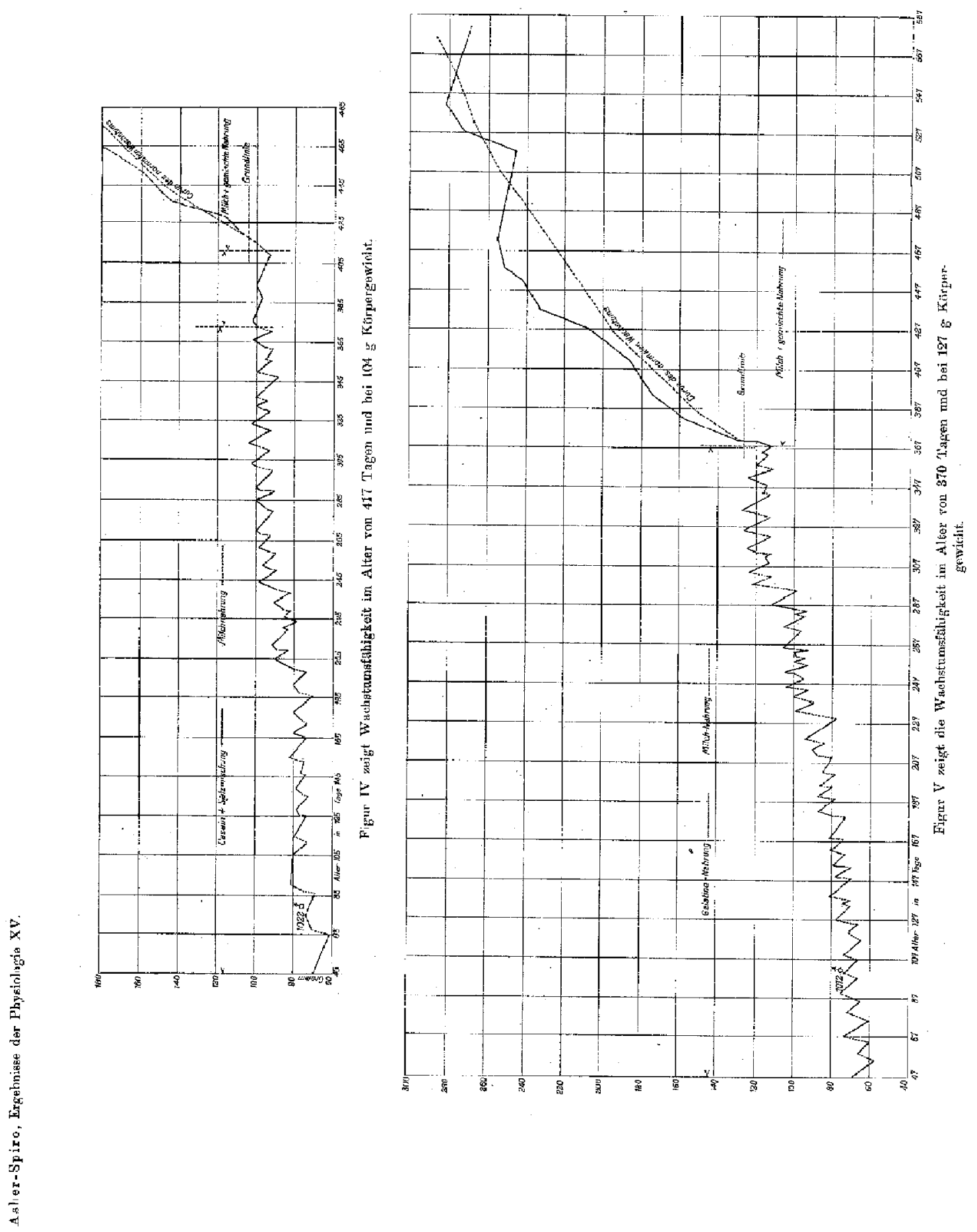